\title{
Relação da coagulação intravascular disseminada pela determinação do dímero-D com a COVID-19: uma revisão integrativa
}

\author{
Relationship of intravascular coagulation disseminated by D-dlimer determination with COVID-19: \\ an integrative review
}

Relación de la coagulación intravascular diseminada por determinación dímero D con COVID-19: una revisión integrativa

\author{
Mariana Lessi da Silva \\ ORCID: https://orcid.org/0000-0002-9339-5018 \\ Universidade São Judas Tadeu, Brasil \\ E-mail: mariana_lessi@hotmail.com \\ Igor de Oliveira Bezerra Alves \\ ORCID: https://orcid.org/0000 -0003-4263-7846 \\ Universidade São Judas Tadeu, Brasil \\ E-mail: igor.oliveira87@yahoo.com.br \\ Carolina Heitmann Mares Azevedo Ribeiro \\ ORCID: https://orcid.org/0000-0002-9457-2733 \\ Universidade Federal do Pará, Brasil \\ E-mail: chribeiro@ufpa.br \\ Ana Cristina Lo Prete \\ ORCID: https://orcid.org/0000-0002-2874-5296 \\ Universidade São Judas Tadeu, Brasil \\ E-mail: analoprete@gmail.com
}

\begin{abstract}
Resumo
A síndrome respiratória aguda grave causada pela COVID-19 foi recentemente relatada em Wuhan, capital da província chinesa de Hubei. A doença pode se manifestar de formas graves, em alguns desses casos, foram identificadas condições de hipercoagulabilidade seguido de alterações hematológicas. Este trabalho trata-se de uma revisão integrativa que avalia a relação da coagulação intravascular disseminada pela determinação do dímero-D com a COVID-19 e correlaciona esse marcador como um possível prognóstico da doença. Durante o estudo foi possível evidenciar que o aumento do dímeroD pode estar associado com uma maior gravidade da COVID-19 e/ou mortalidade, observada pelo aumento da ocorrência de CID, incluindo estudos em pacientes que evoluíram para quadros trombóticos, como TVP, TEV e embolia pulmonar. Além disso, tal associação em outras condições que aumentam a coagulação, como no caso de pacientes diabéticos tipo 2 e em pacientes que fizeram uso de ECMO.
\end{abstract}

Palavras-chave: COVID-19; Coagulação intravascular disseminada; Prognóstico.

\begin{abstract}
Severe acute respiratory syndrome caused by COVID-19 has recently been reported in Wuhan, the capital of the Chinese province of Hubei. The disease can manifest itself in severe ways, in some of these cases, conditions of hypercoagulability have been identified followed by hematological changes. This work is an integrative review that assesses the relationship between intravascular coagulation disseminated by the determination of D-dimer and COVID-19 and correlates this marker as a possible prognosis of the disease. During the study it was possible to show that the increase in D-dimer may be associated with greater severity of COVID-19 and / or mortality, observed by the increase in the occurrence of ICD, including studies in patients who evolved to thrombotic conditions, such as DVT, VTE and pulmonary embolism. In addition, such an association in other conditions that increase coagulation, as in the case of type 2 diabetic patients and in patients who used ECMO.
\end{abstract}

Keywords: COVID-19; Disseminated intravascular coagulation; Prognosis.

\section{Resumen}

El síndrome respiratorio agudo severo causado por COVID-19 se informó recientemente en Wuhan, capital de la provincia china de Hubei. La enfermedad puede manifestarse de forma severa, en algunos de estos casos se identificaron condiciones de hipercoagulabilidad seguidas de alteraciones hematológicas. Este trabajo es una revisión integradora que evalúa la relación entre la coagulación intravascular diseminada mediante la determinación del dímero D con COVID-19 y correlaciona este marcador con un posible pronóstico de la enfermedad. Durante el estudio, se pudo demostrar que el aumento del dímero D puede estar asociado con una mayor gravedad del COVID-19 y / o mortalidad, observada por la 
mayor ocurrencia de DAI, incluyendo estudios en pacientes que progresaron a condiciones trombóticas, tales como TVP, TEV y embolia pulmonar. Además, dicha asociación en otras condiciones que aumentan la coagulación, como en el caso de los pacientes diabéticos tipo 2 y en los pacientes que utilizan ECMO.

Palabras clave: COVID-19; Coagulación intravascular diseminada; Pronóstico.

\section{Introdução}

Em dezembro de 2019, foi relatada pela primeira vez em Wuhan, capital da província chinesa de Hubei, uma síndrome respiratória aguda grave denominada COVID-19. Esta doença é caracterizada por pneumonia, linfocitopenia e uma tempestade de citocinas, o que provoca em alguns casos, uma resposta inflamatória excessiva (Deeh et al., 2020).

A maioria dos pacientes com COVID-19 exibem sintomas leves à moderados, embora aproximadamente 15\% evoluem para pneumonia grave e cerca de $5 \%$ eventualmente desenvolvem síndrome do desconforto respiratório agudo (SDRA), choque séptico e / ou falência de múltiplos órgãos (Huang et al., 2020; Xu, et al., 2020).

Estudos comprovaram que fatores como idade avançada e doenças crônicas (obesidade, diabetes, doenças cardiovasculares, hipertensão e câncer), aumentam o risco de maiores complicações no decorrer da infecção. Além disso, o crescente número de casos começou a elucidar complicações hematológicas, e doenças cardiovasculares como Embolia Pulmonar, por exemplo, alertando a necessidade de nova abordagem à doença (Jordan et al., 2020).

Sabe-se que o vírus penetra nas células através da enzima conversora de angiotensina 2, utilizando-a como um receptor para sua entrada na célula, iniciando um processo inflamatório intenso com liberação de citocinas pró-inflamatórias e ativação do sistema complemento. Esse processo, assim como ocorre na Coagulopatia Induzida pela Sepse (SIC, no inglês) pode gerar um estado pró-trombótico no paciente, culminando em uma Coagulação Intravascular Disseminada (CID) (Toshiaki et al., 2020).

O dímero-D é um marcador para avaliação da CID, sendo um produto de degradação da fibrina, formado pela ação sequencial de 3 enzimas: trombina, fator XIIIa e plasmina (Adam,2009). Estudos de Wuhan indicam que marcadores clínicos como trombocitopenia, elevação do tempo de protrombina e elevação do dímero-D contribuíram para aumento da gravidade da doença e estiveram associados ao aumento da mortalidade entre os pacientes com COVID-19 (Brito, 2020).

Muitos outros artigos vêm sendo publicados analisando a relação do dímero-D com o agravamento do quadro clínico em pacientes com a COVID-19. Deste modo, o presente trabalho teve como intuito revisar de forma integrativa os dados presentes na literatura científica acerca desse tema.

\section{Metodologia}

Para realizar essa revisão integrativa, considerou-se a análise de Koche (2011) sobre fundamentos de metodologia científica e o estudo de Santana et al (2021) sobre análises hematológicas em pacientes com COVID-19, sendo percorridas as seguintes etapas: definição do tema, elaboração da pergunta norteadora, estabelecimento de critérios de busca ou amostragem na literatura, definição das informações extraídas dos artigos (coleta de dados), análise crítica dos artigos incluídos, discussão e apresentação dos resultados.

A análise foi realizada por meio do cruzamento das palavras-chave disponíveis nos Descritores em Ciências da Saúde (DECS). Foram usados os descritores "Dímero-D” e "COVID-19”, nas línguas portuguesa, inglesa e espanhola. O trabalho tem como alvo a seguinte questão: avaliar a relação da coagulação intravascular disseminada pela determinação do dímero-d com a COVID-19.

As buscas foram realizadas na base de dados Medical Literature Analysis and Retrieval System on-line (PUBMED), uma vez que esta base permite buscas simultâneas nas principais fontes nacionais e internacionais.

A pesquisa englobou artigos publicados no período de novembro de 2019 a $1^{\circ}$ de março de 2021. Foram adicionados filtros para a seleção do tipo de publicação: estudo clínico, ensaio clínico e estudo multicêntrico. 
A seleção resultou em 154 artigos. Como critérios de exclusão, foram retirados estudos que não apresentavam resultados sobre avalição do dímero-D ou que se enquadravam em categorias de modelo de carta ao editor, modelo de editorial e relatos de caso, por não se tratar de modelos de forte evidência científica. Após aplicar os critérios de exclusão, o trabalho incluiu para análise 107 artigos, os quais foram utilizados para a revisão de forma integrada (Figura 1).

Figura 1. Seleção de trabalhos.

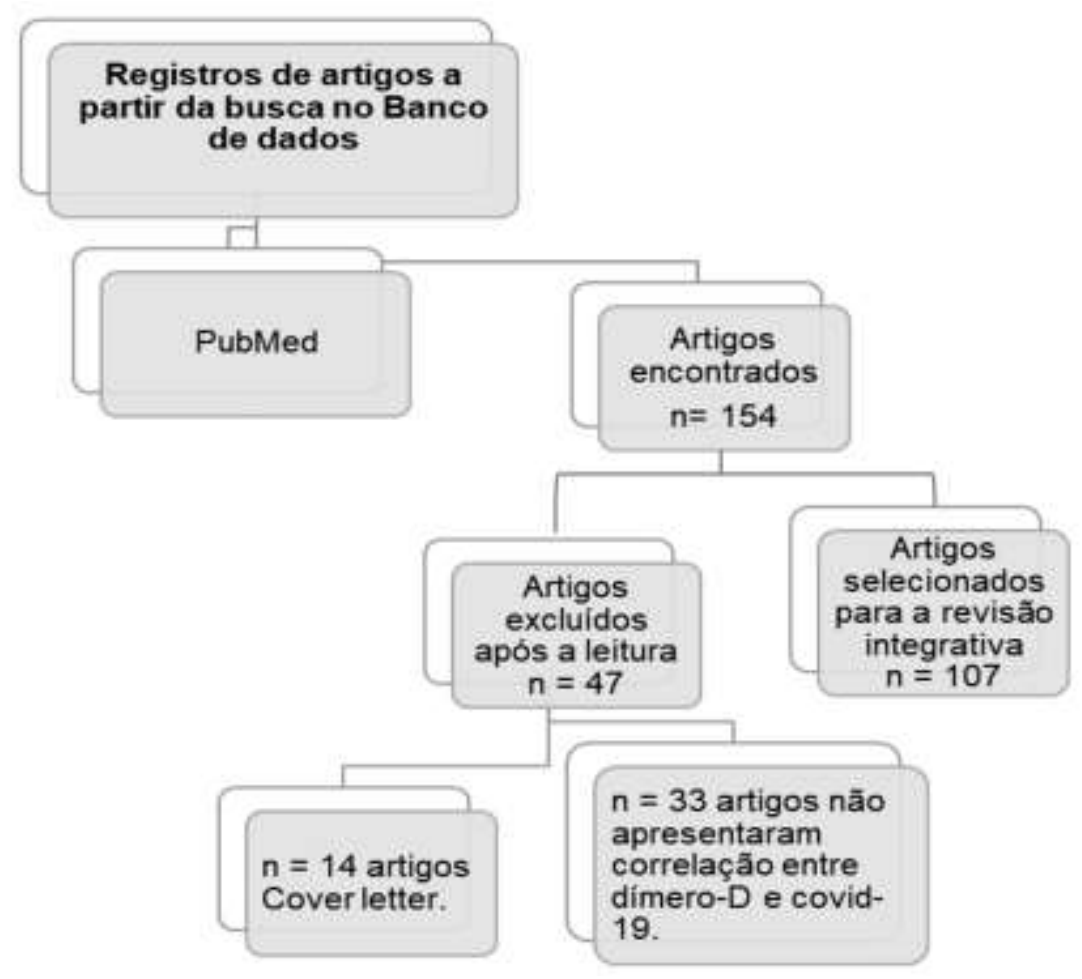

Fonte: Autores (2022).

\section{Resultados}

Cento e sete artigos científicos foram considerados adequados aos critérios de inclusão para essa pesquisa. Os resultados estão apresentados no Quadro 1, na qual se encontram o título e autoria dos trabalhos, objetivo, desenho do estudo, metodologia, resultado e conclusão dos artigos selecionados. Todos os artigos foram numerados para facilitar a apresentação de resultados e discussão dos mesmos. 
Research, Society and Development, v. 11, n. 2, e21011225731, 2022

(CC BY 4.0) | ISSN 2525-3409 | DOI: http://dx.doi.org/10.33448/rsd-v11i2.25731

Quadro 1. Perfil e características dos artigos selecionados.

\begin{tabular}{|c|c|c|c|c|c|c|}
\hline $\mathrm{N}^{\circ}$ & Artigo & Objetivo & $\begin{array}{l}\text { Desenho do } \\
\text { Estudo }\end{array}$ & Metodologia & Resultado & Conclusão \\
\hline 1 & $\begin{array}{l}\text { Pilot prospective open, single-arm } \\
\text { multicentre study on off-label use } \\
\text { of tocilizumab in patients with } \\
\text { severe COVID-19. } \\
\text { (Sciascia et al., 2020). }\end{array}$ & 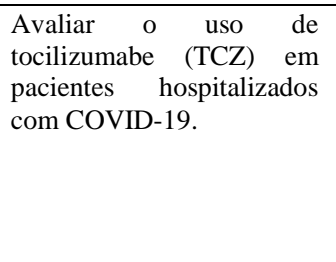 & $\begin{array}{l}\text { Estudo } \\
\text { prospectivo } \\
\text { multicêntrico. }\end{array}$ & $\begin{array}{l}\text { Utilização do TCZ em } 63 \text { pacientes adultos } \\
\text { hospitalizados com COVVID-19. Critérios de } \\
\text { inclusão: (a) confirmação por RT- PCR; b) } \\
\text { avaliaçãa do envolvimento pulmonar; c) } \\
\text { análise do perfil pró-inflamatório e } \\
\text { trombótico. Foram avaliados esses } \\
\text { parâmetros nos dias } 1,2,7 \text { e } 14 .\end{array}$ & $\begin{array}{l}\text { Pacientes COVID-19 em uso de TCZ } \\
\text { obtiveram melhora nos níveis de ferritina, } \\
\text { proteína C, dímero-D e na pressão parcial } \\
\text { de oxigênio. A administração de TCZ logo } \\
\text { na admissão foi associada a aumento da } \\
\text { sobrevida. Nenhum paciente relatou } \\
\text { eventos adversos relacionados com } \\
\text { infusões de TCZ. }\end{array}$ & $\begin{array}{l}\mathrm{O} \text { uso tocilizumab pode ser } \\
\text { considerado uma boa opção para } \\
\text { pacientes para tratar pacientes } \\
\text { adultos com COVID-19. }\end{array}$ \\
\hline 2 & $\begin{array}{l}\text { High risk of throbosis in patiens } \\
\text { with severe SARS- } \text { Cov-2 } \\
\text { infection: a multicenter propective } \\
\text { cohort } \\
\text { (Helms et al., 2020). }\end{array}$ & $\begin{array}{l}\text { Avaliar o risco trombótico } \\
\text { em formas graves de } \\
\text { infecção por SARS-CoV-2. }\end{array}$ & $\begin{array}{l}\text { Estudo de coorte } \\
\text { prospectivo } \\
\text { unicêntrico. }\end{array}$ & $\begin{array}{l}150 \text { pacientes foram encaminhados para } 4 \\
\text { unidades de UTI de dois centros de um } \\
\text { hospital terciário francês para casos de } \\
\text { COVID-19. Histórico médico, sintomas, } \\
\text { dados biológicos e imagens foram coletados. }\end{array}$ & 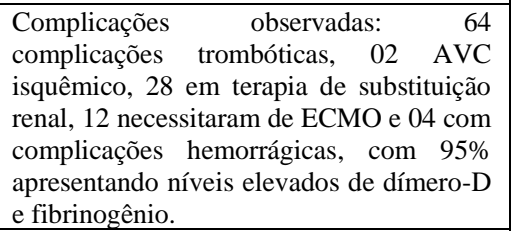 & $\begin{array}{lr}\begin{array}{l}\text { Pacientes com } \\
\text { desenvolveram }\end{array} & \begin{array}{r}\text { COVID-19 } \\
\text { graves }\end{array} \\
\text { complicações } & \text { trombóticas, } \\
\text { associadas com } & \text { aumento do } \\
\text { dímero-D. } & \end{array}$ \\
\hline 3 & $\begin{array}{l}\text { Incidence of asymptomatic deep } \\
\text { vein thrombosis in patients with } \\
\text { COVID-19 pneumonia and } \\
\text { elevated D-dimer levels. } \\
\text { (Demelo-rodríguez et al., 2020) }\end{array}$ & $\begin{array}{l}\text { Avaliar a carga da trombose } \\
\text { venosa } r \text { profunda } \\
\text { assintomática (TVP) em } \\
\text { COVID-19 pacientes com } \\
\text { níveis elevados de dímero- } \\
\text { D. }\end{array}$ & $\begin{array}{l}\text { Estudo } \\
\text { prospectivo } \\
\text { observacional } \\
\text { unicêntrico. }\end{array}$ & $\begin{array}{l}\text { Foram inclusos pacientes maiores de } 18 \text { anos, } \\
\text { com níveis elevados de dímero-D e admissão } \\
\text { hospitalar por pelo menos } 48 \text { h. O diagnóstico } \\
\text { de COVID-19 foi definido por PCR positivo } \\
\text { ou presença de achados radiológicos e } \\
\text { analíticos sugestivos da doença. }\end{array}$ & $\begin{array}{l}\text { De 198 pacientes inicialmente } \\
\text { selecionados, } 37 \text { pacientes foram excluídos } \\
\text { por estarem usando anticoagulantes, } 4 \\
\text { pacientes tinham histórico de TVP de } \\
\text { membros inferiores e um paciente tinha } \\
\text { sintomas de TVP. Os pacientes com TVP } \\
\text { tinham níveis medianos de dímero-D mais } \\
\text { elevados. }\end{array}$ & $\begin{array}{l}\text { Níveis de corte de dímero-D } \\
\text { elevado, pode ser necessário para } \\
\text { o diagnóstico de DVT em } \\
\text { pacientes COVID-19. }\end{array}$ \\
\hline 4 & $\begin{array}{l}\text { The Clinical Characteristics and } \\
\text { Outcomes of Diabetes Mellitus } \\
\text { and Secondary Hyperglycaemia } \\
\text { Patients with Coronavirus Disease } \\
\text { 2019: a Single-center, } \\
\text { Retrospective, observational } \\
\text { Study in Wuhan. } \\
\text { (Y. Zhang et al., 2020) }\end{array}$ & $\begin{array}{l}\text { Analisar se pacientes com } \\
\text { COVID-19 com diabetes e } \\
\text { hiperglicemia secundária } \\
\text { têm características clínicas } \\
\text { e prognósticos diferentes } \\
\text { daqueles sem alterações no } \\
\text { metabolismo dos } \\
\text { carboidratos. }\end{array}$ & $\begin{array}{l}\text { Estudo } \\
\text { observacional } \\
\text { retrospectivo } \\
\text { unicêntrico. }\end{array}$ & $\begin{array}{l}\text { Foram incluídos } 166 \text { pacientes com COVID- } \\
19 \text { divididos em } 3 \text { grupos: } 1 \text { (controle, sem } \\
\text { hiperglicemia); } 2 \text { (hiperglicemia secundária, } \\
\text { sem histórico de diabetes), } 3 \text { (diabetes). } \\
\text { Foram comparadas as características clínicas. }\end{array}$ & $\begin{array}{l}\text { Em comparação com o grupo } 1 \text { (controle), } \\
\text { os grupos } 2 \text { e } 3 \text { apresentaram maiores taxas } \\
\text { de leucocitose, neutrofilia, linfocitopenia, } \\
\text { eosinopenia e níveis de proteína C reativa, } \\
\text { ferritina e dímero-d. A proporção de } \\
\text { pacientes críticos e maior tempo de } \\
\text { hospitalização ocorreu mais nos grupos } \\
\text { com hiperglicemia. }\end{array}$ & $\begin{array}{l}\text { Em pacientes COVID-19, a } \\
\text { hiperglicemia tanto em } \\
\text { decorrência do diabetes quanto } \\
\text { secundária a outras condições } \\
\text { pode indicar mau prognóstico. }\end{array}$ \\
\hline 5 & $\begin{array}{l}\text { SARS2-CoV-2 and Stroke in a } \\
\text { New York Healthcare System. } \\
\text { (Yaghi et al., 2020) }\end{array}$ & $\begin{array}{l}\text { Analisar clinicamente } \\
\text { pacientes afetados por } \\
\text { COVID-19, que poderiam } \\
\text { desenvolver complicações } \\
\text { trombóticas e AVCs }\end{array}$ & $\begin{array}{l}\text { Estudo de coorte } \\
\text { retrospectivo } \\
\text { multicêntrico. }\end{array}$ & $\begin{array}{l}\text { Três grupos analisados: } 1 \text { - pacientes com } \\
\text { AVC isquêmico e COVID-19; } 2 \text { - incluiu } \\
\text { pacientes com AVC isquêmico sem COVID- } \\
19 ; 3 \text { - incluiu pacientes com histórico de } \\
\text { AVC isquêmico com COVID-19 no mesmo } \\
\text { período de tempo. }\end{array}$ & $\begin{array}{l}\text { Pacientes COVID-19 tiveram maior } \\
\text { admissão na escala de pontuação do } \\
\text { hospital para AVC, níveis de dímero-D de } \\
\text { pico mais altos, foram mais propensos a } \\
\text { serem homens mais jovens com troponina } \\
\text { elevada, e apresentavam maior taxa de }\end{array}$ & $\begin{array}{lcr}\text { A maioria } & \text { dos acidentes } \\
\text { vasculares } & \text { cerebrais eram } \\
\text { criptogênicos, } & \text { possivelmente } \\
\text { relacionados } & \text { a uma } \\
\text { hipercoagulabilidade adquirida, e } \\
\text { a mortalidade aumentava. } \\
\end{array}$ \\
\hline
\end{tabular}


Research, Society and Development, v. 11, n. 2, e21011225731, 2022

(CC BY 4.0) | ISSN 2525-3409 | DOI: http://dx.doi.org/10.33448/rsd-v11i2.25731

\begin{tabular}{|c|c|c|c|c|c|c|}
\hline & & & & & $\begin{array}{l}\text { hemossedimentação, com mortalidade } \\
\text { significativamente maior do que controles. }\end{array}$ & \\
\hline 6 & $\begin{array}{l}\text { Epidemiology, clinical course, and } \\
\text { outcomes of critically ill adults } \\
\text { with COVID-19 in New York } \\
\text { City: a prospective cohort study. } \\
\text { (Cummings et al., 2020) }\end{array}$ & $\begin{array}{l}\text { Agravamento de enfermos } \\
\text { em pacientes com COVID- } \\
19 \text { na cidade de Nova York }\end{array}$ & $\begin{array}{l}\text { Estudo de coorte } \\
\text { prospectivo } \\
\text { multicêntrico. }\end{array}$ & $\begin{array}{l}\text { Desfecho primário foi a taxa de mortalidade } \\
\text { hospitalar; desfechos secundários incluíram } \\
\text { frequência e duração da ventilação mecânica } \\
\text { e do uso de vasopressores e terapia de } \\
\text { substituição renal e tempo para deterioraçãoo } \\
\text { clínica hospitalar após a admissão. A relação } \\
\text { entre fatores de risco clínicos, biomarcadores } \\
\text { e mortalidade hospitalar foi modelada usando } \\
\text { a regressão de riscos proporcionais de Cox. }\end{array}$ & $\begin{array}{l}\text { Em } 28 \text { de abril de } 2020,101 \text { pacientes } \\
\text { morreram e } 94 \text { permaneceram } \\
\text { hospitalizados. } 203 \text { pacientes receberam } \\
\text { ventilação mecânica invasiva por uma } \\
\text { mediana de } 18 \text { dias, } 170 \text { de } 257 \text { pacientes } \\
\text { receberam vasopressores e } 79 \text { receberam } \\
\text { terapia de substituição renal. Maiores } \\
\text { concentrações de dímero-D foram } \\
\text { associadas com mortalidade intra- } \\
\text { hospitalar. }\end{array}$ & $\begin{array}{l}\text { A doença crítica entre pacientes } \\
\text { hospitalizados com COVID-19 na } \\
\text { cidade de Nova York é comum e } \\
\text { associada com alta frequência de } \\
\text { ventilação mecânica invasiva, } \\
\text { disfunção } \quad \text { orgânica } \\
\text { extrapulmonar e substancial } \\
\text { mortalidade intra-hospitalar }\end{array}$ \\
\hline 7 & $\begin{array}{l}\text { Enhanced platelet inhibition } \\
\text { treatment improves hypoxemia in } \\
\text { patients with severe COVID-19 } \\
\text { and hypercoagulability. A case } \\
\text { control, proof of concept study. } \\
\text { (Viecca et al., 2020) }\end{array}$ & $\begin{array}{l}\text { Analisar os efeitos da } \\
\text { terapia antiplaquetária na } \\
\text { oxigenação arterial e nos } \\
\text { resultados clínicos em } \\
\text { pacientes com COVID-19 e } \\
\text { hipercoagulação. }\end{array}$ & $\begin{array}{l}\text { Estudo } \\
\text { observacional } \\
\text { caso controle } \\
\text { retrospectivo } \\
\text { multicêntrico. }\end{array}$ & $\begin{array}{l}10 \text { pacientes com COVID-19 e complicação } \\
\text { respiratória grave sob oxigenação foram } \\
\text { divididos em } 2 \text { grupos pareados por idade, } \\
\text { valor de dímero-D e escore para sobrevida. } \\
\text { Todos receberam AAS e clopidogrel. Depois } \\
\text { foram divididos em } 2 \text { grupos. }\end{array}$ & $\begin{array}{l}\text { No grupo tratado com terapia } \\
\text { antiplaquetária, } 4 \text { desmamaram da } \\
\text { oxigenação artificial após } 3 \text { dias, o que não } \\
\text { ocorreu em nenhum paciente do grupo } \\
\text { controle. O dímero-D também apresentou } \\
\text { tendência para decréscimo nos pacientes } \\
\text { tratados, mas não nos de grupo controle. }\end{array}$ & $\begin{array}{l}\text { A terapia antiplaquetária pode ser } \\
\text { eficaz para melhorar a relação } \\
\text { ventilação/perfusão em pacientes } \\
\text { com COVID-19 com } \\
\text { insuficiência respiratória grave. } \\
\text { Os efeitos são evidenciados pela } \\
\text { tendência de redução do dímero- } \\
\text { D. }\end{array}$ \\
\hline 8 & $\begin{array}{l}\text { Systematic assessment of venous } \\
\text { thromboembolism in covid-19 } \\
\text { patients } \quad \text { receiving } \\
\text { thromboprophylaxis: incidence } \\
\text { and role of D-dimer as predictive } \\
\text { factors. } \\
\text { (Artifoni et al., 2020) }\end{array}$ & $\begin{array}{l}\text { Avaliar fatores de risco de } \\
\text { tromboembolismo venoso } \\
(\mathrm{TEV}) \text { em pacientes } \\
\text { internados com COVID-19 } \\
\text { recebendo } \\
\text { tromboprofilaxia. }\end{array}$ & $\begin{array}{l}\text { Estudo de coorte } \\
\text { restrospectivo } \\
\text { multicêntrico. }\end{array}$ & $\begin{array}{l}\text { Pacientes com COVID-19 e idade }>18 \text { anos e } \\
\text { tratados com tromboprofilaxia e dados de } \\
\text { ultrassonografia venosa foram incluídos. } \\
\text { Foram excluídos pacientes com } \\
\text { anticoagulação prévia, internação em UTI e } \\
\text { contraindicação para tromboprofilaxia. Ao } \\
\text { final, foram selecionados } 133 \text { pacientes. }\end{array}$ & $\begin{array}{l}\text { Após início, } 62 \text { foram retirados do estudo: } \\
1 \text { óbito, } 17 \text { transferências para UTI, } 5 \text { altas } \\
\text { precoce, } 9 \text { sob anticoagulante oral prévia, } \\
21 \text { com alta sem ultrassonografia e } 9 \text { que } \\
\text { ainda não receberam alta. Foram então } \\
\text { acompanhados } 71 \text { pacientes, nos quais os } \\
\text { níveis de dímero-D na admissão hospitalar } \\
\text { foram significativamente maiores em } \\
\text { pacientes que desenvolveram TEV durante } \\
\text { a hospitalização. }\end{array}$ & $\begin{array}{l}\text { Apesar da tromboprofilaxia, o } \\
\text { risco de TEV era alto mesmo em } \\
\text { pacientes com COVID-19 não } \\
\text { internados na UTI, dímero-D } \\
\text { acima de } 1,0 \mu \mathrm{g} / \mathrm{mL} \text { sugerem } \\
\text { risco para TEV. }\end{array}$ \\
\hline 9 & $\begin{array}{l}\text { ICU and Ventilator Mortality } \\
\text { Among Critically Ill Adults With } \\
\text { Coronavirus Disease } 2019 . \\
\text { (Auld et al., } 2020\end{array}$ & $\begin{array}{l}\text { Determinar as taxas de } \\
\text { mortalidade entre adultos } \\
\text { com doença crítica por } \\
\text { COVID-19. }\end{array}$ & $\begin{array}{l}\text { Estudo } \\
\text { observacional } \\
\text { retrospectivo } \\
\text { multicêntrico. }\end{array}$ & $\begin{array}{l}\text { Informações sociodemográficas, dados } \\
\text { clínicos e laboratoriais de } 217 \text { pacientes } \\
\text { graves internados com COVID-19 foram } \\
\text { obtidos a partir do registro médico eletrônico. }\end{array}$ & $\begin{array}{l}\text { A mortalidade foi significativamente } \\
\text { associada com idade avançada, menor } \\
\text { índice de massa corporal, doença renal } \\
\text { crônica e elevação de dímero-D, entre } \\
\text { outros. }\end{array}$ & $\begin{array}{l}\text { Os relatórios de taxas de } \\
\text { mortalidade foram superiores a } \\
50 \% \text { entre adultos com COVID- } \\
\text { 19, particularmente entre aqueles } \\
\text { que requerem ventilação } \\
\text { mecânica. }\end{array}$ \\
\hline 10 & $\begin{array}{l}\text { D-dimer in patients infected with } \\
\text { COVID-19 and suspected } \\
\text { pulmonary embolism. } \\
\text { Olivé et al., 2020) }\end{array}$ & $\begin{array}{l}\text { Analisar fatores de risco } \\
\text { para embolia pulmonar } \\
\text { (EP) em pacientes } \\
\text { infectados com COVID-19 } \\
\text { e se os níveis de dímero- D } \\
\text { podem prever o } \\
\text { desenvolvimento de EP. }\end{array}$ & $\begin{array}{l}\text { Estudo } \\
\text { observacional } \\
\text { retrospectivo } \\
\text { unicêntrico. }\end{array}$ & $\begin{array}{l}21 \text { pacientes com infecção grave por COVID- } \\
19 \text { e suspeita de EP foram analisados na } \\
\text { internação e na evolução do quadro por } 12 \\
\text { dias. Foram comparados os dados gerais e } \\
\text { laboratoriais dos que evoluíram para EP com } \\
\text { os que não evoluíram. }\end{array}$ & $\begin{array}{l}\text { Idade, sexo ou dias de internação não foram } \\
\text { associados com um risco aumentado de } \\
\text { desenvolver EP, enquanto níveis elevados } \\
\text { de d-dímero na internação foram } \\
\text { associados com maior risco de intubação e } \\
\text { EP. }\end{array}$ & $\begin{array}{l}\text { Em pacientes COVID-19 graves, } \\
\text { o risco de EP está associado a } \\
\text { níveis progressivamente } \\
\text { aumentados de dímero-D. Há } \\
\text { necessidade de estudos com } \\
\text { maior amostragem para } \\
\text { determinar valores de corte de }\end{array}$ \\
\hline
\end{tabular}


Research, Society and Development, v. 11, n. 2, e21011225731, 2022

(CC BY 4.0) | ISSN 2525-3409 | DOI: http://dx.doi.org/10.33448/rsd-v11i2.25731

\begin{tabular}{|c|c|c|c|c|c|c|}
\hline & & & & & & $\begin{array}{l}\text { dímero-D e criar protocolos de } \\
\text { tratamento anticoagulante e } \\
\text { avaliação diagnóstica de risco } \\
\text { para EP. }\end{array}$ \\
\hline 11 & $\begin{array}{l}\text { Routine } r \text { Venous } \\
\text { Thromboembolism Prophylaxis } \\
\text { May Be Inadequate in the } \\
\text { Hypercoagulable State of Severe } \\
\text { Coronavirus Disease 2019. } \\
\text { (Maatman et al., 2020) }\end{array}$ & \begin{tabular}{l}
\multicolumn{2}{c}{ Determinar a frequência de } \\
tromboembolismo venoso \\
em pacientes com COVID- \\
19 e associar o grau de \\
elevação do marcador \\
inflamatório r ao \\
desenvolvimento \\
condição.
\end{tabular} & $\begin{array}{l}\text { Estudo } \\
\text { Observacional } \\
\text { retrospectivo } \\
\text { multicêntrico. }\end{array}$ & $\begin{array}{l}\text { Foram incluídos os positivos para SARS- } \\
\text { CoV-2, excluindo apenas os menores de } 18 \\
\text { anos, pacientes presos e gestantes, com } \\
\text { inclusão de } 240 \text { pacientes adultos internados; } \\
122 \text { pacientes tinham COVID- } 19 \text { leve / } \\
\text { moderado e } 118 \text { pacientes tinham COVID-19 } \\
\text { grave / fatal. }\end{array}$ & $\begin{array}{l}\text { Cento e nove pacientes desenvolveram } \\
\text { COVID-19 grave em } 2019 \text {, necessitando de } \\
\text { UTI. Tromboembolismo venoso foi } \\
\text { diagnosticado em } 31 \text { pacientes } 07 \text { dias após } \\
\text { a admissão hospitalar, incluindo } 02 \\
\text { pacientes com diagnóstico de } \\
\text { tromboembolismo venoso na apresentação } \\
\text { ao hospital. O dímero-D durante a } \\
\text { admissão e dímero-D de pico foram } \\
\text { associados ao desenvolvimento de } \\
\text { tromboembolismo venoso. }\end{array}$ & $\begin{array}{lr}\text { Pacientes que } & \text { apresentaram } \\
\text { troboembolismo } & \text { venoso } \\
\text { apresentaram aumento e pico de } \\
\text { dímero-D na fase final da doença. }\end{array}$ \\
\hline 12 & $\begin{array}{l}\text { Children in Critical Care Due to } \\
\text { Severe Acute Respiratory } \\
\text { Syndrome Coronavirus } 2 \\
\text { Infection: Experience in a Spanish } \\
\text { Hospital. } \\
\text { (Garcia-Ortega et al., 2020) }\end{array}$ & $\begin{array}{l}\text { Descrever uma série de } \\
\text { crianças internadas em uma } \\
\text { unidade de terapia intensiva } \\
\text { pediátrica na Espanha, um } \\
\text { dos países mais afetados } \\
\text { pelo coronavírus. }\end{array}$ & $\begin{array}{l}\text { Estudo } \\
\text { prospectivo } \\
\text { observacional } \\
\text { unicêntrico. }\end{array}$ & $\begin{array}{l}\text { Foram incluídos os pacientes com COVID-19 } \\
\text { confirmados pelo teste de PCR, dos quais } \\
\text { foram coletadas as características } \\
\text { epidemiológicas, exames de imagem e } \\
\text { laboratoriais sobre admissão, a histórico } \\
\text { farmacológico. }\end{array}$ & $\begin{array}{l}\text { Todos os pacientes desenvolveram } \\
\text { linfopenia, com } 02 \text { durante as primeiras } 24 \\
\text { h de internação. Alguns apresentaram } \\
\text { linfopenia na admissão. Dímero-D e } \\
\text { ferritina estavam elevados em todos os } \\
\text { pacientes. Todos os pacientes necessitaram } \\
\text { de oxigenoterapia por meio de cânula nasal. }\end{array}$ & $\begin{array}{l}\text { Os sintomas respiratórios foram a } \\
\text { principal causa de internação, } \\
\text { fazendo do suporte respiratório a } \\
\text { terapia principal. }\end{array}$ \\
\hline 13 & $\begin{array}{l}\text { Echocardiographic Findings in } \\
\text { Patients With COVID-19 - } \\
\text { Pneumonia. } \\
\text { (Mahmoud-Elsayed et al., 2020) }\end{array}$ & $\begin{array}{l}\text { Caracterizar } \\
\text { ecocardiografia de } \\
\text { pacientes com pneumonia } \\
\text { COVID-19 e sua relação } \\
\text { com biomarcadores. }\end{array}$ & $\begin{array}{l}\text { Estudo } \\
\text { observacional } \\
\text { retrospectivo } \\
\text { unicêntrico. }\end{array}$ & $\begin{array}{l}\text { Foram incluídos adultos com pneumonia } \\
\text { COVID-19 que foram submetidos a ETT em } \\
\text { um centro de referência quaternário de } 1215 \\
\text { leitos. }\end{array}$ & $\begin{array}{l}\text { Em pacientes com pneumonia por COVID- } \\
19 \text {, dilatação e disfunção do VD são } \\
\text { comuns e sua presença está associada a um } \\
\text { estado inflamatório pró-trombótico } \\
\text { refletido em níveis elevados de dímero-D e } \\
\text { PCR. }\end{array}$ & $\begin{array}{l}\text { Em pacientes com pneumonia } \\
\text { COVID-19, a dilatação e } \\
\text { disfunção do RV é comum e sua } \\
\text { presença está associada a um } \\
\text { estado pró-trombótico, } \\
\text { inflamatório refletido em níveis } \\
\text { elevados de dímero-D e proteína } \\
\text { C reativa. }\end{array}$ \\
\hline 14 & $\begin{array}{l}\text { Clinical Characteristics of Elderly } \\
\text { Patients with COVID-19 in Hunan } \\
\text { Province, China: A Multicenter, } \\
\text { Retrospective Study. } \\
\text { (T. Guo et al., 2020) }\end{array}$ & $\begin{array}{l}\text { Analisar as características } \\
\text { clínicas de pacientes idosos } \\
\text { com doença coronavírus } \\
2019 \text { (COVID-19). }\end{array}$ & $\begin{array}{l}\text { Estudo } \\
\text { retrospectivo } \\
\text { multicêntrico. }\end{array}$ & $\begin{array}{l}\text { Dos } 579 \text { pacientes positivos para COVID-19 } \\
\text { admitidos no hospital, todos os idosos (105) } \\
\text { internados de janeiro a fevereiro de } 2020 \\
\text { tiveram seus prontuários avaliados com dados } \\
\text { epidemiológicos, sinais e sintomas na } \\
\text { admissão, resultados laboratoriais e } \\
\text { radiológicos, tratamento e prognóstico. Os } \\
\text { pacientes foram divididos em 02 grupos: } \\
\text { COVID-19 jovem ( } 60-74 \text { anos) e o grupo } \\
\text { COVID-19 idoso ( } \geq 75 \text { anos). }\end{array}$ & $\begin{array}{l}\text { Dos } 105 \text { pacientes, } 81 \% \text { eram do grupo } \\
\text { considerado idosos jovens. Dos pacientes } \\
\text { mais idosos, } 22,9 \% \text { eram graves e } 10,5 \% \\
\text { eram graves críticos. No geral dos } \\
\text { pacientes houve diminuição dos linfócitos } \\
\text { (presente em } 31,4 \% \text { dos pacientes), } \\
\text { aumento de dímero-D (em } 38,1 \% \text { dos } \\
\text { pacientes), entre outros achados, e o tempo } \\
\text { de protrombina e o tempo de } \\
\text { tromboplastina parcial ativada foi ainda } \\
\text { maior entre os mais idosos. }\end{array}$ & $\begin{array}{l}\text { Pacientes idosos são propensos a } \\
\text { desenvolverem condições graves } \\
\text { por SARS-CoV-2 e tendem a } \\
\text { mais complicações do que os } \\
\text { jovens durante hospitalização, } \\
\text { mas com a utilização de } \\
\text { tratamento eficaz, são passíveis } \\
\text { de bons resultados comparando } \\
\text { com o grupo de jovens. }\end{array}$ \\
\hline 15 & $\begin{array}{l}\text { Clinical characteristics and risk } \\
\text { factors associated with COVID-19 } \\
\text { disease severity in patients with } \\
\text { cancer in Wuhan, China: a }\end{array}$ & $\begin{array}{l}\text { Caracterizar } \\
\text { sistematicamente as } \\
\text { características clínicas e } \\
\text { determinar os fatores de }\end{array}$ & $\begin{array}{l}\text { Estudo de coorte } \\
\text { retrospectivo } \\
\text { multicêntrico. }\end{array}$ & $\begin{array}{l}\text { Foram incluídos pacientes adultos com } \\
\text { qualquer tipo de tumores sólidos malignos e } \\
\text { malignidade hematológica com COVID-19. } \\
\text { Exames laboratoriais, gravidade da doença e }\end{array}$ & $\begin{array}{l}\text { Fatores de risco relatados anteriormente em } \\
\text { pacientes sem câncer, como idade } \\
\text { avançada; interleucina } 6 \text { elevada, pro- } \\
\text { calcitonina e dímero-D; e linfócitos }\end{array}$ & $\begin{array}{l}\text { Pacientes com câncer e COVID- } \\
19 \text { foram mais propensos a } \\
\text { doença grave do que aqueles sem } \\
\text { câncer. Os fatores de risco }\end{array}$ \\
\hline
\end{tabular}


Research, Society and Development, v. 11, n. 2, e21011225731, 2022

(CC BY 4.0) | ISSN 2525-3409 | DOI: http://dx.doi.org/10.33448/rsd-v11i2.25731

\begin{tabular}{|c|c|c|c|c|c|c|}
\hline & $\begin{array}{l}\text { multicentre, retrospective, cohort } \\
\text { study. } \\
\text { (Tian et al., 2020) }\end{array}$ & $\begin{array}{l}\text { risco da gravidade } \mathrm{da} \\
\text { doença COVID-19 para } \\
\text { pacientes com câncer e } \\
\text { COVID-19. }\end{array}$ & & $\begin{array}{l}\text { intervenções clínicas foram comparados entre } \\
\text { pacientes com COVID-19 com ou sem } \\
\text { câncer. }\end{array}$ & $\begin{array}{l}\text { reduzidos foram validados em pacientes } \\
\text { com câncer. }\end{array}$ & $\begin{array}{l}\text { identificados podem ser úteis para } \\
\text { a vigilância clínica precoce da } \\
\text { progressão da doença nesses } \\
\text { pacientes. }\end{array}$ \\
\hline 16 & $\begin{array}{l}\text { COVID-19 patients with } \\
\text { hypertension have more severe } \\
\text { disease: a multicenter } \\
\text { retrospective observational study. } \\
\text { (S. Huang et al., 2020) }\end{array}$ & $\begin{array}{l}\text { Explorar o efeito da } \\
\text { hipertensão na progressão } \\
\text { da doença e no prognóstico } \\
\text { em pacientes com doença } \\
\text { coronavírus } 2019 \text { (COVID- } \\
\text { 19). }\end{array}$ & $\begin{array}{l}\text { Estudo } \\
\text { observacional } \\
\text { retrospectivo } \\
\text { multicêntrico. }\end{array}$ & $\begin{array}{l}\text { Foram analisados } 310 \text { pacientes COVID-19, } \\
\text { divididos em 02 grupos: } 113 \text { com hipertensão } \\
\text { e } 197 \text { sem hipertensão. Os dados } \\
\text { demográficos e epidemiológicos, } \\
\text { características clínicas, gravidade da doença, } \\
\text { testes laboratoriais e os resultados do } \\
\text { tratamento dos pacientes foram obtidos a } \\
\text { partir do prontuário médico. }\end{array}$ & $\begin{array}{l}\text { Os índices laboratoriais de todos os } \\
\text { pacientes com COVID-19 demostraram } \\
\text { linfocitopenia, albumina diminuída, e } \\
\text { aumento da lactato desidrogenase (LDH), } \\
\text { da taxa de sedimentação de eritrócitos, da } \\
\text { proteína C reativa, da ferritina sérica, da } \\
\text { interleucina-6 e do dímero-D. Pacientes } \\
\text { hipertensos tiveram contagem de } \\
\text { neutrófilos significativamente mais alta. }\end{array}$ & $\begin{array}{l}\text { Não foi possível demonstrar que a } \\
\text { hipertensão é fator de risco } \\
\text { independente para mortalidade ou } \\
\text { gravidade de COVID-19. No } \\
\text { entanto, pacientes COVID-19 } \\
\text { com hipertensão forma mais } \\
\text { suscetíveis a desenvolver } \\
\text { pneumonia grave, reações } \\
\text { inflamatórias excessivas, danos a } \\
\text { órgãos e deterioração da doença. }\end{array}$ \\
\hline 17 & $\begin{array}{l}\text { COVID-19 and } \begin{array}{r}\text { coagulation: } \\
\text { bleeding and thrombotic }\end{array} \\
\text { manifestations of SARS-CoV-2 } \\
\text { infection. } \\
\text { (Al-Samkari et al., 2020) }\end{array}$ & $\begin{array}{l}\text { Avaliar a taxa e gravidade } \\
\text { de } \quad \text { complicações } \\
\text { trombóticas em pacientes } \\
\text { COVID-19 internados que } \\
\text { receberam anticoagulação } \\
\text { profilática. }\end{array}$ & $\begin{array}{l}\text { Estudo } \\
\text { observacional } \\
\text { retrospectivo } \\
\text { multicêntrico. }\end{array}$ & $\begin{array}{l}\text { Um total de } 400 \text { pacientes com idade de } 18 \\
\text { anos positivo para COVID-19 através do teste } \\
\text { de PCR, foram incluídos neste estudo. O teste } \\
\text { de dímero D foi usado para identificar os } \\
\text { pacientes para este estudo. }\end{array}$ & $\begin{array}{l}\text { Os níveis de dímero-D elevado na } \\
\text { apresentação inicial foram preditivos de } \\
\text { complicações associadas à coagulação } \\
\text { durante a hospitalização (dímero } \mathrm{D}>2500 \\
\text { ng/mL), devido a este aumento foi possível } \\
\text { prever complicações hemorrágicos, } \\
\text { complicações trombóticas, doença crítica e } \\
\text { morte. }\end{array}$ & $\begin{array}{l}\text { Observou-se que o COVID-19 } \\
\text { esteve associado a taxas } \\
\text { semelhantes de trombose e } \\
\text { sangramento em pacientes } \\
\text { hospitalizados com graus } \\
\text { semelhantes de doença crítica. }\end{array}$ \\
\hline 18 & $\begin{array}{l}\text { Multisystem Inflammatory } \\
\text { Syndrome in Children Associated } \\
\text { with Severe Acute Respiratory } \\
\text { Syndrome Coronavirus 2 Infection } \\
\text { (MIS-C): A Multi-institutional } \\
\text { Study from New York City. } \\
\text { (Kaushik et al., 2020) }\end{array}$ & $\begin{array}{l}\text { Avaliar características } \\
\text { clínicas e desfechos da } \\
\text { síndrome respiratória aguda } \\
\text { grave associada à COVID- } \\
19, \text { síndrome inflamatória } \\
\text { multissistêmica em } \\
\text { crianças (MIS-C). }\end{array}$ & $\begin{array}{l}\text { Estudo } \\
\text { prospectivo } \\
\text { observacional } \\
\text { multicêntrico }\end{array}$ & $\begin{array}{l}\text { Este estudo incluiu pacientes pediátricos } \\
\text { (com idade entre } 1 \text { mês e } 21 \text { anos) com } \\
\text { infecção confirmada com SARS-CoV-2 que } \\
\text { atendem aos critérios para MIS-C admitidos a } \\
\text { partir de abril } 23 \text { a } 23 \text { de maio de } 2020 \text {. Dados } \\
\text { demográficos e clínicos foram coletados. }\end{array}$ & $\begin{array}{l}\text { Exames laboratoriais foram realizados e } \\
\text { demonstraram elevação nos níveis de } \\
\text { Proteína C reativa, VHS, procalcitonina e } \\
\text { ferritina. A média de fibrinogênio foi de } \\
627 \mathrm{mg} / \mathrm{dL} \text { e dímero-D foi } 3,7 \mathrm{mg} / \mathrm{mL} \text {. }\end{array}$ & $\begin{array}{l}\text { Crianças em estado crítico com } \\
\text { MIS-C associado à Covid-2019 } \\
\text { têm um espectro de gravidade } \\
\text { mais amplo do que o descrito } \\
\text { anteriormente e ainda requerem } \\
\text { cuidados intensivos de suporte. A } \\
\text { recuperação clínica e miocárdica } \\
\text { rápida e completa foi quase } \\
\text { universal. }\end{array}$ \\
\hline 19 & $\begin{array}{l}\text { Clinical characteristics of } \\
\text { COVID-19 patients in three } \\
\text { consecutive generations of spread } \\
\text { in Zhejiang, China. } \\
\text { (Yao et al., 2020) }\end{array}$ & $\begin{array}{l}\text { Determinar as } \\
\text { características clínicas dos } \\
\text { pacientes com COVID-19. }\end{array}$ & $\begin{array}{l}\text { Estudo de coorte } \\
\text { retrospectivo } \\
\text { multicêntrico. }\end{array}$ & $\begin{array}{l}\text { Foram analisados resultados clínicos e } \\
\text { duração da eliminação viral de } 3 \text { grupos: } 1 \text {. } \\
\text { histórico de viagem para Hubei } 14 \text { d antes do } \\
\text { início da doença; 2- história de contato com } \\
\text { pacientes que viajaram; } 3 \text { - história de contato } \\
\text { com pacientes de tiveram contato com os que } \\
\text { viajaram. }\end{array}$ & $\begin{array}{l}\text { Dos } 171 \text { pacientes incluídos, } 83(48,5 \%) \\
\text { foram do grupo } 1,44(25,7 \%) \text { do grupo } 2 \\
44(25,7 \%) \text { do grupo } 3 \text {. Nos do grupo } 3 \\
\text { foram observados níveis mais elevados de } \\
\text { proteína C reativa e dímero-D. A proporção } \\
\text { de pacientes que desenvolveram doença } \\
\text { grave na terceira geração foi } \\
\text { significativamente maior do que o primeiro } \\
\text { grupo e segundo grupo. }\end{array}$ & $\begin{array}{l}\text { De acordo com o estudo pacientes } \\
\text { da terceira geração eram mais } \\
\text { velhos, tinham maiores } \\
\text { comorbidades subjacentes e } \\
\text { tinham uma maior proporção de } \\
\text { doenças graves ou críticas do que } \\
\text { pacientes de primeira e segunda } \\
\text { geração. }\end{array}$ \\
\hline 20 & $\begin{array}{l}\text { The Epidemiological and Clinical } \\
\text { Characteristics of } 81 \text { Children } \\
\text { with COVID-19 in a Pandemic } \\
\text { Hospital in Turkey: na } \\
\text { Observational Cohort Study. } \\
\text { (Korkmaz et al, 2020) }\end{array}$ & $\begin{array}{l}\text { Avaliar as características } \\
\text { clínicas de crianças com a } \\
\text { COVID-19. }\end{array}$ & $\begin{array}{l}\text { Estudo } \\
\text { observacional } \\
\text { retrospectivo } \\
\text { unicêntrico. }\end{array}$ & $\begin{array}{l}\text { Foram analisados os prontuários médicos de } \\
\text { pacientes menores de } 18 \text { anos com } \\
\text { diagnóstico confirmado de COVID-19. } \\
\text { Todos os pacientes foram avaliados em } \\
\text { termos epidemiológicos e demográficos }\end{array}$ & $\begin{array}{l}\text { Quatro pacientes } \\
\text { comorbidades: dois estavam sendo } \\
\text { acompanhados por doenças cerebrais } \\
\text { paralisia, um para diabetes mellitus tipo } 1 \mathrm{e} \\
\text { um para asma. Os resultados laboratoriais } \\
\text { demostraram valores anormais nos }\end{array}$ & $\begin{array}{l}\text { A COVID-19 é mais brando e } \\
\text { mais distinto em crianças. Como } \\
\text { resultado, abordagens } \\
\text { conservadoras podem } \\
\text { preferidas em ser } \\
\text { crianças para }\end{array}$ \\
\hline
\end{tabular}


Research, Society and Development, v. 11, n. 2, e21011225731, 2022

(CC BY 4.0) | ISSN 2525-3409 | DOI: http://dx.doi.org/10.33448/rsd-v11i2.25731

\begin{tabular}{|c|c|c|c|c|c|c|}
\hline & & & & $\begin{array}{l}\text { características, testes laboratoriais } \mathrm{e} \text { de } \\
\text { radiodiagnóstico. }\end{array}$ & $\begin{array}{l}\text { linfócitos, leucopenia, aumento de LDH, } \\
\text { CRP e prolactina. Pacientes internados } \\
\text { tinham níveis mais elevados de dímero-D } \\
\text { do que os pacientes ambulatoriais. }\end{array}$ & $\begin{array}{l}\text { aplicações diagnósticas, clínicas e } \\
\text { mesmo terapêuticas. }\end{array}$ \\
\hline 21 & $\begin{array}{l}\text { Laboratory findings and a } \\
\text { combined multifactorial approach } \\
\text { to predict death in critically ill } \\
\text { patients with COVID-19: a } \\
\text { retrospective study. } \\
\text { (Liu et al., 2020) }\end{array}$ & $\begin{array}{l}\text { Descrever os achados } \\
\text { laboratoriais de casos de } \\
\text { morte com doença } \\
\text { coronavírus } 2019 \text { (COVID- } \\
\text { 19) e estabelecer um } \\
\text { sistema de pontuação para a } \\
\text { previsão de morte. }\end{array}$ & $\begin{array}{l}\text { Estudo } \\
\text { observacional } \\
\text { retrospectivo } \\
\text { unicêntrico. }\end{array}$ & $\begin{array}{l}\text { Todos os pacientes foram diagnosticados com } \\
\text { COVID-19 tiveram um resultado definitivo } \\
\text { (morte ou alta) entre } 1 \text { de fevereiro de } 2020 \text { e } \\
13 \text { de março. O estudo incluiu } 336 \text { pacientes } \\
\text { adultos com doenças graves ou críticas por } \\
\text { COVID-19. }\end{array}$ & $\begin{array}{l}\text { Em um total de } 336 \text { pacientes, } 182 \text { tinham } \\
\text { um ou mais subjacentes condições. Ao } \\
\text { todo, } 34 \text { pacientes morreram durante a } \\
\text { internação enquanto } 302 \text { tiveram alta. Os } \\
\text { parâmetros laboratoriais demonstraram } \\
\text { níveis de leucócitos, neutrófilos, ureia } \\
\text { sérica, nitrogênio (BUN), dímero-D e } \\
\text { proteína c reativa maiores em pacientes não } \\
\text { sobreviventes. }\end{array}$ & $\begin{array}{l}\text { Três fatores, incluindo } \\
\text { diminuição de linfócitos e } \\
\text { dímero-D elevado foram } \\
\text { relacionados com a mortalidade } \\
\text { de COVID-19. Um multifatorial } \\
\text { combinado modelo de previsão } \\
\text { com alta precisão foi } \\
\text { desenvolvido para prever o } \\
\text { resultado clínico desses pacientes. }\end{array}$ \\
\hline 22 & $\begin{array}{l}\text { Acute cerebrovascular disease } \\
\text { following COVID-19: a single } \\
\text { center, retrospective, } \\
\text { observational study. } \\
\text { (Y. Li et al., 2020c) }\end{array}$ & $\begin{array}{l}\text { Avaliar os pacientes com } \\
\text { COVID-19 com ou sem } \\
\text { início de doença } \\
\text { cerebrovascular aguda. } \\
\text { Saber os índices de DCV } \\
\text { após a COVID-19. }\end{array}$ & $\begin{array}{l}\text { Estudo } \\
\text { retrospectivo } \\
\text { unicêntrico. }\end{array}$ & $\begin{array}{l}\text { Foi incluído um total de } 219 \text { pacientes com } \\
\text { COVID-19 Foram coletados características } \\
\text { demográficas e clínicas, descobertas } \\
\text { laboratoriais, tratamentos e os desfechos } \\
\text { clínicos. Além disso, características clínicas e } \\
\text { achados laboratoriais de pacientes com } \\
\text { COVID-19 com ou sem DCV de início foram } \\
\text { comparados. }\end{array}$ & $\begin{array}{l}\text { De } 219 \text { pacientes, } 11 \text { desenvolveram início } \\
\text { de DCV após infecção por COVID- } 19 \text {. } \\
\text { Pacientes com DCV tinham resposta } \\
\text { inflamatória mais aumentada, incluindo } \\
\text { aumento de leucócito, proteína C reativa e } \\
\text { diminuição de linfócitos, e também } \\
\text { apresentaram maiores níveis de dímero-D, } \\
\text { indicando o estado hipercoagulável. }\end{array}$ & $\begin{array}{l}\text { A DCV aguda não é incomum na } \\
\text { COVID-19. Os resultados } \\
\text { sugerem que pacientes mais } \\
\text { velhos com fatores de risco são } \\
\text { mais propensos a desenvolver } \\
\text { DCV e que estes apresentam } \\
\text { aumento da resposta inflamatória } \\
\text { e do estado de coagulação. }\end{array}$ \\
\hline 23 & $\begin{array}{l}\text { Detection of Pulmonary } \\
\text { Embolism in Returning Travelers } \\
\text { with Hypoxemic Pneumonia due } \\
\text { to COVID-19 in Reunion Island. } \\
\text { (Larsen et al., 2020) }\end{array}$ & $\begin{array}{l}\text { Avaliar a ocorrência de } \\
\text { embolia pulmonar em } \\
\text { viajantes que retornam com } \\
\text { pneumonia hipoxêmica por } \\
\text { COVID-19. }\end{array}$ & $\begin{array}{l}\text { Estudo } \\
\text { observacional } \\
\text { retrospectivo } \\
\text { unicêntrico. }\end{array}$ & $\begin{array}{l}\text { Foram incluídos pacientes com que } \\
\text { retornaram de viagem com pneumonia } \\
\text { hipoxêmica devido a COVID-19 confirmada } \\
\text { por PCR e tomografia computadorizada. }\end{array}$ & $\begin{array}{l}\text { Os fatores associados a embolia pulmonar } \\
\text { e TVP foram níveis mais elevados de } \\
\text { dímero-D e ausência de baixa profilaxia de } \\
\text { heparina. Não houve óbitos no seguimento } \\
\text { (mínimo de } 40 \text { dias) e apenas dois } \\
\text { permaneceram hospitalizados e foram } \\
\text { desmamados da oxigenoterapia). }\end{array}$ & $\begin{array}{l}\text { A incidência de embolia } \\
\text { pulmonar e trombose venosa } \\
\text { profunda na população estudada } \\
\text { foi relativamente alta }(20 \%) \text {. }\end{array}$ \\
\hline 24 & $\begin{array}{l}\text { Clinical Features of Coronavirus } \\
\text { Disease 2019 Patients With } \\
\text { Mechanical Ventilation: A } \\
\text { Nationwide } \\
\text { Study in China. } \\
\text { (Wang et al., 2020) }\end{array}$ & $\begin{array}{l}\text { Delinear as características } \\
\text { clínicas de pacientes com } \\
\text { COVID-19 que estão em } \\
\text { ventilação mecânica. }\end{array}$ & $\begin{array}{l}\text { Estudo } \\
\text { observacional } \\
\text { prospectivo } \\
\text { multicêntrico. }\end{array}$ & $\begin{array}{l}\text { Foram avaliados } 2007 \text { casos de pacientes } \\
\text { hospitalizados de } 575 \text { hospitais na China. } \\
\text { Histórico médico, dados epidemiológicos e } \\
\text { laboratoriais foram obtidos. Desses, } 417 \\
\text { foram excluídos devido a registros médicos } \\
\text { insuficientes. }\end{array}$ & $\begin{array}{l}\text { Entre os } 1.590 \text { casos incluídos neste estudo, } \\
141 \text { receberam VM, } 122 \text { receberam } \\
\text { ventilação mecânica não invasiva (VNI) e } \\
50 \text { receberam IMV por meio de intubação } \\
\text { traqueal. Entre os pacientes que realizaram } \\
\text { testes laboratoriais na admissão, a maioria } \\
\text { dos pacientes apresentou linfocitopenia e } \\
\text { níveis elevados de proteína C reativa, } \\
\text { lactato desidrogenase, aspartato } \\
\text { aminotransferase e dímero-D. }\end{array}$ & $\begin{array}{l}\text { Os dados sugerem que idade } \\
\text { avançada, doença crônica } \\
\text { coexistente, e achados } \\
\text { laboratoriais anormais são } \\
\text { comuns no ambiente VM. } \\
\text { Dímero-d elevado }(>1,5 \mathrm{mg} / \mathrm{L}) \\
\text { na admissão pode sugerir uma } \\
\text { maior possibilidade de exigência } \\
\text { de IMV com o progresso da } \\
\text { doença e coexistência de DPOC } \\
\text { ou doença renal crônica. }\end{array}$ \\
\hline 25 & $\begin{array}{l}\text { Intensive care admissions of } \\
\text { children with } \\
\text { pediatricinflammatory } \\
\text { multisystem syndrome temporally } \\
\text { associated with SARS-CoV-2 } \\
\text { (PIMS-TS) in the UK: a } \\
\text { multicentre observational study. }\end{array}$ & 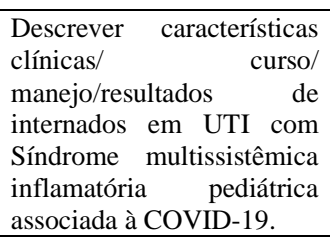 & $\begin{array}{l}\text { Estudo } \\
\text { observacional } \\
\text { prospectivo } \\
\text { multicêntrico. }\end{array}$ & $\begin{array}{l}\text { Incluídos } 78 \text { pacientes menores de } 18 \text { anos, } \\
\text { admitidos em UTI no Reino Unido. Os dados } \\
\text { clínicos e outros foram enviados para análise } \\
\text { central por meio de uma ferramenta de } \\
\text { pesquisa da web. }\end{array}$ & $\begin{array}{l}\text { Durante os primeiros } 4 \text { dias de admissão } \\
\text { ocorreu redução na proteína } C \text { reativa, } \\
\text { dímero-D e ferritina, enquanto aumentaram } \\
\text { os linfócitos e a troponina. Trinta e seis } \\
\text { foram ventilados, } 65 \text { necessitaram de } \\
\text { infusões vasoativas, } 57 \text { receberam } \\
\text { esteroides, } 59 \text { receberam imunoglobulina }\end{array}$ & $\begin{array}{l}\text { Quase um terço dos pacientes } \\
\text { apresentaram anormalidades nas } \\
\text { artérias coronárias, os resultados } \\
\text { de longo prazo para esses achados } \\
\text { não sejam claros. }\end{array}$ \\
\hline
\end{tabular}


Research, Society and Development, v. 11, n. 2, e21011225731, 2022

(CC BY 4.0) | ISSN 2525-3409 | DOI: http://dx.doi.org/10.33448/rsd-v11i2.25731

\begin{tabular}{|c|c|c|c|c|c|c|}
\hline & (Davies et al., 2020) & & & & \begin{tabular}{llll|}
$\begin{array}{l}\text { intravenosa } \\
\text { biológicas. }\end{array}$ & 17 & receberam terapias \\
\end{tabular} & \\
\hline 26 & $\begin{array}{l}\text { Evaluación de las características } \\
\text { clínicas y evolución de pacientes } \\
\text { con COVID-19 a partir de una } \\
\text { serie de } 1000 \text { pacientes atendidos } \\
\text { en servicios de urgencias } \\
\text { españoles. } \\
\text { (Rodrigo-Gil et al., 2020) }\end{array}$ & $\begin{array}{l}\text { Descrever as características } \\
\text { clínicas de covid com } \\
\text { COVID-19 atendidos em } \\
\text { serviços de emergência } \\
\text { Hospitais espanhóis (HED) } \\
\text { e avaliar a sua associação } \\
\text { com os resultados da sua } \\
\text { evolução. }\end{array}$ & $\begin{array}{l}\text { Estudo } \\
\text { observacional } \\
\text { prospectivo } \\
\text { multicêntrico. }\end{array}$ & $\begin{array}{l}\text { Informações demográficas e de saúde de linha } \\
\text { de base, incluindo condições concomitantes; } \\
\text { características clínicas relacionadas à } \\
\text { consulta ao pronto-socorro e resultados de } \\
\text { exames complementares; e os tratamentos } \\
\text { foram registrados durante todo o episódio no } \\
\text { PS. }\end{array}$ & $\begin{array}{l}\text { Foram diretamente associadas a piores } \\
\text { resultados evolutivos (mortalidade e evento } \\
\text { combinado) idade e obesidade; exames } \\
\text { complementares foram infiltrados } \\
\text { pulmonares bilaterais e cardiomegalia } \\
\text { radiológica, além de linfopenia, } \\
\text { hiperplaquetose, dímero-D> } 500 \mathrm{mg} / \mathrm{dL} \text { e } \\
\text { desidrogenase láctica> } 250 \text { UI } / \mathrm{L} \text { em } \\
\text { exames laboratoriais. }\end{array}$ & 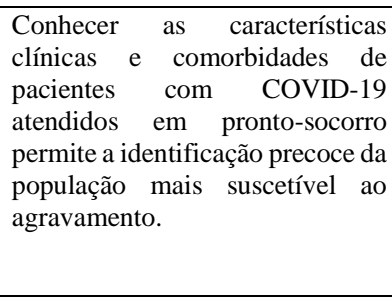 \\
\hline 27 & $\begin{array}{l}\text { Von Willebrand factor (vWF): } \\
\text { marker of endothelial damage and } \\
\text { thrombotic risk in COVID-19? } \\
\text { (Ladikou et al., 2020) }\end{array}$ & $\begin{array}{l}\text { Determinar se o marcador } \\
\text { de endotélio vWF pode } \\
\text { estratificar a doença } \\
\text { COVID-19. }\end{array}$ & $\begin{array}{l}\text { Estudo } \\
\text { observacional } \\
\text { retrospectivo } \\
\text { unicêntrico. }\end{array}$ & $\begin{array}{l}\text { Foram incluídos } 24 \text { pacientes consecutivos } \\
\text { que foram admitidos na UTI ou enfermaria de } \\
\text { alto cuidado para gestão ativa de COVID-19 } \\
\text { e que foram investigados sobre coagulopatia } \\
\text { em seus cuidados hospitalares de rotina. }\end{array}$ & $\begin{array}{l}\text { Tromboembolismo venoso ocorreu em } \\
25 \% \text { dos pacientes e a mortalidade foi de } \\
16,7 \% \text {. Fibrinogênio e dímero-D estavam } \\
\text { aumentados nos pacientes COVID-19, e o } \\
\text { fator VIIIc e FvW foram significativamente } \\
\text { maiores em pacientes que morreram. } \\
\text { Houve também associação entre COVID- } \\
19 \text { e grupo sanguíneo não-O e de TEV com } \\
\text { sangue grupo A. }\end{array}$ & $\begin{array}{l}\text { Mais estudos são necessários para } \\
\text { avaliar o uso do FvW para } \\
\text { estratificar o risco trombótico em } \\
\text { COVID-19 e determinar se o } \\
\text { FvW elevado está contribuindo } \\
\text { para a patogênese da doença. }\end{array}$ \\
\hline 28 & $\begin{array}{l}\text { Historically controlled } \\
\text { comparison of glucocorticoids } \\
\text { with or without tocilizumab versus } \\
\text { supportive care only in patients } \\
\text { with COVID-19-associated } \\
\text { cytokine storm syndrome: results } \\
\text { of the CHIC study. } \\
\text { (Ramiro et al., 2020) }\end{array}$ & $\begin{array}{l}\text { Investigar em pacientes } \\
\text { COVID-19 grave com CSS } \\
\text { se } \\
\text { glicocorticoides/tocilizuma } \\
\text { be promovem melhora e } \\
\text { reduzem mortalidade em } \\
\text { comparação com } \\
\text { tratamento de suporte. }\end{array}$ & $\begin{array}{l}\text { Estudo } \\
\text { observacional } \\
\text { prospectivo } \\
\text { unicêntrico. }\end{array}$ & $\begin{array}{l}\text { Pacientes com COVID-19 associado à CSS } \\
\text { que receberam glicocorticoide e tocilizumabe } \\
\text { foram amostrados e pareados com grupo } \\
\text { controle de COVID-19 que receberam apenas } \\
\text { terapia de suporte (total de } 172 \text { pacientes), } \\
\text { ambos os grupos com pacientes admitidos } \\
\text { entre } 7 \text { de março e } 31 \text { de março. A } \\
\text { distribuição por idade e sexo foram } \\
\text { semelhantes. }\end{array}$ & $\begin{array}{l}\text { Biomarcadores de síndrome de tempestade } \\
\text { de citocinas (CSS) mostraram altos níveis } \\
\text { de proteína C reativa, ferritina e dímero D } \\
\text { em ambos os grupos, sendo esses dois } \\
\text { últimos, ligeiramente mais elevados no } \\
\text { grupo sem tratamento. }\end{array}$ & $\begin{array}{l}\text { A estratégia envolvendo o uso de } \\
\text { metilprednisolona, seguida por } \\
\text { tocilizumabe podem acelerar a } \\
\text { recuperação respiratória ou } \\
\text { diminuir mortalidade hospitalar. }\end{array}$ \\
\hline 29 & $\begin{array}{l}\text { Determinants of COVID-19 } \\
\text { disease severity in patients with } \\
\text { underlying rheumatic disease } \\
\text { Sieiro. } \\
\text { (Santos et al 2020) }\end{array}$ & $\begin{array}{l}\text { Descrever as características } \\
\text { epidemiológicas r de } \\
\text { pacientes com doenças } \\
\text { reumáticas internados com } \\
\text { COVID-19. }\end{array}$ & $\begin{array}{l}\text { Estudo } \\
\text { observacional } \\
\text { prospectivo } \\
\text { unicêntrico. }\end{array}$ & $\begin{array}{l}\text { Foram incluídos pacientes maiores de } 18 \\
\text { anos, pacientes com diagnóstico médico de } \\
\text { doença reumática inflamatória e pacientes } \\
\text { que necessitaram de internação. }\end{array}$ & $\begin{array}{l}\text { Em análises univariadas, pacientes que } \\
\text { morreram de COVID-19 tiveram maior } \\
\text { marcadores de hiperinflamação que os } \\
\text { pacientes que sobreviveram: proteína C } \\
\text { reativa; lactato desidrogenase, ferritina } \\
\text { sérica e dímero-D. }\end{array}$ & $\begin{array}{l}\text { Elevação de LDH, CRP, ferritina } \\
\text { sérica e dímero-D foram mais } \\
\text { frequentemente em pacientes } \\
\text { críticos ao longo da } \\
\text { hospitalização, sugerindo que } \\
\text { doenças reumáticas estão } \\
\text { intimamente relacionadas à } \\
\text { gravidade da COVID-19. }\end{array}$ \\
\hline 30 & $\begin{array}{l}\text { Angiopoietin-2 as a marker of } \\
\text { endothelial activation is a good } \\
\text { predictor factor for intensive care } \\
\text { unit admission of COVID-19 } \\
\text { patients. } \\
\text { (Smadja et al., 2020) }\end{array}$ & $\begin{array}{l}\text { Explorar o dano endotelial } \\
\text { e biomarcadores } \\
\text { relacionados à ativação em } \\
\text { pacientes com COVID-19 } \\
\text { com critérios de internação } \\
\text { para encaminhamento para }\end{array}$ & $\begin{array}{c}\text { Estudo } \\
\text { observacional. }\end{array}$ & $\begin{array}{l}\text { Foram incluídos pacientes adultos, com } \\
\text { síndrome infecciosa e suspeita de COVID- } \\
19 \text { internados na enfermaria ou UTI. }\end{array}$ & $\begin{array}{l}\text { O estudo incluiu } 40 \text { pacientes } \\
\text { consecutivos que se apresentaram no } \\
\text { pronto-socorro com diagnóstico } \\
\text { confirmado de COVID-19. Pacientes } \\
\text { admitidos na UTI tiveram níveis mais } \\
\text { elevados de dímero-D na internação e }\end{array}$ & $\begin{array}{l}\text { Esses dados podem apoiar o uso } \\
\text { de anticoagulação na fase inicial } \\
\text { da doença para prevenir doenças } \\
\text { respiratórias e manifestações } \\
\text { micro trombóticas renais durante } \\
\text { evolução da COVID-19 } \\
\end{array}$ \\
\hline
\end{tabular}


Research, Society and Development, v. 11, n. 2, e21011225731, 2022

(CC BY 4.0) | ISSN 2525-3409 | DOI: http://dx.doi.org/10.33448/rsd-v11i2.25731

\begin{tabular}{|c|c|c|c|c|c|c|}
\hline & & $\begin{array}{l}\text { UTI e / ou piora } \\
\text { respiratória. }\end{array}$ & & & $\begin{array}{l}\text { níveis de E-selectina e angiopoietina-2 } \\
\text { aumentados em relação ao grupo da } \\
\text { enfermaria. }\end{array}$ & \\
\hline 31 & $\begin{array}{l}\text { Clinical characteristics and risk } \\
\text { factors of patients with severe } \\
\text { COVID-19 in Jiangsu province, } \\
\text { China: a retrospective multicentre } \\
\text { cohort study. } \\
\text { (S. Liu et al., 2020) }\end{array}$ & $\begin{array}{l}\text { Descrever as características } \\
\text { dos pacientes com COVID- } \\
19 \text { e fatores associados à } \\
\text { apresentação grave ou } \\
\text { criticamente doente na } \\
\text { província de Jiangsu, } \\
\text { China. }\end{array}$ & $\begin{array}{l}\text { Estudo } \\
\text { retrospectivo } \\
\text { multicêntrico. }\end{array}$ & $\begin{array}{l}\text { Todos os pacientes incluídos tiveram } \\
\text { diagnóstico de COVID-19 baseado na } \\
\text { história epidemiológica, clínica, } \\
\text { manifestações, imagem de pneumonia em } \\
\text { Tomografias computadorizadas } \\
\text { confirmação laboratorial. }\end{array}$ & $\begin{array}{l}561(89,8 \%) \text { pacientes eram assintomáticos } \\
\text { / leves / moderados e } 64(10,2 \%) \text { graves ou } \\
\text { críticos. Casos graves apresentaram } \\
\text { aumento de proteína C reativa, fibrinogênio } \\
\text { e dímero-D. Fatores também associados a } \\
\text { graves ou infecção crítica incluiu idade, } \\
\text { contagem de linfócitos e opacidade } \\
\text { pulmonar na TC na admissão. }\end{array}$ & $\begin{array}{l}\text { A gravidade da COVID-19 está } \\
\text { associada à características } \\
\text { epidemiológicas, clínicas, testes } \\
\text { laboratoriais e achados } \\
\text { radiológicos. Idade, contagem de } \\
\text { linfócitos e opacidade pulmonar } \\
\text { na TC na admissão foi associada } \\
\text { ao risco de COVID-19 grave. }\end{array}$ \\
\hline 32 & $\begin{array}{l}\text { Remote rehabilitation for patients } \\
\text { with COVID-19. } \\
\text { (Sakai et al., 2020) }\end{array}$ & $\begin{array}{lrr}\text { Descrever a } & \text { eficácia } & \text { e } \\
\text { risco da } & \text { gestão } & \text { de } \\
\text { reabilitação } & \text { remota } & \text { para } \\
\text { pacientes } & \text { com doença } \\
\text { COVID-19. } & & \end{array}$ & $\begin{array}{l}\text { Estudo coorte } \\
\text { retrospectivo } \\
\text { unicêntrico. }\end{array}$ & $\begin{array}{l}\text { Foram coletados dados de idade, sexo, } \\
\text { capacidade física, reabilitação, necessidade } \\
\text { de intubação ou oxigenação por membrana } \\
\text { extracorpórea, grau de pneumonia, } \\
\text { oxigenoterapia desde o início da reabilitação, } \\
\text { dímero-D e níveis de proteína C reativa. Os } \\
\text { pacientes }\end{array}$ & $\begin{array}{l}\text { Dos } 44 \text { pacientes hospitalizados na } \\
\text { enfermaria de COVID-19, 43 foram } \\
\text { submetidos à reabilitação, sendo 18, sob } \\
\text { reabilitação remota, ao quais eram mais } \\
\text { jovens, e o restante à reabilitação direta (no } \\
\text { hospital). Níveis de D-dímero e PCR no } \\
\text { início da reabilitação e ao longo do curso da } \\
\text { doença foram significativamente maiores } \\
\text { no grupo de reabilitação direta. }\end{array}$ & $\begin{array}{l}\text { A reabilitação eficaz e segura foi } \\
\text { realizada em } 41,9 \% \text { dos pacientes } \\
\text { com COVID- } 19 \text { neste estudo, o } \\
\text { que resultou em melhor nas zonas } \\
\text { de COVID- } 19 .\end{array}$ \\
\hline 33 & $\begin{array}{l}\text { Thrombotic and haemorrhagic } \\
\text { complications in critically ill } \\
\text { patients with COVID-19: a } \\
\text { multicentre observational study. } \\
\text { (Shah et al., 2020) }\end{array}$ & $\begin{array}{l}\text { Definir a incidência de } \\
\text { trombose e } \\
\text { complicações hemorrágicas } \\
\text { em pacientes graves com } \\
\text { COVID-19. }\end{array}$ & $\begin{array}{l}\text { Estudo } \\
\text { observacional } \\
\text { retrospectivo } \\
\text { multicêntrico. }\end{array}$ & $\begin{array}{l}\text { O estudo incluiu } 187 \text { pacientes entre } 49 \text { e } 64 \\
\text { anos. Características clínicas, dados } \\
\text { laboratoriais, perfis de tromboelastografia e } \\
\text { dados de resultados clínicos foram avaliados } \\
\text { entre pacientes com e sem complicações } \\
\text { trombóticas. }\end{array}$ & $\begin{array}{l}\text { Pacientes que apresentaram complicações } \\
\text { trombóticas tinham dímero-D, ferritina, } \\
\text { troponina e níveis de contagem de } \\
\text { leucócitos mais elevados na admissão à } \\
\text { UTI e permaneceram por mais tempo } \\
\text { quando comparados aos que não } \\
\text { desenvolveram este evento. }\end{array}$ & $\begin{array}{l}\text { Pacientes críticos com COVID- } \\
19 \text { apresentaram taxas de } \\
\text { complicações trombóticas. }\end{array}$ \\
\hline 34 & $\begin{array}{l}\text { Thrombo-inflammatory features } \\
\text { predicting mortality in patients } \\
\text { with COVID-19: The FAD-85 } \\
\text { score. } \\
\text { (J. Wang et al., 2020b) }\end{array}$ & $\begin{array}{l}\text { Determinar parâmetros } \\
\text { trombo inflamatórios para } \\
\text { determinar a gravidade e } \\
\text { prognóstico da COVID-19. }\end{array}$ & $\begin{array}{l}\text { Estudo } \\
\text { retrospectivo } \\
\text { unicêntrico. }\end{array}$ & $\begin{array}{l}\text { Foram incluídos } 234 \text { pacientes adultos } \\
\text { internados. No total, } 199 \text { e } 44 \text { pacientes foram } \\
\text { incluídos nos conjuntos de treinamento e } \\
\text { teste, respectivamente para explorar } \\
\text { preditores de doença e mortalidade. }\end{array}$ & $\begin{array}{l}\text { Aumento de ferritina, fator de necrose } \\
\text { tumoral e dímero-D e diminuição de } \\
\text { albumina foram associados à gravidade da } \\
\text { doença. Idade avançada e aumento de } \\
\text { ferritina e interleucina-6 foram associadas } \\
\text { à mortalidade. }\end{array}$ & $\begin{array}{l}\text { Biomarcadores } \\
\text { tromboinflamatórios foram } \\
\text { associados à gravidade e } \\
\text { resultado de COVID-19. }\end{array}$ \\
\hline 35 & $\begin{array}{l}\text { Overview of Early Cases of } \\
\text { Coronavirus Disease 2019 } \\
\text { (COVID-19) at a Tertiary Care } \\
\text { Centre in North India. } \\
\text { (Sharma et al., 2020) }\end{array}$ & $\begin{array}{l}\text { Descrever a experiência do } \\
\text { tratamento dos primeiros } \\
\text { casos de pacientes com } \\
\text { COVID-19 na índia. }\end{array}$ & $\begin{array}{l}\text { Estudo } \\
\text { observacional } \\
\text { retrospectivo } \\
\text { unicêntrico. }\end{array}$ & $\begin{array}{l}\text { Foram incluídos } 75 \text { pacientes positivos para } \\
\text { COVID-19, dos quais, } 56 \text { eram homens. } \\
\text { Dados clínico, epidemiológicos, } \\
\text { laboratoriais, de tratamento e de resultados } \\
\text { dos pacientes foram avaliados. }\end{array}$ & $\begin{array}{l}\mathrm{Na} \text { análise, houve linfopenia, eosinopenia e } \\
\text { trombocitopenia nos pacientes estudados. } \\
\text { Proteína C reativa, dímero- D, ferritina, } \\
\text { PDF e Il-6 foram maiores em pacientes que } \\
\text { necessitaram de oxigenoterapia. }\end{array}$ & $\begin{array}{lll}\text { Sem terapia } & \text { comprovada } & \text { para } \\
\text { combater a } & \text { pandemia e sem } \\
\text { previsão de vacinas no futuro } \\
\text { próximo, deve-se } & \text { adotar } \\
\text { estratégias preventivas. } & \\
\end{array}$ \\
\hline 36 & $\begin{array}{l}\text { COVID-19 and } \\
\text { Thromboembolism in } \\
\text { Intensive } \\
\text { Care or Medical Ward. } \\
\\
\text { (Avruscio et al., 2020) }\end{array}$ & $\begin{array}{l}\text { Avaliar a incidência de } \\
\text { trombo embolismo venoso } \\
\text { (TEV) em pacientes com } \\
\text { COVID-19 internados em } \\
\text { unidades de terapia }\end{array}$ & $\begin{array}{c}\text { Estudo } \\
\text { observacional } \\
\text { prospectivo } \\
\text { unicêntrico. }\end{array}$ & $\begin{array}{l}\text { Foi incluído } 85 \text { pacientes. Os pacientes foram } \\
\text { submetidos a ultrassonografia sistemática da } \\
\text { jugular interna e das veias dos membros } \\
\text { superiores e inferiores a cada } 7 \text { dias }( \pm 1 \text { dia) } \\
\text { após a admissão; e, se negativo, uma vez por } \\
\text { semana até a alta ou óbito. Em caso de }\end{array}$ & $\begin{array}{l}\text { Dos } 85 \text { pacientes, } 44 \text { foram internados na } \\
\text { enfermaria e } 41 \text { na UTI. Evento } \\
\text { hemorrágico foi observado em } 1 \text { paciente } \\
\text { de UTI em alta dose de enoxaparina; } 3 \\
\text { pacientes apresentaram TEV. Trombose } \\
\text { relacionada ao cateter ocorreu em } 11\end{array}$ & $\begin{array}{l}\text { Os pacientes com COVID-19 } \\
\text { internados em enfermaria ou UTI } \\
\text { apresentaram alta frequência de } \\
\text { tromboembolismo venoso, apesar } \\
\text { da tromboprofilaxia em dose } \\
\text { padrão ou alta. }\end{array}$ \\
\hline
\end{tabular}


Research, Society and Development, v. 11, n. 2, e21011225731, 2022

(CC BY 4.0) | ISSN 2525-3409 | DOI: http://dx.doi.org/10.33448/rsd-v11i2.25731

\begin{tabular}{|c|c|c|c|c|c|c|}
\hline & & $\begin{array}{l}\text { intensiva } \quad(\mathrm{UTI}) \\
\text { enfermarias médicas. }\end{array}$ & & $\begin{array}{l}\begin{array}{l}\text { suspeita de embolia } \\
\text { angiotomografi }\end{array} \\
\begin{array}{c}\text { pulmonar, uma } \\
\text { computadorizada }\end{array} \\
\text { multidetectores foram realizadas. }\end{array}$ & $\begin{array}{l}\text { pacientes. Os pacientes apresentaram } \\
\text { contagem de plaquetas e tempos de } \\
\text { coagulação dentro da faixa normal, embora } \\
\text { níveis elevados de dímero-D, sendo ainda } \\
\text { maiores nos da UTI do que na enfermaria. }\end{array}$ & \\
\hline 37 & $\begin{array}{l}\text { Risk factors for severe covid-19 in } \\
\text { middle-aged patients without } \\
\text { comorbidities: a multicentre } \\
\text { retrospective study. } \\
\text { (P. Wang et al., 2020) }\end{array}$ & \begin{tabular}{l}
\multicolumn{3}{l}{ Avaliar os fatores de risco } \\
em pacientes com \\
comorbidades portadores \\
de COVID-19.
\end{tabular} & $\begin{array}{l}\text { Estudo } \\
\text { observacional } \\
\text { retrospectivo } \\
\text { multicêntrico. }\end{array}$ & $\begin{array}{l}\text { Foram incluídos } 441 \text { pacientes com COVID- } \\
\text { 19. A presença de SARS COV-2 em amostras } \\
\text { respiratórias foi confirmada por RT-PCR. Os } \\
\text { pacientes com comorbidades, mulheres } \\
\text { grávidas e pacientes mais jovens maiores de } \\
18 \text { anos foram excluídos. }\end{array}$ & $\begin{array}{l}\text { Os níveis de glóbulos brancos, contagem de } \\
\text { neutrófilos, ALT, LDH e prolactina foram } \\
\text { maiores em pacientes com } \\
\text { desenvolvimento de grave doença, além de } \\
\text { aumento da proporção de neutrófilos para } \\
\text { linfócitos e dímero-D. }\end{array}$ & $\begin{array}{l}\text { O índice combinado de NLR e } \\
\text { dímero-D maior que } 1 \mu \mathrm{g} / \mathrm{ml} \\
\text { pode ser um preditor potencial e } \\
\text { confiável para a incidência de } \\
\text { doença grave em pacientes com } \\
\text { COVID-19. }\end{array}$ \\
\hline 38 & $\begin{array}{l}\text { D-dimer cut-off points and risk of } \\
\text { venous thromboembolism in adult } \\
\text { hospitalized patients with } \\
\text { COVID-19. } \\
\text { (Choi et al., 2020) }\end{array}$ & $\begin{array}{l}\text { Relatar as taxas de } \\
\text { trombose endovenosa } \\
\text { (TEV) e analisar o } \\
\text { desempenho do diagnóstico } \\
\text { e relação do D-dímero com } \\
\text { o tromboembolismo } \\
\text { venoso. }\end{array}$ & $\begin{array}{l}\text { Estudo } \\
\text { observacional } \\
\text { retrospectivo } \\
\text { multicêntrico. }\end{array}$ & $\begin{array}{l}\text { Um total de } 1.739 \text { pacientes hospitalizados } \\
\text { com COVID- } 19 \text { foram incluídos no estudo. } \\
\text { Foram incluídos todos os adultos } \\
\text { confirmados por teste de PCR. O desfecho } \\
\text { primário foi TEV, compreendendo trombose } \\
\text { venosa profunda (TVP) da extremidade } \\
\text { superior ou inferior e embolia pulmonar } \\
\text { aguda. }\end{array}$ & $\begin{array}{l}\text { Uma proporção maior de pacientes que } \\
\text { necessitaram de ventilação mecânica teve } \\
\text { TEV em comparação com os que não } \\
\text { necessitaram. Na análise do dímero-D, a } \\
\text { elevação deste foi associada com maior } \\
\text { risco de TEV. }\end{array}$ & $\begin{array}{l}\text { A elevações acentuadas do } \\
\text { dímero-D é um fator de risco para } \\
\text { TEV em pacientes com COVID- } \\
19 .\end{array}$ \\
\hline 39 & $\begin{array}{l}\text { Analysis of dynamic disturbance } \\
\text { in blood coagulation function of } \\
\text { patients with Coronavirus Disease } \\
2019 \text {. } \\
\text { (N. Chen et al., 2020) }\end{array}$ & $\begin{array}{l}\text { Avaliar as diferenças e } \\
\text { mudanças da função de } \\
\text { coagulação do sangue em } \\
\text { pacientes com COVID-19. }\end{array}$ & $\begin{array}{l}\text { Estudo } \\
\text { observacional } \\
\text { retrospectivo } \\
\text { unicêntrico. }\end{array}$ & $\begin{array}{l}\text { Foram avaliados os dados clínicos de } 261 \\
\text { pacientes com COVID-19 confirmados por } \\
\text { PCR em tempo real (RT-PCR) positiva para } \\
\text { SARS-CoV-2 }\end{array}$ & $\begin{array}{l}\mathrm{Na} \text { admissão, as diferenças estatísticas } \\
\text { foram observadas nos parâmetros } \\
\text { laboratoriais entre pacientes comuns, } \\
\text { graves e críticos. No decorrer internação, os } \\
\text { valores de pico de coagulação e a rotina } \\
\text { sanguínea foram monitorados. Houve } \\
\text { aumento entre pacientes comuns, graves e } \\
\text { críticos em níveis de dímero-D. }\end{array}$ & $\begin{array}{l}\text { A função de coagulação dos } \\
\text { pacientes com COVID-19 } \\
\text { mostrou diferentes graus de } \\
\text { anormalidade. Os índices da } \\
\text { função de coagulação, como D- } \\
\text { dímero e FDP, podem servir } \\
\text { como marcadores para estimar a } \\
\text { taxa mortalidade entre pacientes } \\
\text { com COVID-19. }\end{array}$ \\
\hline 40 & $\begin{array}{l}\text { Pulmonary embolism in COVID- } \\
\text { 19: Clinical characteristics and } \\
\text { cardiac implications. } \\
\text { (Kho et at., 2020) }\end{array}$ & $\begin{array}{l}\text { Avaliar as características de } \\
\text { pacientes com COVID-19 } \\
\text { com diagnóstico de embolia } \\
\text { pulmonar (EP). }\end{array}$ & $\begin{array}{l}\text { Estudo } \\
\text { observacional } \\
\text { retrospectivo } \\
\text { multicêntrico. }\end{array}$ & $\begin{array}{l}\text { O estudo foi realizado em pacientes } \\
\text { diagnosticados com COVID-19 e EP EP } \\
\text { diagnosticados com EP após tomografia. } \\
\text { Dados demográficos dos pacientes, } \\
\text { comorbidades, queixas apresentadas e } \\
\text { investigações de pacientes internados foram } \\
\text { registrados. }\end{array}$ & $\begin{array}{l}\text { Dentre os sintomas mais comuns foram } \\
\text { relatadas dispneia e febre antes da } \\
\text { admissão. Todos os pacientes tiveram } \\
\text { níveis de dímero-D significativamente } \\
\text { elevados, lactato desidrogenase (LDH), } \\
\text { proteína C reativa (CRP), ferritina e } \\
\text { protrombina vezes. A distribuição dos EP } \\
\text { correlacionou-se com o padrão de } \\
\text { consolidação observado na tomografia em } \\
9 \text { pacientes. }\end{array}$ & 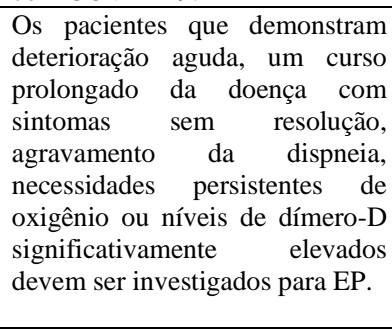 \\
\hline 41 & $\begin{array}{l}\text { Clinical Characteristics } \\
\text { Outcomes of Patients With } \\
\text { Diabetes Admitted for COVID-19 } \\
\text { Treatment in Dubai: Single-Centre } \\
\text { Cross-Sectional Study. } \\
\text { (Bhatti et al., 2020). }\end{array}$ & $\begin{array}{l}\text { Descrever as características } \\
\text { clínicas e os resultados de } \\
\text { pacientes com diabetes que } \\
\text { foram internados ao nosso } \\
\text { hospital para tratamento } \\
\text { com COVID-19. }\end{array}$ & $\begin{array}{l}\text { Estudo } \\
\text { observacional } \\
\text { retrospectivo } \\
\text { transversal } \\
\text { unicêntrico. }\end{array}$ & $\begin{array}{l}\text { Este estudo incluiu pacientes com diabetes ou } \\
\text { pré-diabetes internados com COVID- } 19 \text {. } \\
\text { Dados demográficos, laboratoriais e achados } \\
\text { de imagem (radiografia de tórax e TCAR de } \\
\text { tórax), e o teste de glicose no sangue capilar } \\
\text { foram realizados na admissão e extraídos dos } \\
\text { prontuários médicos. }\end{array}$ & $\begin{array}{l}\text { Foram incluídos } 103 \text { pacientes que } \\
\text { apresentavam diabetes ou pré-diabetes. } \\
\text { Dados laboratoriais demonstraram que } \\
\text { pacientes que precisavam de enfermaria ou } \\
\text { aqueles que necessitavam de cuidados } \\
\text { intensivos apresentaram níveis elevados de }\end{array}$ & $\begin{array}{l}\text { Análises laboratoriais revelaram } \\
\text { aumento de fibrinogênio, dímero- } \\
\mathrm{D} \text {, ferritina e proteína C reativa na } \\
\text { admissão em pacientes que } \\
\text { posteriormente precisaram de } \\
\text { cuidados intensivos do que }\end{array}$ \\
\hline
\end{tabular}


Research, Society and Development, v. 11, n. 2, e21011225731, 2022

(CC BY 4.0) | ISSN 2525-3409 | DOI: http://dx.doi.org/10.33448/rsd-v11i2.25731

\begin{tabular}{|c|c|c|c|c|c|c|}
\hline & & & & & $\begin{array}{l}\text { fibrinogênio, dímero-D, proteína } \mathrm{C} \text { reativa, } \\
\text { entre outros. }\end{array}$ & $\begin{array}{l}\text { naqueles que precisaram de } \\
\text { enfermaria. }\end{array}$ \\
\hline 42 & $\begin{array}{l}\text { Clinical analysis of } 132 \text { cases } \\
\text { COVID-19 from Wuhan. } \\
\text { (H. Y. Li et al., 2020). }\end{array}$ & $\begin{array}{l}\text { Determinar correlações de } \\
\text { parâmetros dos pacientes } \\
\text { com a gravidade da doença } \\
\text { em pacientes com COVID- } \\
19 .\end{array}$ & $\begin{array}{l}\text { Estudo } \\
\text { observacional } \\
\text { retrospectivo } \\
\text { unicêntrico. }\end{array}$ & $\begin{array}{l}\text { Foram analisados } 132 \text { pacientes com } \\
\text { COVID-19 diagnosticados por PCR. De } \\
\text { acordo com a gravidade eram classificados } \\
\text { como portador de doença crítica, grave ou } \\
\text { leve. Foram analisados dados demográficos, } \\
\text { sinais, sintomas, resultados laboratoriais e } \\
\text { achados de TC. }\end{array}$ & $\begin{array}{l}\text { Noventa pacientes apresentaram doença } \\
\text { leve, } 32 \text { doenças grave e } 10 \text { doença crítica. } \\
\text { O grupo grave/crítico eram de idosos e com } \\
\text { maior proporção de homens e mortalidade. } \\
\text { Em relação ao grupo leve, o grave/crítico } \\
\text { teve aumento de leucócitos, proteína C } \\
\text { reativa, dímero-D, peptídeo natriurético } \\
\text { tipo B (BNP), enzima hepática e } \\
\text { miocárdicas, e diminuição dos níveis de } \\
\text { linfócitos e pressão parcial de oxigênio no } \\
\text { sangue. }\end{array}$ & $\begin{array}{l}\text { Pacientes graves eram mais } \\
\text { propensas a ser do sexo masculino } \\
\text { e idosos. A gravidade da doença } \\
\text { se correlacionou com o aumento } \\
\text { de leucócitos, proteína C reativa, } \\
\text { BNP, enzimas hepáticas e } \\
\text { miocárdicas e diminuição da } \\
\text { pressão parcial de linfócitos e } \\
\text { oxigênio no sangue. }\end{array}$ \\
\hline 43 & $\begin{array}{l}\text { Risk factors for non- } \\
\text { invasive/invasive } \text { ventilatory } \\
\text { support inpatients with COVID-19 } \\
\text { pneumonia: A retrospective study } \\
\text { within a multidisciplinary } \\
\text { approach. } \\
\text { (Suardi et al., 2020). }\end{array}$ & $\begin{array}{l}\text { Investigar os fatores de } \\
\text { risco para suporte } \\
\text { ventilatório não invasivo / } \\
\text { invasivo (NI / I-VS) em } \\
\text { pacientes com doença de } \\
\text { coronavírus } 2019 \text { (COVID- } \\
\text { 19). }\end{array}$ & $\begin{array}{l}\text { Estudo } \\
\text { observacional } \\
\text { retrospectivo } \\
\text { unicêntrico }\end{array}$ & $\begin{array}{l}\text { Foram incluídos } 97 \text { pacientes. NI/I-VS foi } \\
\text { definido como a necessidade de pressão } \\
\text { positiva contínua nas vias aéreas (CPAP) ou } \\
\text { pressão positiva de } 2 \text { níveis nas vias aéreas } \\
\text { (BPAP) ou ventilação mecânica. }\end{array}$ & $\begin{array}{l}\text { A idade média foi de } 64 \text { anos; } \\
\text { comorbidades estavam presentes em } 60 \% \\
\text { dos pacientes, com hipertensão sendo o } \\
\text { mais comum, seguido pelo DM2. Pacientes } \\
\text { com índice de massa corporal> } 30 \text {, diabetes } \\
\text { mellitus tipo } 2 \text { e dímero-D elevado na } \\
\text { admissão foram mais frequentemente } \\
\text { submetidos a NI/I-VS. }\end{array}$ & $\begin{array}{l}\text { Temperatura }>38 \mathrm{C}, \mathrm{LDH}>250 \mathrm{U} \\
/ 1 \text { e dímero } \mathrm{D}>1000 \mathrm{ng} / \mathrm{mL} \text { foram } \\
\text { relacionados a fatores de risco } \\
\text { independentes para NI / I-VS em } \\
\text { pacientes com COVID- } 19 .\end{array}$ \\
\hline 44 & $\begin{array}{l}\text { Risk factors for the critical illness } \\
\text { in SARSCoV-2 infection: a } \\
\text { multicenter retrospective cohort } \\
\text { study. } \\
\text { (Cheng et al., 2020) }\end{array}$ & $\begin{array}{l}\text { Identificar fatores de risco } \\
\text { independentes para servir } \\
\text { como marcadores de } \\
\text { previsão para doenças } \\
\text { críticas de infecção por } \\
\text { SARS-CoV-2. }\end{array}$ & $\begin{array}{l}\text { Estudo } \\
\text { observacional } \\
\text { retrospectivo } \\
\text { multicêntrico. }\end{array}$ & $\begin{array}{l}\text { O estudo envolveu } 252 \text { pacientes com } \\
\text { confirmação COVID-19, admitidos nos } \\
\text { hospitais por causa de febre, tosse, dispneia e } \\
\text { achados de TC de tórax indicando Pneumonia } \\
\text { SARS-CoV-2. }\end{array}$ & $\begin{array}{l}\text { Durante a admissão, os pacientes críticos } \\
\text { apresentavam dispneia com mais } \\
\text { frequência e frequência respiratória mais } \\
\text { elevada. Marcadores para a função de } \\
\text { coagulação APTT, fibrinogênio e dímero-d } \\
\text { foram mais elevados em pacientes críticos, } \\
\text { em comparação com pacientes não críticos. }\end{array}$ & $\begin{array}{l}\text { Características demográficas, } \\
\text { sintomas clínicos e medições } \\
\text { laboratoriais na admissão que } \\
\text { foram correlacionados com } \\
\text { doença crítica em COVID-19. }\end{array}$ \\
\hline 45 & $\begin{array}{l}\text { Incidence and determinants of } \\
\text { high-sensitivity troponin and } \\
\text { natriuretic peptides elevation at } \\
\text { admission in hospitalized } \\
\text { covid-19 pneumonia patients. } \\
\text { (Arcari et al., 2020). }\end{array}$ & $\begin{array}{l}\text { Realizar uma avaliação } \\
\text { conjunta de hs-troponina e } \\
\text { peptídeos natriuréticos } \\
\text { (PN) em pacientes } \\
\text { hospitalizados r por } \\
\text { pneumonia COVID-19. }\end{array}$ & $\begin{array}{l}\text { Estudo } \\
\text { observacional } \\
\text { retrospectivo } \\
\text { multicêntrico. }\end{array}$ & $\begin{array}{l}\text { Foram analisados } 188 \text { pacientes. O } \\
\text { diagnóstico de infeçãa por COVID-19 foi } \\
\text { confirmado antes da admissão por de RT- } \\
\text { PCR, enquanto o envolvimento pulmonar foi } \\
\text { demonstrado em todos os pacientes por meio } \\
\text { de uma TC. Os sintomas na apresentação e a } \\
\text { história clínica foram avaliados pelo médico } \\
\text { que o aceitou. }\end{array}$ & $\begin{array}{l}\text { Aumento de troponina e NP foram } \\
\text { encontrados em } 38 \text { e } 56 \% \text { dos casos. Esses } \\
\text { pacientes eram mais velhos, tinham maior } \\
\text { prevalência de doenças cardiovasculares } \\
\text { mais graves. Na análise multivariável, } \\
\text { associações independentes foram } \\
\text { encontradas de troponina vs idade, PaO2 / } \\
\text { FIO2 e dímero-D. Tanto troponina quanto } \\
\text { NP foram maiores em pacientes com } \\
\text { mortalidade intra-hospitalar }\end{array}$ & $\begin{array}{l}\text { O envolvimento miocárdico na } \\
\text { admissão é comum na pneumonia } \\
\text { por COVID-19. Associações } \\
\text { independentes de troponina vs } \\
\text { com marcadores de gravidade da } \\
\text { doença e de PN com DCV } \\
\text { subjacente podem apontar para } \\
\text { diferentes mecanismos existentes } \\
\text { levando à sua elevação neste } \\
\text { cenário. }\end{array}$ \\
\hline 46 & $\begin{array}{l}\text { Coagulation parameters and } \\
\text { venous thromboembolism in } \\
\text { patients with andwithout COVID- } \\
19 \text { admitted to the Emergency } \\
\text { Department for Acute respiratory } \\
\text { insufficiency } \\
\text { (Pizzi et al., 2020). }\end{array}$ & $\begin{array}{l}\text { Comparar os parâmetros de } \\
\text { coagulação na admissão } \\
\text { entre pacientes COVID-19 } \\
\text { e não COVID-19 com } \\
\text { insuficiência respiratória } \\
\text { aguda e TEV diagnosticado } \\
\text { na entrada. }\end{array}$ & $\begin{array}{l}\text { Estudo } \\
\text { observacional } \\
\text { retrospectivo } \\
\text { unicêntrico. }\end{array}$ & $\begin{array}{l}\text { Foram inscritos } 324 \text { pacientes consecutivos, } \\
162 \text { diagnosticados com COVID-19. Os } \\
\text { pacientes incluídos foram encaminhados } \\
\text { devido à febre ou insuficiência respiratória } \\
\text { exigindo hospitalização. Foram comparados } \\
\text { sintomas entre grupos controles e grupos de } \\
\text { pacientes com COVID-19. }\end{array}$ & $\begin{array}{l}\text { Dos pacientes restantes, a grande maioria } \\
\text { tinha pneumonia bacteriana. Pacientes } \\
\text { COVID-19 eram significativamente mais } \\
\text { jovens do que os controles, e tinham menos } \\
\text { histórico de doenças cardiovasculares. } \\
\text { Dímero-D estava aumentado em } 86,5 \% \text { dos } \\
\text { pacientes com COVID-19 e em } 84,9 \% \\
\text { pacientes não COVID-19. }\end{array}$ & $\begin{array}{l}\text { Níveis de dímero D, marcador de } \\
\text { mau prognóstico e de aumento do } \\
\text { risco de TEV intra-hospitalar e } \\
\text { pós-alta, podem estar igualmente } \\
\text { aumentados em pacientes com } \\
\text { febre, insuficiência respiratória } \\
\text { com e sem doença relacionada à } \\
\text { SARS-CoV. }\end{array}$ \\
\hline
\end{tabular}


Research, Society and Development, v. 11, n. 2, e21011225731, 2022

(CC BY 4.0) | ISSN 2525-3409 | DOI: http://dx.doi.org/10.33448/rsd-v11i2.25731

\begin{tabular}{|c|c|c|c|c|c|c|}
\hline 47 & $\begin{array}{l}\text { Corona Virus Disease } 2019 \\
\text { patients with different } \\
\text { severity or age range. } \\
\text { (L. Ren et al., 2020). }\end{array}$ & $\begin{array}{l}\text { Descrever as características } \\
\text { clínicas e o prognóstico de } \\
\text { pacientes com Doença do } \\
\text { Vírus Corona } 2019 \\
\text { (COVID-19). }\end{array}$ & $\begin{array}{l}\text { Estudo } \\
\text { observacional } \\
\text { retrospectivo } \\
\text { unicêntrico. }\end{array}$ & $\begin{array}{l}\text { Foram incluídos } 129 \text { pacientes com COVID- } \\
19 \text { diagnosticados por teste de PCR. } \\
\text { Informações sobre dados demográficos, } \\
\text { comorbidades, histórias, sintomas clínicos e } \\
\text { achados laboratoriais no momento da } \\
\text { admissão hospitalar foram coletados. }\end{array}$ & $\begin{array}{l}\text { A taxa de mortalidade foi de } 5,4 \% \text {. } \\
\text { Pacientes graves/críticos exibiram aumento } \\
\text { de neutrófilos, proteína C reativa, } \\
\text { calcitonina, alfa hidroxibutírico } \\
\text { desidrogenase, lactato desidrogenase, } \\
\text { aspartato aminotransferase, gama glutamil } \\
\text { transferase, creatinina e níveis de dímero - } \\
\text { D. }\end{array}$ & $\begin{array}{l}\text { Febre, tosse, cansaço e anorexia } \\
\text { são sintomas comuns em } \\
\text { pacientes com COVID-19. Outras } \\
\text { análises em pacientes críticos } \\
\text { apresentaram disfunção de } \\
\text { múltiplos órgãos e imunológica, } \\
\text { além da idade avançada poder ser } \\
\text { um fator crítico para aumentar a } \\
\text { gravidade da doença. }\end{array}$ \\
\hline 48 & $\begin{array}{l}\text { Multisystem inflammatory } \\
\text { syndrome in children (MIS-C): } \\
\text { Report of the clinical and } \\
\text { epidemiological characteristics of } \\
\text { cases in Santiago de Chile during } \\
\text { the SARS-CoV-2 pandemic. } \\
\text { (Torres et al., 2020). }\end{array}$ & 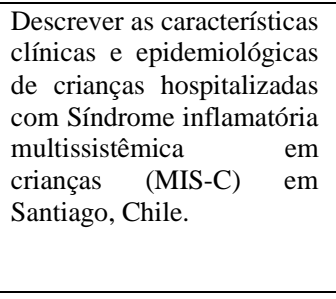 & $\begin{array}{l}\text { Estudo } \\
\text { observacional } \\
\text { retrospectivo } \\
\text { multicêntrico. }\end{array}$ & $\begin{array}{l}\text { O estudo foi conduzido com crianças com } \\
\text { inclusão de } 220 \text { pacientes pediátricos. } \\
\text { Características demográficas e dados } \\
\text { epidemiológicos, histórico médico, exames } \\
\text { laboratoriais, avaliações cardiológicas, } \\
\text { tratamento e desfechos clínicos foram } \\
\text { analisados. }\end{array}$ & $\begin{array}{l}\text { O grupo grave apresentou níveis mais } \\
\text { baixos de hemoglobina e albumina, } \\
\text { diminuição da contagem de plaquetas e } \\
\text { maior valor de dímero-D durante a } \\
\text { evolução da doença. Ecocardiografia } \\
\text { mostrou anormalidades (miocárdicas, } \\
\text { pericárdicas ou coronárias) em } 12 \text { pacientes } \\
\text { durante a internação. }\end{array}$ & $\begin{array}{l}\text { Este estudo descreve a primeira } \\
\text { série }(\mathrm{n}=27) \text { de crianças com } \\
\text { MIS-C na América Latina, } \\
\text { mostrando desfechos clínicos } \\
\text { favoráveis. Educação e alertas são } \\
\text { necessários para as equipes } \\
\text { clínicas para estabelecer um } \\
\text { diagnóstico precoce e tratamento } \\
\text { imediato. }\end{array}$ \\
\hline 49 & $\begin{array}{l}\text { A novel risk score to predict } \\
\text { cardiovascular complications in } \\
\text { patients with coronavirus disease } \\
2019 \quad \text { (COVID-19): A } \\
\text { retrospective, multicenter, } \\
\text { observational study } \\
\text { (D. Huang et al., 2020). }\end{array}$ & 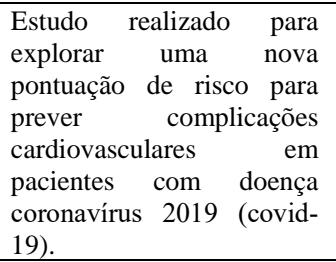 & $\begin{array}{l}\text { Estudo } \\
\text { observacional } \\
\text { retrospectivo } \\
\text { multicêntrico. }\end{array}$ & $\begin{array}{l}1.207 \text { pacientes com COVID-19 foram } \\
\text { incluídos e coletados os dados da admissão. } \\
\text { Os pacientes foram divididos aleatoriamente } \\
\text { em treinamento e teste ( } 70 \% \text { vs. } 30 \%) \text {. } \\
\text { Fatores de risco independentes foram } \\
\text { identificados por meio de análise de regressão } \\
\text { logística. }\end{array}$ & $\begin{array}{l}\text { Dez fatores de risco independentes } \\
\text { associados a complicações } \\
\text { cardiovasculares foram identificados no } \\
\text { treinamento conjunto. Quando comparado } \\
\text { com o grupo de teste, o grupo treinamento } \\
\text { apresentou níveis mais elevados de dímero- } \\
\mathrm{D} \text {, tromboplastina parcial ativada e } \\
\text { procalcitonina. }\end{array}$ & $\begin{array}{l}\text { Uma nova pontuação de risco, } \\
\text { que tem uma capacidade preditiva } \\
\text { promissora para complicações } \\
\text { cardiovasculares em pacientes } \\
\text { com COVID-19. }\end{array}$ \\
\hline 50 & $\begin{array}{l}\text { Differences of inflammatory and } \\
\text { non-inflammatory indicators in } \\
\text { Coronavirus disease-19 (COVID- } \\
\text { 19) with different severity. } \\
\text { (Wang et al., 2020) }\end{array}$ & $\begin{array}{l}\text { Investigar a associação } \\
\text { desses indicadores no } \\
\text { COVID-19 com diferentes } \\
\text { gravidades. }\end{array}$ & $\begin{array}{l}\text { Estudo } \\
\text { observacional } \\
\text { retrospectivo } \\
\text { multicêntrico. }\end{array}$ & $\begin{array}{l}\text { Foram coletados dados clínicos e } \\
\text { laboratoriais de } 46 \text { pacientes com COVID-19 } \\
\text { grave e } 31 \text { pacientes críticos. As } \\
\text { características gerais e comorbidades dos } \\
\text { pacientes foram analisadas, além das análises } \\
\text { de concentrações iniciais e máximas de } \\
\text { troponina, dímero-D, proteína C reativa, IL-6 } \\
\text { e contagem de neutrófilos. }\end{array}$ & $\begin{array}{l}\text { Parâmetros laboratoriais como troponinas, } \\
\text { dímero-D, proteína } C \text { reativa, interleucina- } \\
6 \text { e contagem de neutrófilos foram maiores } \\
\text { no grupo crítico do que no grupo grave, e o } \\
\text { aumento de linfócitos no grupo crítico foi } \\
\text { maior do que no grupo grave. }\end{array}$ & $\begin{array}{l}\text { O aumento da cTnI, PCR, IL-6, } \\
\text { PCT, neutrófilos e diminuição } \\
\text { dos linfócitos indicou quadro } \\
\text { grave. }\end{array}$ \\
\hline 51 & $\begin{array}{l}\text { Prognostic Value of Right } \\
\text { Ventricular Longitudinal Strain in } \\
\text { Patients With COVID-19. } \\
\text { (Y. Li et al., 2020a). }\end{array}$ & $\begin{array}{l}\text { Investigar se o strain } \\
\text { longitudinal ventricular } \\
\text { direito (RVLS) } \\
\text { independente preditivo de } \\
\text { maior mortalidade em } \\
\text { pacientes com doença } \\
\text { coronavírus-2019 } \\
(\text { COVID-19). }\end{array}$ & $\begin{array}{l}\text { Estudo } \\
\text { observacional } \\
\text { prospectivo } \\
\text { unicêntrico. }\end{array}$ & $\begin{array}{l}\text { Foram incluídos } 150 \text { pacientes adultos } \\
\text { diagnosticados COVID-19. Pacientes com } \\
\text { cardiomiopatia, infarto do miocárdio prévio } \\
\text { ou imagens abaixo do ideal foram excluídos. } \\
\text { O restante (n=120) dos pacientes foi incluído. } \\
\text { O grupo controle foi composto por } 37 \\
\text { voluntários saudáveis que não tinha doença } \\
\text { cardiopulmonar com base em exame físico, } \\
\text { eletrocardiograma, tórax radiografia e } \\
\text { ecocardiografia. }\end{array}$ & $\begin{array}{l}\text { Em comparação com os pacientes no tercil } \\
\text { mais alto do RVLS, aqueles no tercil mais } \\
\text { baixo eram mais propensos à alta } \\
\text { frequência cardíaca, níveis elevados de } \\
\text { dímero-D e proteína C reativa e mais alta } \\
\text { mortalidade. Após acompanhamento, } 18 \\
\text { pacientes morreram. Os não sobreviventes } \\
\text { exibiam câmaras cardíacas direitas } \\
\text { aumentadas, função do VD diminuída e } \\
\text { pressão sistólica da artéria pulmonar } \\
\text { elevada. }\end{array}$ & $\begin{array}{l}\text { O estudo demonstrou que RVLS é } \\
\text { um determinante independente de } \\
\text { resultados em pacientes com } \\
\text { COVID-19. É importante } \\
\text { ressaltar que este índice pode ter } \\
\text { valor preditivo adicional sobre } \\
\text { outros parâmetros } \\
\text { ecocardiográficos. par. }\end{array}$ \\
\hline
\end{tabular}


Research, Society and Development, v. 11, n. 2, e21011225731, 2022

(CC BY 4.0) | ISSN 2525-3409 | DOI: http://dx.doi.org/10.33448/rsd-v11i2.25731

\begin{tabular}{|c|c|c|c|c|c|c|}
\hline 52 & $\begin{array}{l}\text { Thromboelastography clot } \\
\text { strength profiles and effect of } \\
\text { systemic anticoagulation in } \\
\text { COVID-19 acute respiratory } \\
\text { distress syndrome: a prospective, } \\
\text { observational study. } \\
\text { (Bocci et al., 2020) }\end{array}$ & $\begin{array}{l}\text { Analisar padrões de } \\
\text { coagulação de pacientes da } \\
\text { unidade de cuidados } \\
\text { COVID-19 com os do } \\
\text { laboratórios padrão e testes } \\
\text { viscoelásticos, além da } \\
\text { presença de coagulopatia } \\
\text { no início da infeção após } \\
\text { sete dias de anticoagulante. }\end{array}$ & $\begin{array}{l}\text { Estudo } \\
\text { observacional } \\
\text { prospectivo } \\
\text { unicêntrico. }\end{array}$ & $\begin{array}{l}40 \text { pacientes com SARS-CoV-2 foram } \\
\text { inscritos no estudo. Eles receberam } \\
\text { anticoagulação em dose completa, incluindo } \\
\text { Enoxaparina } 0,5 \mathrm{mg} \cdot \mathrm{kg}-1 \text { por via subcutânea } \\
\text { duas vezes ao dia, heparina não fracionada } \\
7500 \text { UI por via subcutânea três vezes ao dia. }\end{array}$ & $\begin{array}{l}\text { No início do estudo, os pacientes } \\
\text { apresentavam elevada atividade de } \\
\text { fibrinogênio e aumento na amplitude } \\
\text { máxima da força de coágulo. Os } \\
\text { parâmetros de coagulação estavam na faixa } \\
\text { de } 1,02 \text { a } 42,2 \text { aPTT. Além disso, os níveis } \\
\text { de dímero-D e fibrinogênio plasmático } \\
\text { aumentaram acima do intervalo de } \\
\text { referência. }\end{array}$ & 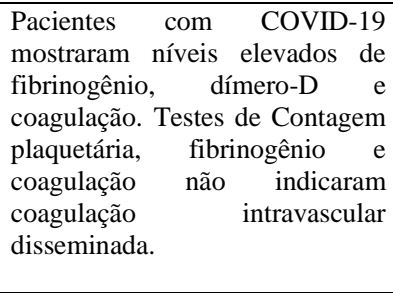 \\
\hline 53 & $\begin{array}{l}\text { Clinical characteristics and } \\
\text { outcomes of critically ill patients } \\
\text { with novel coronavirus infectious } \\
\text { disease (covid-19) in China: a } \\
\text { retrospective multicenter study. } \\
\text { (J. Xie et al., 2020) }\end{array}$ & $\begin{array}{l}\text { Descrever as características } \\
\text { clínicas e os resultados de } \\
\text { pacientes gravemente } \\
\text { enfermos com COVID-19 e } \\
\text { descobrir os fatores de risco } \\
\text { de mortalidade. }\end{array}$ & $\begin{array}{l}\text { Estudo } \\
\text { observacional } \\
\text { retrospectivo } \\
\text { multicêntrico. }\end{array}$ & $\begin{array}{l}\text { Foram incluídos pacientes desde } 1 \text { de janeiro } \\
\text { a } 29 \text { de fevereiro de } 2020 \text {, seguindo os } \\
\text { critérios de inclusão: (1)>18 anos de idade; } \\
\text { (2) diagnóstico confirmado por laboratório de } \\
\text { COVID-19; (3) insuficiência respiratória } \\
\text { grave exigindo suporte de respiração. }\end{array}$ & $\begin{array}{l}\text { A taxa de mortalidade dos pacientes em } 28 \\
\text { dias foi de 53,8\%. A insuficiência } \\
\text { respiratória foi a mais comum. A análise de } \\
\text { regressão multivariada de Cox mostrou que } \\
\text { idade avançada, neoplasias, escore } \\
\text { APACHE II alto e nível alto de dímero-D } \\
\text { foram fatores de risco de mortalidade em } \\
\text { pacientes gravemente enfermos com } \\
\text { COVID-19. }\end{array}$ & $\begin{array}{l}\text { Mais da metade dos pacientes } \\
\text { morreram no dia 28. A maior } \\
\text { porcentagem de falência de } \\
\text { órgãos nesses pacientes indicou } \\
\text { uma demanda significativa de } \\
\text { recursos de cuidados intensivos. }\end{array}$ \\
\hline 54 & $\begin{array}{l}\text { COVID-19 in solid organ } \\
\text { transplant recipients: Dynamics of } \\
\text { disease progression and } \\
\text { inflammatory markers in ICU and } \\
\text { non- ICU admitted patients. } \\
\text { (Roberts et al 2020) }\end{array}$ & $\begin{array}{l}\text { Analisar a progressão da } \\
\text { doença e marcadores } \\
\text { inflamatórios em pacientes } \\
\text { que com COVID-19 que } \\
\text { sofreram transplante de } \\
\text { órgão sólido (SOT). }\end{array}$ & $\begin{array}{l}\text { Estudo } \\
\text { observacional } \\
\text { retrospectivo } \\
\text { multicêntrico. }\end{array}$ & $\begin{array}{l}\text { Foram coletados dados de pacientes maiores } \\
\text { de } 18 \text { anos com teste positivo para COVID- } \\
19 \text { entre } 1 \text { de fevereiro e } 6 \text { de maio de } 2020 \text {. } \\
\text { Os pacientes eram do sexo masculino e } \\
\text { tinham idade média de } 58 \text { anos. }\end{array}$ & $\begin{array}{l}\text { Dos } 52 \text { pacientes positivos para COVID- } \\
19,77 \% \text { foram hospitalizados e } 35 \% \\
\text { necessitaram de UTI. Nos primeiros } 5 \text { dias } \\
\text { de doença, os marcadores inflamatórios } \\
\text { tiveram um aumento moderado. } \\
\text { Posteriormente, proteína C reativa, ferritina } \\
\text { e dímero-D aumentaram com a } \\
\text { permanência na UTI. Cinco pacientes } \\
\text { vieram a óbito. }\end{array}$ & $\begin{array}{l}\text { SOT está associado a alta taxa de } \\
\text { hospitalização, admissão na UTI } \\
\text { e óbito por COVID-19 em } \\
\text { comparação com os dados em } \\
\text { geral de pacientes com COVID- } \\
\text { 19. }\end{array}$ \\
\hline 55 & $\begin{array}{l}\text { Symptomless multi-variable } \\
\text { apnea prediction index assesses } \\
\text { adverse outcomes in patients with } \\
\text { Corona Virus Disease } 2019 . \\
\text { (S. Zhang et al., 2020) }\end{array}$ & $\begin{array}{l}\text { Analisar a relação entre a } \\
\text { previsão de apneia } \\
\text { multivariada sem sintomas } \\
\text { (sMVAP) índice e } \\
\text { resultados adversos de } \\
\text { pacientes com COVID-19. }\end{array}$ & $\begin{array}{l}\text { Estudo } \\
\text { retrospectivo } \\
\text { unicêntrico. }\end{array}$ & $\begin{array}{l}\text { Foram analisados } 352 \text { pacientes confirmados } \\
\text { para COVID-19. Foram avaliados: registro } \\
\text { médico eletrônico, registros de enfermagem, } \\
\text { achados laboratoriais e exames radiológicos. } \\
\text { Modelos de razão de risco proporcional foram } \\
\text { usados para determinar o risco de fatores } \\
\text { associados ao óbito hospitalar. }\end{array}$ & $\begin{array}{l}\text { Dos } 352 \text { pacientes, } 251 \text { foram excluídos } \\
\text { por não apresentarem registro de IMC, } 3 \\
\text { por não ter nenhum achado laboratorial e } 1 \\
\text { continuou no hospital, assim incluindo } 97 \\
\text { pacientes. Nos modelos de Cox } \\
\text { proporcionais de RH foi descoberto que } \\
\text { doença cardíaca coronária, dímero-d alto e } \\
\text { sMVAP na admissão aumentava as chances } \\
\text { de óbito. }\end{array}$ & $\begin{array}{l}\text { Usar o índice sMVAP para risco } \\
\text { de síndrome de apneia e } \\
\text { hipopneia obstrutiva do sono } \\
\text { (SAHOS) e, em seguida, prever } \\
\text { os resultados adversos de } \\
\text { pacientes com COVID-19 é um } \\
\text { método eficaz. }\end{array}$ \\
\hline 56 & $\begin{array}{l}\text { Decreased complement C3 levels } \\
\text { are associated with poor prognosis } \\
\text { in patients with COVID-19: A } \\
\text { retrospective cohort study. } \\
\text { (S. Fang et al., 2020) }\end{array}$ & $\begin{array}{l}\text { Descrever a característica } \\
\text { imune humoral de pacientes } \\
\text { com COVID- } 19 \text {. }\end{array}$ & $\begin{array}{l}\text { Estudo } \\
\text { observacional } \\
\text { retrospectivo } \\
\text { unicêntrico. }\end{array}$ & $\begin{array}{l}\text { Foram incluídos } 236 \text { pacientes. Foi analisado } \\
\text { os níveis de imunoglobulinas totais (IgG, } \\
\text { IgM, IgA e IgE) e resultados do complemento } \\
\text { (C3, C4). Os pacientes foram divididos em } \\
\text { dois grupos, sendo eles: grupo de } \\
\text { sobreviventes e grupo de não sobreviventes. }\end{array}$ & $\begin{array}{l}\text { Dos } 236 \text { pacientes, } 169 \text { foram transferidos } \\
\text { para outra instituição ou tiveram alta } \\
\text { (sobreviventes) e } 67 \text { morreram no hospital } \\
\text { (não sobreviventes). Comparado com os } \\
\text { sobreviventes, os níveis de IgA, IgE e } \\
\text { dímero-D em não sobreviventes } \\
\text { aumentaram e o nível de complemento C3 } \\
\text { diminuiu. }\end{array}$ & $\begin{array}{l}\text { Baixo nível de complemento C3 } \\
\text { pode ser um alerta para os } \\
\text { pacientes com COVID-19, } \\
\text { podendo a inibição da via do } \\
\text { complemento ser uma terapêutica } \\
\text { eficaz. } 63 \% \text { dos pacientes eram } \\
\text { homens mais velhos com dímero- } \\
\text { d mais alto no momento da } \\
\text { admissão e estes eram do grupo } \\
\text { de não sobreviventes. }\end{array}$ \\
\hline
\end{tabular}


Research, Society and Development, v. 11, n. 2, e21011225731, 2022

(CC BY 4.0) | ISSN 2525-3409 | DOI: http://dx.doi.org/10.33448/rsd-v11i2.25731

\begin{tabular}{|c|c|c|c|c|c|c|}
\hline 57 & $\begin{array}{l}\text { Clinical features and risk factors } \\
\text { for severe inpatients with COVID- } \\
\text { 19: A retrospective study in China. } \\
\text { (J. Wang et al., 2020a) }\end{array}$ & $\begin{array}{l}\text { Analisar os fatores de risco } \\
\text { em pacientes com } \\
\text { diferentes níveis de } \\
\text { progressão da COVID-19. }\end{array}$ & $\begin{array}{l}\text { Estudo de caso } \\
\text { retrospectivo } \\
\text { multicêntrico. }\end{array}$ & $\begin{array}{l}\text { Foram incluídos } 562 \text { pacientes com COVID- } \\
19 \text {, confirmado por teste em laboratório. As } \\
\text { informações clínicas, terapias e dados de } \\
\text { imagem relacionados foram extraídos de } \\
\text { registros médicos eletrônicos e comparados } \\
\text { entre pacientes em estado grave e estado não } \\
\text { grave. }\end{array}$ & $\begin{array}{l}509 \text { pacientes foram classificados como } \\
\text { não grave e } 53 \text {, como grave. Os graves com } \\
\text { idade maior que } 60 \text { anos eram mais } \\
\text { propensos a ter febre, asma e níveis de } \\
\text { dímero-D mais elevado. Os pacientes } \\
\text { graves eram mais propensos ao aumento da } \\
\text { cistatina C, nível médio de hemoglobina e } \\
\text { diminuição da saturação de oxigênio. }\end{array}$ & $\begin{array}{l}\text { Os potenciais fatores de risco } \\
\text { encontrados neste estudo } \\
\text { mostraram uma grande } \\
\text { significância para conseguir } \\
\text { prevenir o agravamento da } \\
\text { COVID-19 em pacientes com } \\
\text { estado crítico durante o } \\
\text { tratamento. }\end{array}$ \\
\hline 58 & $\begin{array}{l}\text { Clinical characteristics and viral } \\
\text { shedding kinetics of } 38 \\
\text { asymptomatic patients with } \\
\text { coronavirus disease } 2019 . \\
\text { (Y. Li et al., 2020b) }\end{array}$ & $\begin{array}{l}\text { Investigar as características } \\
\text { clínicas e cinéticas } \\
\text { eliminação de } \\
\text { paciral dentes assintomáticos } \\
\text { com coronavírus. }\end{array}$ & $\begin{array}{l}\text { Estudo } \\
\text { observacional } \\
\text { retrospectivo } \\
\text { unicêntrico }\end{array}$ & $\begin{array}{l}\text { Um total de } 38 \text { pacientes assintomáticos com } \\
\text { um teste de ácido nucleico SARS-CoV-2 } \\
\text { positivo foram incluídos neste estudo. Foram } \\
\text { registrados os níveis de contagem de } \\
\text { leucócitos, dímero-D Proteína C reativa, } \\
\text { procalcitonina, entre outros. }\end{array}$ & $\begin{array}{l}\text { A contagem de glóbulos brancos, o valor de } \\
\text { linfócito, dímero-D e proteína C reativa } \\
\text { (PCR) foram normais. Manifestações de } \\
\text { pneumonia não foram encontradas na } \\
\text { tomográfica computadorizada do tórax } \\
\text { (TC) o tempo de eliminação viral foi de } 6 \\
\text { dias. }\end{array}$ & $\begin{array}{l}\text { Os pacientes assintomáticos com } \\
\text { COVID-19 tinham um histórico } \\
\text { de contato próximo ou exposição } \\
\text { ao vírus. Os exames laboratóriais } \\
\text { estavam normais. Nas imagens de } \\
\text { tórax não foram achados } \\
\text { nenhuma manifestação de } \\
\text { pneumonia. }\end{array}$ \\
\hline 59 & $\begin{array}{l}\text { Prognostic value of bedside lung } \\
\text { ultrasound score in patients with } \\
\text { covid-19. } \\
\text { (L. Ji et al., 2020) }\end{array}$ & $\begin{array}{l}\text { Investigar o } \quad \text { valor } \\
\text { prognóstico do LUS } \\
\text { escore em pacientes } \\
\text { COVID-19. }\end{array}$ & $\begin{array}{l}\text { Estudo } \\
\text { observacional } \\
\text { prospectivo } \\
\text { unicêntrico. }\end{array}$ & $\begin{array}{l}\text { O estudo foi realizado em } 280 \text { pacientes que } \\
\text { tinham a COVID-19. Foram avaliadas a } \\
\text { consolidação pulmonar e anormalidades da } \\
\text { linha pleural. Os critérios de inclusão } \\
\text { consistiram no diagnóstico de COVID-19 de } \\
\text { acordo com a orientação provisória da OMS } \\
\text { com idade > } 18 \text { anos. }\end{array}$ & $\begin{array}{l}\text { Pacientes com níveis altos de pontuação de } \\
\text { ultrassom pulmonar (LUS) apresentaram } \\
\text { menor porcentagem de linfócitos, níveis } \\
\text { mais altos de proteína C reativa, troponina, } \\
\text { dímero-D e creatina quinase e tiveram } \\
\text { maior taxa de mortalidade. Após } 14 \text { dias de } \\
\text { acompanhamento, } 37 \text { pacientes } \\
\text { desenvolveram Síndrome de angústia } \\
\text { respiratória do adulto (SDRA) e } 13 \text { vieram } \\
\text { a óbito. }\end{array}$ & $\begin{array}{l}\text { A pontuação LUS desenvolvida } \\
\text { pelo grupo mostrou um bom } \\
\text { desempenho na previsão de } \\
\text { resultados adversos em pacientes } \\
\text { com COVID-19 e é importante } \\
\text { para a estratificação de risco em } \\
\text { pacientes com COVID-19. }\end{array}$ \\
\hline 60 & $\begin{array}{l}\text { Risk Factors for Poor Outcomes of } \\
\text { Diabetes Patients With COVID- } \\
\text { 19: A Single-Center, } \\
\text { Retrospective Study in Early } \\
\text { Outbreak in China. } \\
\text { (N. Zhang et al., 2020) }\end{array}$ & $\begin{array}{l}\text { Avaliar as características } \\
\text { clínicas de pacientes com } \\
\text { diabetes com COVID- } 19 .\end{array}$ & $\begin{array}{l}\text { Estudo } \\
\text { observacional } \\
\text { retrospectivo } \\
\text { unicêntrico. }\end{array}$ & $\begin{array}{l}\text { Foram revisados os registros médicos de } 563 \\
\text { pacientes com COVID-19. Análises } \\
\text { univariadas e multivariadas foram realizadas } \\
\text { para avaliar os fatores de risco associados aos } \\
\text { eventos graves. Os pacientes foram divididos } \\
\text { em grupos grave e não grave. }\end{array}$ & $\begin{array}{l}\text { Dos } 563 \text { pacientes com COVID-19, foram } \\
\text { excluídos } 496 \text { pacientes que não tinham } \\
\text { diabetes. Os eventos graves foram } \\
\text { associados com contagens mais altas de } \\
\text { leucócitos, neutrófilos e procalcitonina } \\
\text { (PCT) em comparação com o grupo não } \\
\text { grave, além de níveis ligeiramente mais } \\
\text { alto de troponina I cardíaca (cTNI) e } \\
\text { dímero-D. }\end{array}$ & $\begin{array}{l}\text { Pacientes com diabetes e COVID- } \\
19 \text { apresentaram desfechos } \\
\text { clínicos ruins. O monitoramento } \\
\text { vigoroso de cTNI deve ser } \\
\text { recomendado para os pacientes } \\
\text { com diabetes com COVID-19. O } \\
\text { uso de inibidores de a-glucosidase } \\
\text { pode ser um potencial protetor } \\
\text { para os pacientes com diabetes e } \\
\text { COVID-19. }\end{array}$ \\
\hline 61 & $\begin{array}{l}\text { Risk factors for disease } \\
\text { progression in patients with mild } \\
\text { to moderate coronavirus disease } \\
\text { 2019da multi-centre observational } \\
\text { study. } \\
\text { (Cen et al., 2020) }\end{array}$ & $\begin{array}{l}\text { Investigar os fatores de } \\
\text { risco para } \\
\text { progressão da doença em } \\
\text { indivíduos com COVID-19 } \\
\text { leve a moderado. }\end{array}$ & $\begin{array}{l}\text { Estudo } \\
\text { observacional } \\
\text { prospectivo } \\
\text { multicêntrico. }\end{array}$ & $\begin{array}{l}\text { O estudo foi feito com } 1.007 \text { pacientes com } \\
\text { COVID-19 leve a moderado. Foram coletadas } \\
\text { as características clínicas e os achados } \\
\text { laboratoriais de base. } \\
\text { Os pacientes foram acompanhados por } 28 \\
\text { dias para observação da progressão da } \\
\text { doença. }\end{array}$ & $\begin{array}{l}\text { Dos dos } 1007 \text { pacientes, } 720 \text { se } \\
\text { recuperaram ou ficaram estáveis, } 222 \\
\text { progrediram para estado grave e desses, } 22 \\
\text { para gravemente doentes (permanecendo } \\
\text { vivos) e } 43 \text { progrediram para estágio crítico } \\
\text { e vieram a óbito. Aumento de Dímero-D, } \\
\text { proteína C reativa, procalcitonina e lactato } \\
\text { desidrogenase foram maiores nos grupos de } \\
\text { progressão. }\end{array}$ & $\begin{array}{l}\text { Mais estudos clínicos são } \\
\text { necessários para se ter uma } \\
\text { abordagem mais convincente. No } \\
\text { presente estudo não foi } \\
\text { encontrado associação entre } \\
\text { terapia antiviral e a progressão da } \\
\text { COVID-19. }\end{array}$ \\
\hline
\end{tabular}


Research, Society and Development, v. 11, n. 2, e21011225731, 2022

(CC BY 4.0) | ISSN 2525-3409 | DOI: http://dx.doi.org/10.33448/rsd-v11i2.25731

\begin{tabular}{|c|c|c|c|c|c|c|}
\hline 62 & $\begin{array}{l}\text { Intravenous tPA for Acute } \\
\text { Ischemic Stroke in Patients with } \\
\text { COVID-19. } \\
\text { (Carneiro et al., 2020) }\end{array}$ & $\begin{array}{l}\text { Avaliar os resultados da } \\
\text { administração de ativador } \\
\text { de plasmogênio tecidual } \\
\text { intravenoso (IV tPA) em } \\
\text { pacientes com COVID-19 }\end{array}$ & $\begin{array}{l}\text { Estudo } \\
\text { retrospectivo } \\
\text { multicêntrico. }\end{array}$ & $\begin{array}{l}\text { O estudo incluiu um total de } 13 \text { pacientes com } \\
\text { COVID-19. Eles receberam tPA IV por } \\
\text { déficits neurológicos agudos. O mecanismo } \\
\text { de AVC foi definido principalmente usando a } \\
\text { classificação TOAST, com alguns traços } \\
\text { classificados como AVC embólico de fonte } \\
\text { indeterminada (ESUS). }\end{array}$ & $\begin{array}{l}\text { Não foram observadas hemorragias } \\
\text { sistêmicas ou intracranianas. três pacientes } \\
\text { tiveram ataques isquêmicos transitórios ou } \\
\text { derrames. De } 12 \text { pacientes, } 2 \text { tiveram níveis } \\
\text { elevados de fibrinogênio na admissão. De } \\
11 \text { pacientes, } 7 \text { tinham um nível elevado de } \\
\text { dímero-D. }\end{array}$ & $\begin{array}{l}\text { A utilização de ativador de } \\
\text { plasminogênio tecidual (IV tPA) } \\
\text { pode ser seguro e eficaz contra a } \\
\text { COVID-19, mas ainda sim se faz } \\
\text { necessário estudos maiores para } \\
\text { validar os resultados. }\end{array}$ \\
\hline 63 & $\begin{array}{l}\text { Anticoagulation Management in } \\
\text { Severe Coronavirus Disease } 2019 \\
\text { Patients on Extracorporeal } \\
\text { Membrane Oxygenation. } \\
\text { (Z. Guo et al., 2020) }\end{array}$ & $\begin{array}{l}\text { Analisar as características } \\
\text { de coagulação e } \\
\text { gerenciamento de } \\
\text { anticoagulação racerorana por membrana } \\
\text { oxigenação por } \\
\text { extracorpórea (ECMO) em } \\
\text { pacientes com COVID-19. }\end{array}$ & $\begin{array}{l}\text { Estudo } \\
\text { observacional } \\
\text { retrospectivo } \\
\text { unicêntrico. }\end{array}$ & $\begin{array}{l}\text { Foram analisados } 667 \text { pacientes. Foram } \\
\text { coletados os dados de comorbidades, } \\
\text { resultados laboratoriais, demográficos e } \\
\text { parâmetros de coagulação, todos estes } \\
\text { relacionados com a ECMO. }\end{array}$ & $\begin{array}{l}\text { Dos } 667 \text { pacientes com COVID-19, } 22 \\
\text { estavam em estado crítico. Destes } 22,8 \\
\text { foram incluídos para o estudo e receberam } \\
\text { suporte de ECMO venoso por causa da } \\
\text { insuficiência respiratória hipoxêmica. Os } 8 \\
\text { pacientes que receberam ECMO tinham um } \\
\text { nível elevado de dímero-D antes e durante } \\
\text { o suporte com ECMO. }\end{array}$ & $\begin{array}{l}\text { A hiperfibrinólise secundária e a } \\
\text { hipercoagulabilidade durante o } \\
\text { suporte de ECMO em pacientes } \\
\text { com COVID-19 são comuns e } \\
\text { possivelmente aumentam a } \\
\text { incidência de eventos trombóticos } \\
\text { e a falha do oxigenador. }\end{array}$ \\
\hline 64 & $\begin{array}{l}\text { Non invasive ventilation for acute } \\
\text { hypoxemic respiratory failure in } \\
\text { patients with COVID-19. } \\
\text { (Avdeev et al 2020) }\end{array}$ & $\begin{array}{l}\text { Avaliar os resultados da } \\
\text { aplicação de VNI em } \\
\text { pacientes com COVID-19 e } \\
\text { AHRF. }\end{array}$ & $\begin{array}{l}\text { Estudo } \\
\text { observacional } \\
\text { retrospectivo } \\
\text { multicêntrico. }\end{array}$ & $\begin{array}{l}\text { Foram incluídos } 61 \text { pacientes no estudo. } \\
\text { Todos os pacientes incluídos foram tratados } \\
\text { de forma isolada em salas de pressão neutra. } \\
\text { Dados demográficos, comorbidades e dados } \\
\text { laboratoriais clínicos foram registrados na } \\
\text { admissão. }\end{array}$ & $\begin{array}{l}\text { A ventilação não invasiva (VNI) foi bem- } \\
\text { sucedida em } 44 \text { pacientes e } 17 \text { pacientes } \\
\text { que não tiveram sucesso com a ventilação } \\
\text { não invasiva precisaram ser intubados. } \\
\text { Destes } 17,15 \text { vieram a óbito. Os pacientes } \\
\text { que falharam na VNI eram mais velhos e } \\
\text { tinham níveis elevados de dímero-D antes } \\
\text { do uso de VNI. }\end{array}$ & $\begin{array}{l}\text { A VNI é viável em pacientes com } \\
\text { COVID-19 e AHRF fora da } \\
\text { unidade de terapia intensiva e } \\
\text { pode ser considerada como uma } \\
\text { opção valiosa para o tratamento } \\
\text { de AHRF nesses pacientes. }\end{array}$ \\
\hline 65 & $\begin{array}{l}\text { Biomarkers of acute respiratory } \\
\text { distress syndrome in adults } \\
\text { hospitalised for } \\
\text { SARS-CoV-2 infection in } \\
\text { Tenerife Island, Spain. } \\
\\
\text { (Gonçalves et al., 2020) }\end{array}$ & 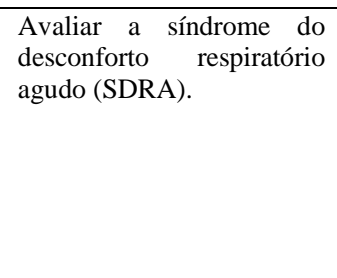 & $\begin{array}{l}\text { Estudo } \\
\text { Observacional } \\
\text { retrospectivo } \\
\text { multicêntrico. }\end{array}$ & $\begin{array}{l}\text { Foram analisados } 160 \text { pacientes de acordo } \\
\text { com os seguintes critérios de inclusão: idade } \\
\geq 18 \text { anos,; diagnóstico confirmado de } \\
\text { COVID-19 por RT-PCR de amostras de } \\
\text { esfregaços nasofaríngeos; primeira admissão } \\
\text { em um dos dois hospitais participantes. }\end{array}$ & $\begin{array}{l}\text { Dos } 160 \text { pacientes, } 7 \text { foram excluídos por } \\
\text { apresentarem neoplasia. Não foi verificada } \\
\text { correlação entre Sp02/Fi02 e os dímeros-D. } \\
\text { Seis pacientes vieram a óbito e } 19 \text { foram } \\
\text { internados na UTI. Após } 72 \text { horas de } \\
\text { admissão hospitalar, 13\% dos pacientes } \\
\text { começaram a preencher os critérios para } \\
\text { SDRA. }\end{array}$ & $\begin{array}{l}\text { Níveis elevados de LDH se } \\
\text { correlacionam com a ocorrência } \\
\text { de ARDS conforme determinado } \\
\text { a partir da relação } \mathrm{SpO} 2 \text { / FiO2. }\end{array}$ \\
\hline 66 & $\begin{array}{l}\text { Correlation between the variables } \\
\text { collected at admission and } \\
\text { progression to severe cases during } \\
\text { hospitalization among patients } \\
\text { with COVID-19 in Chongqing. } \\
\text { (Dua et al., 2020) }\end{array}$ & $\begin{array}{l}\text { Identificar os fatores de } \\
\text { risco para prever se os } \\
\text { pacientes iriam progredir } \\
\text { para casos graves. }\end{array}$ & $\begin{array}{l}\text { Estudo } \\
\text { Observacional } \\
\text { retrospectivo } \\
\text { multicêntrico. }\end{array}$ & $\begin{array}{l}\text { Foram selecionados } 397 \text { pacientes para o } \\
\text { estudo. Foi realizado teste de RT-PCR para } \\
\text { COVID-19 e utilizado cotonete nasofágico. } \\
\text { Foi inscrito apenas pacientes em estado não } \\
\text { grave da COVID-19. }\end{array}$ & $\begin{array}{l}\text { Dos } 397 \text { pacientes, } 44 \text { apresentaram quadro } \\
\text { grave logo na admissão e } 5 \text { não tinham } \\
\text { dados disponíveis, assim, } 348 \text { pacientes } \\
\text { foram incluídos para o estudo. Dos } 348 \\
\text { pacientes, } 20 \text { casos tornaram-se graves } \\
\text { após } 4 \text { dias. A creatinina, e o dímero-D } \\
\text { tinham níveis normais. Maior nível de } \\
\text { proteína C reativa foi associada a um menor } \\
\text { tempo para evolução de casos graves. }\end{array}$ & $\begin{array}{l}\text { O estudo relatou } 19 \text { potenciais } \\
\text { variáveis que foram coletadas na } \\
\text { admissão para poder prever os } \\
\text { pacientes que progrediriam para } \\
\text { casos graves. Seis variáveis } \\
\text { mostraram bom poder preditivo, } \\
10 \text { mostraram poder preditivo } \\
\text { moderado e quatro mostraram } \\
\text { poder preditivo leve. }\end{array}$ \\
\hline
\end{tabular}


Research, Society and Development, v. 11, n. 2, e21011225731, 2022

(CC BY 4.0) | ISSN 2525-3409 | DOI: http://dx.doi.org/10.33448/rsd-v11i2.25731

\begin{tabular}{|c|c|c|c|c|c|c|}
\hline 67 & $\begin{array}{l}\text { Kidney transplant patients with } \\
\text { sars-CoV-2 infection: The brescia } \\
\text { renal covid task force experience. } \\
\text { (Bossini et al.,2020) }\end{array}$ & $\begin{array}{l}\text { Descrever as características } \\
\text { clínicas, evolução da } \\
\text { doença e fatores de risco em } \\
\text { pacientes com COVID-19. }\end{array}$ & $\begin{array}{l}\text { Estudo coorte } \\
\text { retrospectivo } \\
\text { multicêntrico. }\end{array}$ & $\begin{array}{l}\text { Foram analisados } 53 \text { pacientes. Foi utilizado } \\
\text { Terapia antiviral com Lopinavir / Ritonavir } \\
\text { associado à hidroxicloroquina, considerada } \\
\text { para todos os pacientes que requerem } \\
\text { admissão, se não for contraindicada, para uma } \\
\text { duração de tratamento de um mínimo de } 7 \\
\text { dias até um máximo de } 15 \text { de acordo com a } \\
\text { evolução ou tratamento com glicocorticoides } \\
\text { e/ou tocilizumabe. }\end{array}$ & $\begin{array}{l}\text { Dos } 53 \text { pacientes, } 45 \text { precisaram de } \\
\text { internação e } 8 \text { não necessitaram de } \\
\text { internação nem vieram a óbito e nem } \\
\text { desenvolveram SDRA. dexametasona e } \\
\text { tocilizumab foram utilizados em caso de } \\
\text { SDRA. 33\% dos pacientes vieram a óbito. } \\
\text { A trombocitopenia foi associada a ARDS } \\
\text { enquanto dímero-D ao risco de morte. }\end{array}$ & $\begin{array}{l}\text { A infecção por COVID-19 pode } \\
\text { ter um resultado variável em } \\
\text { pacientes que fizeram transplante } \\
\text { renal, com maior risco de } \\
\text { desenvolver SDRA. }\end{array}$ \\
\hline 68 & $\begin{array}{l}\text { Use of tocilizumab in kidney } \\
\text { transplant recipients with COVID- } \\
19 . \\
\text { (Sáez-Pérez et al., 2020) }\end{array}$ & $\begin{array}{l}\text { Avaliar o uso de } \\
\text { tocilizumab em pacientes } \\
\text { com COVID-19 que } \\
\text { precisam de transplante de } \\
\text { rim. }\end{array}$ & $\begin{array}{l}\text { Estudo de coorte } \\
\text { multicêntrico. }\end{array}$ & $\begin{array}{l}\text { Foram analisados } 468 \text { pacientes e } 73 \text { foram } \\
\text { incluídos por terem feito uso de tocilizumabe, } \\
\text { depois foram incluídos mais } 7 \text { pacientes, } \\
\text { totalizando os } 80 \text { pacientes incluídos no } \\
\text { estudo. O tempo médio para } \\
\text { acompanhamento desde o início dos sintomas } \\
\text { foi de } 25 \text { dias. }\end{array}$ & $\begin{array}{l}\text { Dos } 80 \text { pacientes, } 54 \text { sobreviveram e } 26 \\
\text { vieram a óbito. Os pacientes que vieram a } \\
\text { óbito eram mais velhos e obesos do que os } \\
\text { sobreviventes. Na admissão houve baixa de } \\
\text { linfócitos e marcadores inflamatórios } \\
\text { elevados. O dímero-D estava maior em } \\
\text { pacientes que vieram a óbito. }\end{array}$ & $\begin{array}{l}\text { Não houve problemas de } \\
\text { segurança relacionadas com a } \\
\text { administração de tocilizumab. }\end{array}$ \\
\hline 69 & $\begin{array}{l}\text { Tocilizumab Treatment for } \\
\text { Cytokine Release Syndrome in } \\
\text { Hospitalized Patients With } \\
\text { Coronavirus Disease 2019. } \\
\text { (Prince et al., 2020). }\end{array}$ & 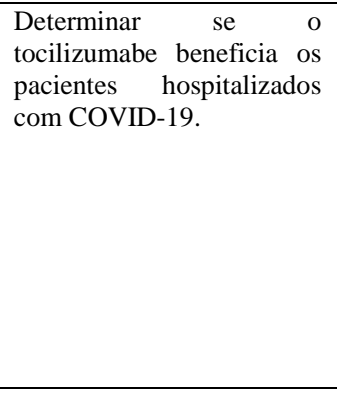 & $\begin{array}{l}\text { Estudo } \\
\text { observacional } \\
\text { prospectivo } \\
\text { unicêntrico. }\end{array}$ & $\begin{array}{l}\text { Os pacientes foram tratados com } \\
\text { tocilizumabe (TCZ). Os resultados de } \\
\text { sobrevivência e ventilação mecânica (VM) } \\
\text { foram relatados por } 14 \text { dias e estratificado de } \\
\text { acordo com a gravidade da doença designada } \\
\text { na admissão. }\end{array}$ & $\begin{array}{l}\text { Doença grave foi associada a menor } \\
\text { sobrevivência. Pacientes graves que foram } \\
\text { tratados com TCZ tiveram níveis elevados } \\
\text { de proteína C reativa. Para pacientes } \\
\text { tratados com TCZ requerendo VM, a } \\
\text { sobrevivência foi de } 75 \% \text {. Após o } \\
\text { tratamento com TCZ foi observado um } \\
\text { aumento nos níveis de dímero-D. A } \\
\text { sobrevivência em pacientes negros e } \\
\text { hispânicos, após o controle da idade, foi } \\
\text { significativamente maior do que em } \\
\text { pacientes brancos. }\end{array}$ & $\begin{array}{l}\text { TCZ tem como alvo uma via } \\
\text { específica na SRC, mas outros } \\
\text { imunomoduladores devem ser } \\
\text { avaliados para benefício } \\
\text { adicional. Embora muitos } \\
\text { pacientes tenham recebido TCZ } \\
\text { no início da hospitalização, } \\
\text { identificação mais precisa de } \\
\text { preditores da progressão da } \\
\text { doença pode ajudar a estabelecer } \\
\text { o momento ideal para tratamento } \\
\text { com TCZ. }\end{array}$ \\
\hline 70 & $\begin{array}{l}\text { Curative anticoagulation prevents } \\
\text { endothelial lesion in COVID-19 } \\
\text { patients. } \\
\text { (Khider et al., 2020) }\end{array}$ & $\begin{array}{l}\text { Explorar a coagulopatia e a } \\
\text { disfunção endotelial em } \\
\text { pacientes com COVID-19. }\end{array}$ & $\begin{array}{l}\text { Estudo } \\
\text { observacional } \\
\text { prospectivo } \\
\text { unicêntrico. }\end{array}$ & $\begin{array}{l}\text { O estudo analisou perfis clínicos e } \\
\text { biológicos de pacientes com suspeita de } \\
\text { infecção por COVID-19 na admissão, } \\
\text { incluindo testes de hemostasia e } \\
\text { quantificação de células endoteliais } \\
\text { circulantes (CECs). }\end{array}$ & $\begin{array}{l}\text { Pacientes com COVID-19 apresentaram } \\
\text { febre e pneumonia na tomografia } \\
\text { computadorizada. O dímero-D foi maior } \\
\text { em pacientes COVID-19 positivos. } \\
\text { Nenhum sinal de coagulação intravascular } \\
\text { disseminada foi identificado. } \\
\text { Curiosamente, os pacientes tratados com } \\
\text { anticoagulação curativa e IECA ou BRA } \\
\text { tiveram ainda menos CECs. }\end{array}$ & $\begin{array}{l}\text { A anticoagulação curativa pode } \\
\text { prevenir a coagulopatia associada } \\
\text { a COVID-19 e a lesão endotelial. }\end{array}$ \\
\hline 71 & $\begin{array}{l}\text { Thrombotic circuit complications } \\
\text { during venovenous extracorporeal } \\
\text { membrane oxygenation in } \\
\text { covid-19 } \\
\text { (Bemtgen et al., 2020) }\end{array}$ & $\begin{array}{l}\text { Investigar a taxa de } \mathrm{V}-\mathrm{V} \\
\text { ECMO e } \\
\text { complicações em pacientes } \\
\text { com COVID-19. }\end{array}$ & $\begin{array}{l}\text { Estudo } \\
\text { retrospectivo } \\
\text { unicêntrico. }\end{array}$ & $\begin{array}{l}\text { O estudou analisou } 66 \text { pacientes. O registro } \\
\text { retrospectivo incluiu todos os pacientes em } \\
\text { V-V ECMO tratados no centro entre 01/2018 } \\
\text { e 04/2020. Casos COVID-19 foram } \\
\text { comparados com casos de não COVID-19, } \\
\text { dividindo estes em dois grupos. }\end{array}$ & $\begin{array}{l}\text { Dos } 66 \text { pacientes, } 11 \text { apresentavam } \\
\text { COVID-19. Os níveis de dímero D antes } \\
\text { dos eventos trombóticos foram } \\
\text { significativamente maiores nos pacientes } \\
\text { com COVID-19. A infecção induzida por } \\
\text { SARS-CoV-2 está associada a maiores } \\
\text { taxas de eventos trombóticos do corpo } \\
\text { durante a terapia com V-V ECMO } \\
\text { (oxigenação por membrana extracorpórea). }\end{array}$ & $\begin{array}{l}\text { A formação de trombo no } \\
\text { circuito extracorpóreo em } \\
\text { pacientes com COVID-19 é } \\
\text { comum e potencialmente fatal. }\end{array}$ \\
\hline
\end{tabular}


Research, Society and Development, v. 11, n. 2, e21011225731, 2022

(CC BY 4.0) | ISSN 2525-3409 | DOI: http://dx.doi.org/10.33448/rsd-v11i2.25731

\begin{tabular}{|c|c|c|c|c|c|c|}
\hline 72 & $\begin{array}{l}\text { High D dimers and low global } \\
\text { fibrinolysis coexist in covid } \\
\text { patients: what is going on in there? } \\
\text { (Ibanez et al., 2020). }\end{array}$ & $\begin{array}{l}\text { Avaliar coagulopatia } \\
\text { associada a COVID-19 } \\
\text { relacionada a mortalidade } \\
\text { significativa. }\end{array}$ & $\begin{array}{l}\text { Estudo } \\
\text { observacional } \\
\text { retrospectivo } \\
\text { unicêntrico. }\end{array}$ & $\begin{array}{l}\text { Foram incluídos } 19 \text { pacientes, tendo sido } \\
\text { excluídos os que estavam em tratamento } \\
\text { com anticoagulante. A tromboprofilaxia foi } \\
\text { administrada de acordo com o protocolo } \\
\text { local (enoxaparina } 40-60 \mathrm{mg} / \text { dia). O teste } \\
\text { de coagulação padrão de laboratório e } \\
\text { tromboelastometria foram realizados } \\
\text { simultaneamente na } 1^{\mathrm{a}} \mathrm{h} \text { após a admissão na } \\
\text { UTI. }\end{array}$ & $\begin{array}{l}\text { Após o início do estudo, } 4 \text { pacientes } \\
\text { vieram a óbito, } 3 \text { permaneceram } \\
\text { hospitalizados, } 2 \text { apresentaram } \\
\text { sangramento, } 5 \text { tiveram complicações } \\
\text { trombóticas e } 2 \text { tiveram complicações } \\
\text { hemorrágicas e trombóticas. Na admissão, } \\
\text { altos níveis de fibrinogênio e dímero-D } \\
\text { foram observados. }\end{array}$ & $\begin{array}{l}\text { Em pacientes com COVID-19, o } \\
\text { padrão ROTE foi caracterizado } \\
\text { por um estado hipercoagulável } \\
\text { com capacidade fibrinolítica } \\
\text { diminuída, apesar de um } \\
\text { aumento paradoxal nos níveis de } \\
\text { dímero-D. Sugere-se que, em } \\
\text { pacientes com COVID-19, os } \\
\text { pulmões podem ser a principal } \\
\text { fonte de dímero-D, enquanto um } \\
\text { estado hipofbrinolítico sistêmico } \\
\text { coexiste. }\end{array}$ \\
\hline 73 & 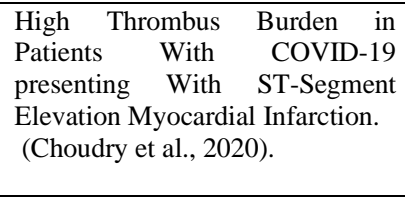 & $\begin{array}{l}\text { Comparar as características } \\
\text { angiográficas e resultados } \\
\text { clínicos de pacientes } \\
\text { COVID-19 positivos com } \\
\text { ou sem STEMI. }\end{array}$ & $\begin{array}{l}\text { Estudo } \\
\text { observacional } \\
\text { retrospectivo } \\
\text { unicêntrico. }\end{array}$ & $\begin{array}{l}\text { Foram incluídos } 115 \text { pacientes que sofreram } \\
\text { infarto com elevação do segmento ST } \\
\text { (STEMI) e apresentavam infecção por } \\
\text { COVID-19. Estes receberam dose de ataque } \\
\text { de aspirina, clopidogrel e ticagrelor antes } \\
\text { dos procedimentos. }\end{array}$ & $\begin{array}{l}\text { Pacientes com STEMI apresentando } \\
\text { infeçãao concomitante por COVID-19 } \\
\text { tinham níveis mais elevados de troponina } \\
\text { T e níveis mais baixos de linfócitos, mas } \\
\text { dímero-D e proteína C reativa elevados. }\end{array}$ & $\begin{array}{l}\text { Em pacientes que apresentaram } \\
\text { as condições concomitantes há } \\
\text { maior risco de trombo e piores } \\
\text { desfechos. }\end{array}$ \\
\hline 74 & $\begin{array}{l}\text { Pulmonary Embolism in Patients } \\
\text { Hospitalized With COVID-19 } \\
\text { (From a New York Health } \\
\text { System) } \\
\text { (H. Xu et al., 2020). }\end{array}$ & $\begin{array}{l}\text { Descrever as características } \\
\text { clínicas } \\
\text { e estratégias de } \\
\text { estratificação de risco de } \\
\text { pacientes hospitalizados } \\
\text { com COVID-19 com EP. }\end{array}$ & $\begin{array}{l}\text { Estudo } \\
\text { observacional } \\
\text { retrospectivo } \\
\text { multicêntrico. }\end{array}$ & $\begin{array}{l}\text { Foram analisados } 101 \text { pacientes } \\
\text { hospitalizados com infecção por COVID-19e } \\
\text { EP aguda. Os resultados clínicos avaliados } \\
\text { para admissão à unidade de terapia intensiva } \\
\text { foram: ventilação mecânica, eventos de } \\
\text { sangramento, transfusão, lesão renal aguda } \\
\text { (LRA) e mortalidade. }\end{array}$ & $\begin{array}{l}\text { Anormalidades do dímero-D foram } \\
\text { observadas na admissão com um aumento } \\
\text { de } 3 \text { vezes no momento do diagnóstico de } \\
\text { EP; 05 pacientes necessitaram de } \\
\text { trombólise sistêmica, } 12 \text { pacientes } \\
\text { apresentaram sangramento } \\
\text { moderado/severo, } 31 \text { desenvolveram LRA, } \\
1 \text { necessitou de terapia de substituição renal } \\
\text { e } 23 \text { foram internados em UTI. }\end{array}$ & $\begin{array}{l}\text { Resultados de dímero-D e } \\
\text { pontuação de PESI são essenciais } \\
\text { para avaliar a gestão de risco em } \\
\text { pacientes com COVID-19. }\end{array}$ \\
\hline 75 & 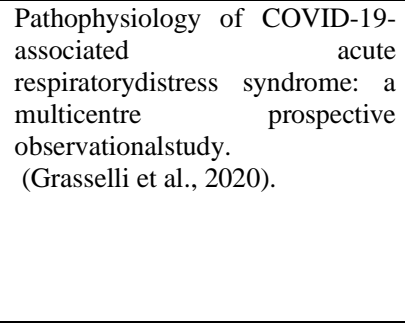 & 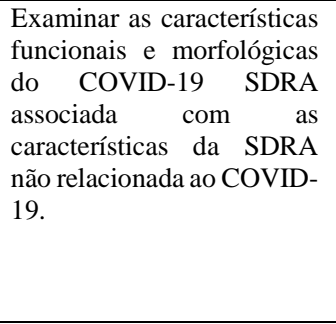 & $\begin{array}{l}\text { Estudo } \\
\text { observacional } \\
\text { prospectivo } \\
\text { multicêntrico. }\end{array}$ & $\begin{array}{l}\text { Os pacientes foram sedados, paralisados e } \\
\text { receberam ventilação mecânica. Tomografias } \\
\text { computadorizadas de pulmão e angiografias } \\
\text { foram realizadas quando clinicamente } \\
\text { indicado. as concentrações de dímero-D } \\
\text { foram medidas dentro de } 24 \text { horas após a } \\
\text { admissão na UTI. }\end{array}$ & $\begin{array}{l}\text { Pacientes dímero-D maiores do que a } \\
\text { mediana apresentavam áreas bilaterais de } \\
\text { hipoperfusão, compatíveis com doença } \\
\text { tromboembólica. Pacientes com } \\
\text { complacência estática igual ou menor do } \\
\text { que a mediana e as concentrações de } \\
\text { dímero-D maiores do que a mediana } \\
\text { aumentou acentuadamente a mortalidade } \\
\text { comparação com outros subgrupos de } \\
\text { pacientes. }\end{array}$ & 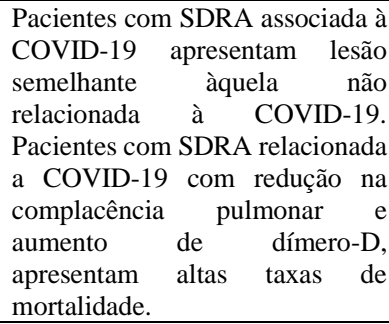 \\
\hline 76 & $\begin{array}{l}\text { Myocardial injury and risk factors } \\
\text { for mortality in patients with } \\
\text { COVID-19 pneumonia } \\
\text { (Yang et al., 2020). }\end{array}$ & $\begin{array}{l}\text { Explorar a prevalência de } \\
\text { lesão miocárdica e os } \\
\text { fatores de risco para } \\
\text { mortalidade em pacientes } \\
\text { com pneumonia COVID- } \\
19 .\end{array}$ & $\begin{array}{l}\text { Estudo } \\
\text { retrospectivo } \\
\text { multicêntrico. }\end{array}$ & $\begin{array}{l}\text { Foram analisados os desfechos definitivos } \\
\text { (alta ou óbito) de } 224 \text { pacientes. Os resultados } \\
\text { laboratoriais, incluindo biomarcadores } \\
\text { miocárdicos, saturação de oxigênio, } \\
\text { indicadores inflamatórios e função de } \\
\text { coagulação foram comparados entre } \\
\text { sobreviventes e não sobreviventes. }\end{array}$ & $\begin{array}{l}\text { Duzentos e três pacientes foram incluídos } \\
\text { na análise final, consistindo em } 145 \\
\text { pacientes que se recuperaram e } 58 \\
\text { pacientes que morreram. Em comparação } \\
\text { com os sobreviventes, os não sobreviventes } \\
\text { eram mais velhos, com mais comorbidades, } \\
\text { inflamação mais grave e função de } \\
\text { coagulação ativa. Dímero-D elevado, }\end{array}$ & $\begin{array}{l}\text { Os resultados sugerem que a } \\
\text { infecção por SARS-CoV-2 } \\
\text { podem induzir lesão no miocárdio } \\
\text { e consequentemente exacerbar o } \\
\text { curso clínico e piorar o } \\
\text { prognóstico. Marcadores como } \\
\text { dímero-D anormal, CK-MB, } \\
\text { troponina I e CRP são fatores de }\end{array}$ \\
\hline
\end{tabular}


Research, Society and Development, v. 11, n. 2, e21011225731, 2022

(CC BY 4.0) | ISSN 2525-3409 | DOI: http://dx.doi.org/10.33448/rsd-v11i2.25731

\begin{tabular}{|c|c|c|c|c|c|c|}
\hline & & & & & $\begin{array}{l}\text { Troponina e proteína } \mathrm{C} \text { reativa foram } \\
\text { fatores de risco para mortalidade. }\end{array}$ & $\begin{array}{l}\text { risco para mortalidade de curto } \\
\text { prazo. }\end{array}$ \\
\hline 77 & $\begin{array}{l}\text { Relation of D-dimer levels of } \\
\text { COVID-19 patients with diabetes } \\
\text { mellitus. } \\
\text { (Mishra et al., 2020) }\end{array}$ & $\begin{array}{l}\text { Estudar os níveis de } \\
\text { dímero-D em pessoas com } \\
\text { diabetes em comparação } \\
\text { com aqueles sem diabetes } \\
\text { entre os pacientes com } \\
\text { infecção por COVID-19. }\end{array}$ & $\begin{array}{l}\text { Estudo } \\
\text { observacional } \\
\text { prospectivo } \\
\text { unicêntrico. }\end{array}$ & $\begin{array}{l}\text { Foram incluídos } 98 \text { pacientes com COVID- } \\
19 \text { em estado moderado a grave. O grupo de } \\
\text { estudo foi dividido em pacientes com diabetes } \\
\text { e sem diabetes. O pico de dímero-D foi } \\
\text { medido em ambos os grupos e comparados } \\
\text { usando testes estatísticos. }\end{array}$ & $\begin{array}{l}\text { Os níveis máximos de dímero-D foram } \\
2.420 \mathrm{ng} / \mathrm{mL} \text { em pessoas com diabetes e } \pm \\
624 \mathrm{ng} / \mathrm{mL} \text { em pacientes sem diabetes. } \\
\text { Pacientes com diabetes apresentaram níveis } \\
\text { mais elevados de dímero-D. }\end{array}$ & $\begin{array}{l}\text { Pacientes COVID-19 portadores } \\
\text { de DM tinham níveis de dímero- } \\
\text { D mais elevados, sendo possível } \\
\text { que essa infecção em diabéticos } \\
\text { tenha maior probabilidade de } \\
\text { causar hipercoagulabilidade, } \\
\text { estado com pior prognóstico. }\end{array}$ \\
\hline 78 & $\begin{array}{l}\text { Characteristics of coagulation } \\
\text { alteration in patients with COVID- } \\
19 \\
\text { (Luo et al.,2020). }\end{array}$ & 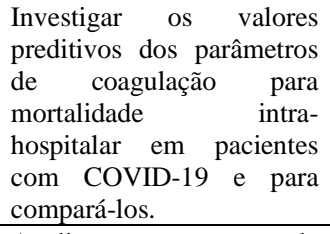 & $\begin{array}{l}\text { Estudo de coorte } \\
\text { retrospectivo } \\
\text { unicêntrico. }\end{array}$ & $\begin{array}{l}\text { Foram incluídos } 85 \text { pacientes divididos em } 2 \\
\text { grupos: sobreviventes e não sobreviventes. } \\
\text { Foram coletadas amostras de esfregaço do } \\
\text { nariz e garganta, realizado tomografia } \\
\text { computadorizada e realizado teste de } \\
\text { coagulação dentro de 12h após a admissão. }\end{array}$ & $\begin{array}{l}\text { O tempo de protrombina de admissão (TP), } \\
\text { níveis de dímero-D e produtos de } \\
\text { degradação de fibrina / fibrinogênio (FDP) } \\
\text { foram maiores em pacientes que vieram a } \\
\text { óbito do que em pacientes sobreviventes. }\end{array}$ & $\begin{array}{l}\text { A COVID-19 é frequentemente } \\
\text { acompanhado por coagulação } \\
\text { anormal. PT, dímero-D e FDP são } \\
\text { preditores significativos de } \\
\text { mortalidade. }\end{array}$ \\
\hline 79 & $\begin{array}{l}\text { Microcirculation alterations in } \\
\text { severe COVID-19 pneumonia. } \\
\text { (Edul et al., 2020) }\end{array}$ & $\begin{array}{l}\text { Avaliar a presença de } \\
\text { alterações } \\
\text { microcirculação sublingual } \\
\text { e da perfusão cutânea no } \\
\text { COVID-19 pneumonia. }\end{array}$ & $\begin{array}{l}\text { Estudo } \\
\text { observacional } \\
\text { prospectivo } \\
\text { multicêntrico. }\end{array}$ & $\begin{array}{l}\text { Foram incluídos } 27 \text { pacientes ventilados } \\
\text { mecanicamente com dificuldade respiratória } \\
\text { aguda síndrome secundária a COVID-19. A } \\
\text { microcirculação sublingual foi avaliada por } \\
\text { videomicroscopia manual. }\end{array}$ & $\begin{array}{l}\text { Os pacientes estavam hemodinamicamente } \\
\text { estáveis, apresentaram níveis de lactato } \\
\text { dentro da normalidade e dímero-D elevado. } \\
\text { A microcirculação sublingual foi } \\
\text { caracterizada por diminuições na proporção } \\
\text { de vasos perfundidos e na velocidade do } \\
\text { fluxo, juntamente com altas densidades } \\
\text { vasculares. }\end{array}$ & $\begin{array}{l}\text { Os pacientes com COVID-19 } \\
\text { apresentaram alteração da } \\
\text { perfusão tecidual. }\end{array}$ \\
\hline 80 & $\begin{array}{l}\text { Laboratory markers associated } \\
\text { with COVID-19 progression in } \\
\text { patients with or without } \\
\text { comorbidity: A retrospective } \\
\text { study. } \\
\text { (Z. Chen et al., 2020) }\end{array}$ & $\begin{array}{lr}\text { Investigar } & \text { marcadores } \\
\text { laboratoriais } & \text { para } \\
\text { progressão de } & \text { COVID-19 } \\
\text { em pacientes r com } \\
\text { diferentes } & \text { condições } \\
\text { médicas. } & \end{array}$ & $\begin{array}{l}\text { Estudo } \\
\text { multicêntrico } \\
\text { retrospectivo. }\end{array}$ & $\begin{array}{l}\text { Foi realizado um estudo de } 836 \text { casos em } \\
\text { Hubei. A análise foi realizada em pacientes } \\
\text { com as comorbidades mais comuns. Foram } \\
\text { utilizadas análise de regressão logística } \\
\text { multivariável e análise de regressão de riscos } \\
\text { para explorar os fatores de risco associados a } \\
\text { gravidade da doença e mortalidade. }\end{array}$ & $\begin{array}{l}\text { O risco de mortalidade foi associado com } \\
\text { aumento da idade, LDH, proteína C reativa } \\
\text { (PCR), dímero D, além da linfopenia e } \\
\text { comorbidades. Proteína C C reativa foi um } \\
\text { fator de risco associado à mortalidade de } \\
\text { curto prazo em pacientes com hipertensão, } \\
\text { mas não doenças hepáticas. Além disso, o } \\
\text { dímero-D foi um fator de risco para morte } \\
\text { em pacientes com doenças hepáticas. }\end{array}$ & $\begin{array}{l}\text { Os biomarcadores para risco de } \\
\text { mortalidade não foram idênticos } \\
\text { em pacientes com comorbidades, } \\
\text { sugerindo múltiplos mecanismos } \\
\text { fisiopatológicos após infecção } \\
\text { por COVID-19. }\end{array}$ \\
\hline 81 & $\begin{array}{l}\text { Clinical characteristics and short- } \\
\text { term outcomes after recovery from } \\
\text { COVID-19 in patients with and } \\
\text { without diabetes in Bangladesh } \\
\text { (Akter et al., 2020) }\end{array}$ & $\begin{array}{l}\text { Investigar as manifestações } \\
\text { clínicas, resultados e } \\
\text { complicações de longo } \\
\text { prazo em pacientes } \\
\text { internados com COVID-19. }\end{array}$ & $\begin{array}{l}\text { Estudo transversal } \\
\text { multicêntrico. }\end{array}$ & $\begin{array}{l}\text { Foram incluídos } 734 \text { pacientes. Foi } \\
\text { investigado variação nas características } \\
\text { clínicas, histórico de contato, comorbidades, } \\
\text { padrões de tratamento e complicações pós- } \\
\text { covid imediatas. }\end{array}$ & $\begin{array}{l}\text { Entre os parâmetros bioquímicos, glicose } \\
\text { plasmática, dímero-D, e os níveis de } \\
\text { troponina-I foram significativamente } \\
\text { elevados em pacientes diabéticos com } \\
\text { COVID-19. }\end{array}$ & $\begin{array}{l}\text { Indivíduos com diabetes } \\
\text { apresentaram manifestações } \\
\text { graves de COVID-19 e pós } \\
\text { complicações da doença. }\end{array}$ \\
\hline 82 & $\begin{array}{l}\text { Effectiveness and safety of } \\
\text { intravenous tocilizumab to treat } \\
\text { COVID-19-associated } \\
\text { hyperinflammatory syndrome: }\end{array}$ & $\begin{array}{l}\text { Avaliar a eficácia e } \\
\text { segurança do Tocilizumabe } \\
\text { em pacientes internados } \\
\text { com COVID-19. }\end{array}$ & $\begin{array}{l}\text { Estudo } \\
\text { observacional } \\
\text { retrospectivo } \\
\text { unicêntrico. } \\
\end{array}$ & $\begin{array}{l}\text { O TCZ foi administrado a } 104 \text { pacientes que } \\
\text { clinicamente pioraram e foram incluídos na } \\
\text { presente análise. Foram revisados os } \\
\text { prontuários médicos e coletado dados }\end{array}$ & $\begin{array}{l}\text { Resposta inflamatória sistêmica grave foi } \\
\text { confirmada através de altos níveis de } \\
\text { dímero-D }(>1500 \text { ng/mL) ou } \\
\text { progressivamente aumento do dímero-D }\end{array}$ & $\begin{array}{l}\text { A administração precoce } \\
\text { antagonistas de } \\
\text { pacientes COVID-19, pode ser } \\
\text { um tratamento seguro e eficaz } \\
\end{array}$ \\
\hline
\end{tabular}


Research, Society and Development, v. 11, n. 2, e21011225731, 2022

(CC BY 4.0) | ISSN 2525-3409 | DOI: http://dx.doi.org/10.33448/rsd-v11i2.25731

\begin{tabular}{|c|c|c|c|c|c|c|}
\hline & $\begin{array}{l}\text { Covizumab-6 observational } \\
\text { cohort } \\
\text { (Corominas et al., 2020). }\end{array}$ & & & $\begin{array}{l}\text { demográficos, comorbidades básicas e fatores } \\
\text { predisponentes. Foi avaliado resultados de } \\
\text { laboratório, sendo eles: hemoglobina, } \\
\text { ferritina, plaquetas, dímero-D e contagem de } \\
\text { leucócitos. }\end{array}$ & $\begin{array}{l}\text { ou, níveis elevados de IL-6 (> } 40 \mathrm{pg} / \mathrm{mL}) \\
\text { Foi observado que o TCZ diminuiu } \\
\text { rapidamente reagentes de fase aguda, } \\
\text { ferritina, liberação de proteínas do fígado e } \\
\text { diminuição lenta no nível de dímero-D. }\end{array}$ & $\begin{array}{l}\text { como prevenção de futuras } \\
\text { complicações. }\end{array}$ \\
\hline 83 & $\begin{array}{l}\text { Prevalence and characteristics of } \\
\text { pulmonary embolism in } 1042 \\
\text { COVID-19 patients with } \\
\text { respiratory symptoms: A nested } \\
\text { case-control study } \\
\text { (Planquette et al., 2020). }\end{array}$ & $\begin{array}{l}\text { Estimar a prevalência de EP } \\
\text { sintomática em pacientes } \\
\text { com COVID-19 e } \\
\text { identificar o quadro clínico, } \\
\text { características radiológicas } \\
\text { ou biológicas associadas ao } \\
\text { PE. }\end{array}$ & $\begin{array}{l}\text { Estudo de caso } \\
\quad \text { controle } \\
\text { retrospectivo } \\
\text { multicêntrico. }\end{array}$ & $\begin{array}{l}\text { Esse estudo incluiu } 1042 \text { pacientes com } \\
\text { COVID-19 associados com o risco de } \\
\text { embolia pulmonar. Pacientes com PE com } \\
\text { COVID-19 foram comparados aos pacientes } \\
\text { nos quais a EP foi descartada (controles } \\
\text { CTPA) e nos quais a EP não foi investigada } \\
\text { (controles CT). }\end{array}$ & $\begin{array}{l}\text { Os níveis de dímero-D foram } 5 \text { vezes } \\
\text { maiores em pacientes com PE do que em } \\
\text { controles CTPA. }\end{array}$ & $\begin{array}{l}\text { O estudo demonstrou que o } \\
\text { aumento do marcador dímero-D } \\
\text { está associado com o risco de } \\
\text { embolia pulmonar em paciente } \\
\text { com COVID-19. }\end{array}$ \\
\hline 84 & $\begin{array}{l}\text { The relation between left } \\
\text { ventricular global longitudinal } \\
\text { strain and troponin levels in } \\
\text { patients hospitalized with } \\
\text { covid-19 pneumonia. } \\
\text { (Kocas et al., 2020). }\end{array}$ & $\begin{array}{l}\text { Investigar a relação entre } \\
\text { níveis de troponina e } \\
\text { valores de LVGLS em } \\
\text { pacientes com COVID-19. }\end{array}$ & $\begin{array}{l}\text { Estudo } \\
\text { observacional } \\
\text { prospectivo } \\
\text { unicêntrico. }\end{array}$ & $\begin{array}{l}\text { Foi analisado um total de } 128 \text { pacientes com } \\
\text { COVID-19. Dos pacientes selecionados, } 90 \\
\text { foram excluídos. As informações } \\
\text { demográficas, laboratoriais e clínicas foram } \\
\text { recolhidos durante a hospitalização e os } \\
\text { pacientes foram divididos em dois grupos. }\end{array}$ & $\begin{array}{l}\text { Dos } 38 \text { pacientes incluídos, foram } \\
\text { divididos em } 2 \text { grupos: grupo 1, com } 11 \\
\text { pacientes com níveis elevados de troponina } \\
\text { e grupo 2, com } 27 \text { pacientes com níveis } \\
\text { negativos de troponina. O grupo de } \\
\text { troponina positiva tinham níveis mais altos } \\
\text { de dímero-D do que o grupo da troponina } \\
\text { negativa. Não houve diferença } \\
\text { estatisticamente significativa entre os } \\
\text { grupos em termos de DM, hipertensão, } \\
\text { sexo, taxas de tabagismo e níveis de IMC. }\end{array}$ & $\begin{array}{l}\text { Pacientes que apresentaram } \\
\text { troponina sérica alta, } \\
\text { consequentemente apresentaram } \\
\text { aumento nos marcadores dímero- } \\
\text { D, CRP, procalcitonina, ferritina, } \\
\text { creatinina e alanina. }\end{array}$ \\
\hline 85 & $\begin{array}{l}\text { Cardiac injury is associated with } \\
\text { inflammation in geriatric COVID- } \\
19 \text { patients } \\
\text { (Yan et al., 2020). }\end{array}$ & 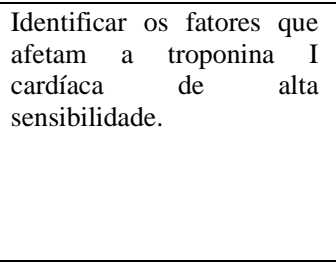 & $\begin{array}{l}\text { Estudo } \\
\text { observacional } \\
\text { retrospectivo } \\
\text { multicêntrico. }\end{array}$ & $\begin{array}{l}\text { Foram analisados } 180 \text { pacientes com mais de } \\
60 \text { anos. O quadro clínico, características e } \\
\text { resultados laboratoriais foram analisados. A } \\
\text { correlação entre lesão cardíaca e variáveis } \\
\text { clínicas/laboratoriais foi analisada e } \\
\text { posteriormente avaliado se as variáveis } \\
\text { influenciam na lesão cardíaca de pacientes } \\
\text { geriátricos. }\end{array}$ & $\begin{array}{l}\text { Dos } 180 \text { pacientes analisados, foram } \\
\text { incluídos } 119 \text { pacientes com COVID- } 19 . \\
\text { Níveis de dímero-D e lactato desidrogenase } \\
\text { foram maiores no grupo positivo para } \\
\text { troponina. No grupo positivo os valores de } \\
\text { leucócitos e neutrófilos foram maiores. }\end{array}$ & $\begin{array}{l}\text { A idade e os fatores inflamatórios } \\
\text { influenciam a lesão cardíaca em } \\
\text { pacientes idosos com COVID-19. }\end{array}$ \\
\hline 86 & $\begin{array}{l}\text { The diferences of clinical } \\
\text { characteristics and outcomes } \\
\text { between imported and local } \\
\text { patients of COVID-19 in Hunan: a } \\
\text { two-center retrospective study } \\
\text { (C. Wang et al., 2020). }\end{array}$ & $\begin{array}{l}\text { Analisar diferenças e } \\
\text { características clínicas } \\
\text { entre dois grupos de } \\
\text { pacientes. }\end{array}$ & $\begin{array}{l}\text { Estudo } \\
\text { retrospectivo } \\
\text { multicêntrico. }\end{array}$ & $\begin{array}{l}\text { Foram analisados } 169 \text { casos de pneumonia } \\
\text { COVID-19 em dois centros na província de } \\
\text { Hunan, e separados em dois grupos de acordo } \\
\text { com a história epidemiológica, "pacientes } \\
\text { importados" refere-se a pacientes com uma } \\
\text { história clara de ter viajado em Wuhan dentro } \\
\text { de } 14 \text { dias antes do início, e "pacientes locais" } \\
\text { refere-se a um residente local sem um } \\
\text { histórico recente de viagem em Wuhan. }\end{array}$ & $\begin{array}{l}\text { A incidência de febre na admissão em } \\
\text { pacientes importados foi maior do que em } \\
\text { pacientes locais. Observou-se aumento de } \\
\text { sinais pulmonares anormais, hipocalemia, } \\
\text { hiponatremia, TP prolongado, dímero- D e } \\
\text { glicose elevados nos pacientes importados. } \\
\text { Comparado com os pacientes locais, a } \\
\text { proporção o uso de antibióticos, } \\
\text { glicocorticoides e gamaglobulina foram } \\
\text { significativamente maiores nos pacientes } \\
\text { importados. }\end{array}$ & $\begin{array}{l}\text { Os casos importados eram mais } \\
\text { propensos a evoluir para casos } \\
\text { graves, em comparação com } \\
\text { pacientes locais e requeria } \\
\text { tratamentos mais poderosos. }\end{array}$ \\
\hline
\end{tabular}


Research, Society and Development, v. 11, n. 2, e21011225731, 2022

(CC BY 4.0) | ISSN 2525-3409 | DOI: http://dx.doi.org/10.33448/rsd-v11i2.25731

\begin{tabular}{|c|c|c|c|c|c|c|}
\hline 87 & $\begin{array}{l}\text { COVID-19 in older adults: What } \\
\text { are the differences with younger } \\
\text { patients? } \\
\text { (Gomez-Beld et al., 2020). }\end{array}$ & $\begin{array}{l}\text { Avaliar as características } \\
\text { clínicas distintas em idosos } \\
\text { com COVID-19, em } \\
\text { comparação com pacientes } \\
\text { mais jovens e identificar } \\
\text { fatores de risco para } \\
\text { mortalidade. }\end{array}$ & $\begin{array}{l}\text { Estudo } \\
\text { observacional } \\
\text { retrospectivo } \\
\text { unicêntrico. }\end{array}$ & $\begin{array}{l}\text { O estudo analisou } 340 \text { pacientes jovens e } \\
\text { velhos. Todos os casos foram diagnosticados } \\
\text { por reação em cadeia da polimerase de } \\
\text { transcrição reversa ou por teste de sorologia } \\
\text { para detecção de anticorpos. }\end{array}$ & $\begin{array}{l}\text { Dos } 340 \text { pacientes analisados, } 152 \text { tinham } \\
\text { idade maior que } 70 \text { anos. As comorbidades } \\
\text { foram mais comuns em pacientes mais } \\
\text { velhos. Neutrofilia, dímero-D, creatinina, } \\
\text { lactato desidrogenase e creatina quinase } \\
\text { foram maiores nos grupos de adultos mais } \\
\text { velhos. }\end{array}$ & $\begin{array}{l}\text { A proporção de pacientes com } \\
\text { dímero-D }>0,5 \mathrm{mg} / \mathrm{L} \text { foi maior } \\
\text { entre os adultos mais velhos, bem } \\
\text { como com tempo de } \\
\text { protrombina }>16 \mathrm{~s} \text {. }\end{array}$ \\
\hline 88 & $\begin{array}{l}\text { Coagulation dysfunction in ICU } \\
\text { patients with coronavirus disease } \\
2019 \text { in Wuhan, China: a } \\
\text { retrospective observational study } \\
\text { of } 75 \text { fatal cases. } \\
\text { (Shi et al., 2020). }\end{array}$ & $\begin{array}{l}\text { Avaliar a eficácia do uso de } \\
\text { anticoagulante em } \\
\text { pacientes portadores de } \\
\text { COVID-19 na Unidade de } \\
\text { Terapia Intensiva. }\end{array}$ & $\begin{array}{l}\text { Estudo } \\
\text { observacional } \\
\text { retrospectivo } \\
\text { unicêntrico. }\end{array}$ & $\begin{array}{l}\text { Foram revisados } 75 \text { casos fatais de COVID- } \\
19 \text { que foram admitidos na unidade de terapia } \\
\text { intensiva do Hospital Jinyintan (Wuhan, } \\
\text { China). A idade média dos casos foi de } 67 \\
\text { anos. Cinquenta pacientes foram } \\
\text { diagnosticados com coagulação intravascular } \\
\text { disseminada. }\end{array}$ & $\begin{array}{l}\text { Aproximadamente } 90 \% \text { dos pacientes } \\
\text { tinham dímero-D elevado e produtos de } \\
\text { degradação do fibrinogênio, que diminuiu } \\
\text { continuamente após o tratamento com } \\
\text { anticoagulante e foi acompanhada por } \\
\text { albumina elevada. O tempo médio de } \\
\text { sobrevivência de pacientes tratados com } \\
\text { anticoagulante foi de } 9,0 \text { dias em } \\
\text { comparação com } 7,0 \text { dias em pacientes sem } \\
\text { terapia anticoagulante. }\end{array}$ & $\begin{array}{l}\text { Os distúrbios de coagulação } \\
\text { foram generalizados em situações } \\
\text { críticas em pacientes com } \\
\text { COVID-19 em UTIs, havendo } 2 / 3 \\
\text { dos pacientes fatais } \\
\text { diagnosticados com CID após } \\
\text { admissão na UTI. Em pacientes } \\
\text { críticos, anticoagulante melhorou } \\
\text { a hipercoagulabilidade, tempo de } \\
\text { sobrevida na UTI, inflamąão e } \\
\text { lesão cardíaca. }\end{array}$ \\
\hline 89 & $\begin{array}{l}\text { Pulmonary Embolism and Deep } \\
\text { Vein Thrombosis in COVID-19: } \\
\text { A Systematic Review and Meta- } \\
\text { Analysis. } \\
\text { (Suh, Y. J. et al., 2020) }\end{array}$ & $\begin{array}{l}\text { Avaliar incidência de } \\
\text { embolia pulmonar (EP) e } \\
\text { Trombose venosa profunda } \\
\text { (TVP) na COVID-19 e a } \\
\text { precisão do diagnóstico } \\
\text { pelo dímero-D. }\end{array}$ & $\begin{array}{c}\text { Revisão } \\
\text { sistemática. }\end{array}$ & $\begin{array}{l}\text { Foi realizada revisão sistemática da literatura } \\
\text { sobre a incidência de embolia pulmonar e } \\
\text { trombose venosa profunda em pacientes com } \\
\text { COVID-19. Vinte e sete estudos com } 3342 \\
\text { pacientes com COVID-19 foram incluídos na } \\
\text { análise. }\end{array}$ & $\begin{array}{l}\text { Treze estudos (1896 pacientes) relataram a } \\
\text { incidência de EP e TVP enquanto nove } \\
\text { estudos (1.022 pacientes) e cinco estudos } \\
\text { (424 pacientes) relataram a incidência de } \\
\text { EP. Os níveis de dímero-D mostraram alta } \\
\text { sensibilidade em TVP, mas baixa } \\
\text { especificidade em EP. }\end{array}$ & $\begin{array}{l}\text { EP e TVP ocorreram em } 16,5 \% \\
\text { dos pacientes com COVID-19 } \\
\text { e >50\% com EP não } \\
\text { apresentavam TVP. Os pontos de } \\
\text { corte dos níveis de dímero D } \\
\text { costumavam excluir em pacientes } \\
\text { com COVID- } 19 .\end{array}$ \\
\hline 90 & $\begin{array}{lcr}\text { Development } & \text { and } & \text { external } \\
\text { validation of a } & \text { COVID-19 } \\
\text { mortality risk } & \text { prediction } \\
\text { algorithm: a } & \text { multicentre } \\
\text { retrospective cohort study. } \\
\text { (Mei et al., 2020) }\end{array}$ & $\begin{array}{lr}\text { Desenvolver } & \mathrm{e} \\
\text { externamente } & \text { validar um } \\
\text { algoritmo de } & \text { predição de } \\
\text { risco de } & \text { mortalidade } \\
\text { COVID-19. } & \end{array}$ & $\begin{array}{l}\text { Estudo de coorte } \\
\text { retrospectivo } \\
\text { multicêntrico. }\end{array}$ & $\begin{array}{l}\text { Foi coletado dados médicos de } 1364 \\
\text { pacientes adultos confirmados com COVID- } \\
\text { 19. Entre eles, } 1.088 \text { pacientes de dois } \\
\text { hospitais designados em Wuhan estavam } \\
\text { acostumados a desenvolver o modelo } \\
\text { prognóstico, e } 276 \text { pacientes de três hospitais } \\
\text { fora de Wuhan foram usados para validação } \\
\text { externa. }\end{array}$ & $\begin{array}{l}\text { O modelo completo incluiu idade, } \\
\text { insuficiência respiratória, determinação de } \\
\text { leucócitos e plaquetas, dímero-D e lactato } \\
\text { desidrogenase. O simples continha idade, } \\
\text { insuficiência respiratória, doença } \\
\text { coronariana, insuficiência renal e } \\
\text { insuficiência cardíaca. Dímero-D e lactato } \\
\text { desidrogenase também foram mostrados } \\
\text { como fatores de risco independentes } \\
\text { associados à gravidade e mortalidade de } \\
\text { COVID-19. }\end{array}$ & $\begin{array}{l}\text { Os modelos de previsão } \\
\text { mostraram um bom modelo } \\
\text { desempenho na identificaçãa de } \\
\text { pacientes com COVID-19 com } \\
\text { um alto risco de morte em } 60 \text { dias. } \\
\text { Pode ser útil para casos agudos } \\
\text { classificação de risco. }\end{array}$ \\
\hline 91 & $\begin{array}{llr}\text { Subarachnoid } & \text { hemorrhage } & \text { and } \\
\text { COVID-19. } & \text { Association } & \text { or } \\
\text { coincidence? } & & \\
\text { (Junior-Cezar et al., 2020) } & \end{array}$ & $\begin{array}{l}\text { Analisar a relação da } \\
\text { doença COVID-19 com a } \\
\text { doença } \quad \text { hemorragia } \\
\text { subaracnóidea. }\end{array}$ & $\begin{array}{c}\text { Estudo } \\
\text { retrospectivo } \\
\text { unicêntrico. }\end{array}$ & $\begin{array}{l}\text { Foi coletado dados de } 4 \text { pacientes que } \\
\text { desenvolveram hemorragia subaracnóidea } \\
\text { repentina durante a infecção por COVID- } 19 \text {. } \\
\text { Os dados clínicos foram extraídos de registros } \\
\text { médicos eletrônicos, e os dados neurológicos } \\
\text { foram verificados em detalhes por uma } \\
\text { equipe treinada de neurocirurgiões e neuro } \\
\text { radiologistas. }\end{array}$ & $\begin{array}{l}\text { Pneumonia relacionada a COVID- } 19 \text { foi } \\
\text { grave em } 3 \text { de } 4 \text { casos. Todos necessitaram } \\
\text { de cuidados intensivos durante internação e } \\
\text { apresentaram comprometimento da } \\
\text { consciência associado à HAS. Os } \\
\text { marcadores inflamatórios estavam bastante } \\
\text { elevados, com um dímero D médio de } \\
2336 \mathrm{mg} / \mathrm{L} \text {. }\end{array}$ & $\begin{array}{l}\text { A influência de um exacerbado } \\
\text { processo inflamatório sistêmico } \\
\text { causado por este vírus pode ser } \\
\text { uma das possíveis razões para } \\
\text { SHA nesses pacientes, podendo } \\
\text { estar ser incluída como } \\
\text { manifestação neurológica grave } \\
\text { na COVID-19. }\end{array}$ \\
\hline
\end{tabular}


Research, Society and Development, v. 11, n. 2, e21011225731, 2022

(CC BY 4.0) | ISSN 2525-3409 | DOI: http://dx.doi.org/10.33448/rsd-v11i2.25731

\begin{tabular}{|c|c|c|c|c|c|c|}
\hline 92 & $\begin{array}{l}\text { Clinical characteristics and } \\
\text { predictors of mortality in young } \\
\text { adults with severe covid-19: a } \\
\text { retrospective observational study. } \\
\text { (Lu et al.,2020) }\end{array}$ & $\begin{array}{l}\text { Investigar as características } \\
\text { clínicas e fornecer } \\
\text { preditores de } \\
\text { em jovens. }\end{array}$ & $\begin{array}{l}\text { Estudo } \\
\text { observacional } \\
\text { retrospectivo } \\
\text { unicêntrico. }\end{array}$ & $\begin{array}{l}\text { Foram analisados } 376 \text { pacientes com } \\
\text { COVID-19. Os pacientes foram divididos em } \\
\text { dois grupos, grupo de sobreviventes e grupo } \\
\text { de não sobreviventes. Foi coletado dados } \\
\text { demográficos, características clínicas e } \\
\text { registros médicos. Os pacientes foram } \\
\text { acompanhados desde a admissão até a alta ou } \\
\text { morte. }\end{array}$ & $\begin{array}{l}\text { Dos } 376 \text { pacientes analisados, foram } \\
\text { excluídos } 299 \text { casos por serem inelegíveis, } \\
\text { incluindo um total de } 77 \text { pacientes com } \\
\text { COVID-19 para o estudo. A análise } \\
\text { demonstrou linfopenia, nível elevado de } \\
\text { dímero-d, troponina I cardíaca } \\
\text { hipersensível (hs-CTnI) e proteína C } \\
\text { reativa de alta sensibilidade foram } \\
\text { preditores independentes de mortalidade } \\
\text { em adultos jovens com COVID-19 grave. }\end{array}$ & $\begin{array}{l}\text { Linfopenia, nível elevado de } \\
\text { dímero-d, hs-CTnI e hs-CRP } \\
\text { previram resultados clínicos de } \\
\text { jovens adultos com COVID-19 } \\
\text { grave. }\end{array}$ \\
\hline 93 & $\begin{array}{l}\text { Pulmonary thromboembolism in } \\
\text { coronavirus disease } 2019 \text { patients } \\
\text { undergoing thromboprophylaxis. } \\
\text { (Schiaffino et al.,2020) }\end{array}$ & $\begin{array}{l}\text { Investigar a prevalência de } \\
\text { tromboembolismo } \\
\text { pulmonar (TEP) e sua } \\
\text { associação com variáveis } \\
\text { clínicas. }\end{array}$ & $\begin{array}{l}\text { Estudo } \\
\text { observacional } \\
\text { retrospectivo } \\
\text { unicêntrico. }\end{array}$ & $\begin{array}{l}\text { Foram incluídos } 45 \text { pacientes. Os pacientes } \\
\text { incluídos estavam recebendo heparina de } \\
\text { baixo peso molecular (HBPM) em dosagem } \\
\text { profilática desde a admissão. Foram } \\
\text { encaminhados para ultrassom de Doppler } \\
\text { venoso de membros inferiores. }\end{array}$ & $\begin{array}{l}\text { Doze pacientes foram diagnosticados TEP. } \\
\text { Nos } 33 \text { pacientes restantes foi feito exame } \\
\text { de doppler antes de realizar o CTPA. Um } \\
\text { paciente apresentou trombose venosa } \\
\text { profunda (TVP). Antes dos exames de } \\
\text { CTPA, } 5 \text { pacientes tinham altos níveis de } \\
\text { dímero-D e fibrinogênio e 11, altos níveis } \\
\text { de proteína C reativa. }\end{array}$ & $\begin{array}{l}\text { A alta incidência de TEP (60\%) } \\
\text { em pacientes hospitalizados por } \\
\text { COVID-19 sob LMWH } \\
\text { profilático poderia justificar a } \\
\text { adaptação adicional de terapia de } \\
\text { anticoagulação. }\end{array}$ \\
\hline 94 & $\begin{array}{l}\text { Incidence, risk factors, and } \\
\text { thrombotic load of pulmonary } \\
\text { embolism in patients hospitalized } \\
\text { for COVID-19 infection. } \\
\text { (Ortega-García et al.,2020) }\end{array}$ & $\begin{array}{l}\text { Determinar a incidência, } \\
\text { características e fatores de } \\
\text { risco de embolia pulmonar } \\
(\text { EP) entre os pacientes } \\
\text { hospitalizados por COVID- } \\
19 .\end{array}$ & $\begin{array}{l}\text { Estudo } \\
\text { observacional } \\
\text { prospectivo } \\
\text { unicêntrico. }\end{array}$ & $\begin{array}{l}\text { Foram selecionados } 119 \text { pacientes } \\
\text { aleatoriamente a partir de } 372 \text { internados no } \\
\text { hospital para infecção por COVID-19 durante } \\
\text { o período de estudo. Cerca de } 50 \% \text { dos } \\
\text { especialistas envolvidos foram selecionados } \\
\text { aleatoriamente para participar no estudo. }\end{array}$ & $\begin{array}{l}\text { A análise multivariada mostrou que a } \\
\text { frequência cardíaca, saturação de oxigênio } \\
\text { do ar ambiente, dímero-D e níveis de } \\
\text { proteína C reativa no momento da admissão } \\
\text { foram preditores independentes de } \\
\text { incidentes de EP durante a hospitalização. }\end{array}$ & $\begin{array}{l}\text { Nossos achados confirmaram } \\
\text { uma alta incidência de EP em } \\
\text { pacientes hospitalizados com } \\
\text { COVID-19. Frequência cardíaca, } \\
\text { níveis de spO2, dímero-D e PCR } \\
\text { na admissão foram associados a } \\
\text { taxas mais altas de EP durante a } \\
\text { hospitalização. }\end{array}$ \\
\hline 95 & $\begin{array}{l}\text { Incidence and characterization of } \\
\text { acute pulmonary embolism in } \\
\text { patients with SARSCoV-2 } \\
\text { pneumonia: A multicenter Italian } \\
\text { experience. } \\
\text { (Loffi et al.,2021) }\end{array}$ & $\begin{array}{l}\text { Avaliar a ocorrência de } \\
\text { embolia pulmonar entre os } \\
\text { pacientes com infeç̧ão por } \\
\text { SARS-CoV-2 }\end{array}$ & $\begin{array}{c}\text { Estudo } \\
\text { retrospectivo } \\
\text { multicêntrico. }\end{array}$ & $\begin{array}{l}\text { Foram incluídos } 333 \text { pacientes com COVID- } \\
\text { 19. Os pacientes foram divididos em dois } \\
\text { grupos, sendo eles grupo com embolia } \\
\text { pulmonar e grupo sem embolia pulmonar. Os } \\
\text { pacientes foram submetidos a angiografia } \\
\text { pulmonar computadorizada para a deteção } \\
\text { de EP. Dados clínicos, laboratoriais e } \\
\text { radiológicos também foram analisados. }\end{array}$ & $\begin{array}{l}\text { Dos } 333 \text { pacientes, EP foi detectada em } 109 \\
\text { pacientes. No CTPA, foi detectado } \\
\text { subsegmental, segmentar, lobar e trombos } \\
\text { centrais em 31, 50, 20 e } 8 \text { pacientes } \\
\text { respectivamente. } 29 \text { pacientes do grupo de } \\
\text { EP vieram a óbito e } 47 \text { pacientes do grupo } \\
\text { sem EP vieram a óbito. Níveis de dímero- } \\
\text { D maiores que } 0,5 u g / m l \text { foram encontrados } \\
\text { em } 184 \text { pacientes. }\end{array}$ & $\begin{array}{l}\text { Apesar da baixa taxa de fatores de } \\
\text { risco para tromboembolismo } \\
\text { venoso, EP esteve presente em } 1 \\
\text { de cada } 3 \text { pacientes com } \\
\text { pneumonia por SARS-CoV-2 nos } \\
\text { quais houve elevado nível de } \\
\text { dímero-D e sunais } \\
\text { ecocardiográficos de disfunção } \\
\text { ventricular direita. }\end{array}$ \\
\hline 96 & $\begin{array}{l}\text { Effectiveness of mid-regional } \\
\text { proadrenomedullin } \quad \text { (MR- } \\
\text { proADM) as prognostic marker in } \\
\text { COVID-19 critically ill patients: } \\
\text { An observational prospective } \\
\text { study. } \\
\text { (Montrucchio et al.,2021) }\end{array}$ & $\begin{array}{l}\text { Avaliar eficácia da pró- } \\
\text { adrenomedulina média } \\
\text { regional (MR-proADM) } \\
\text { em comparação à proteína } \\
\text { C reativa, procalcitonina, } \\
\text { dímero D e lactato } \\
\text { desidrogenase em predição } \\
\text { de mortalidade em } \\
\text { pacientes com COVID-19 } \\
\text { em UTI. }\end{array}$ & $\begin{array}{l}\text { Estudo } \\
\text { observacional } \\
\text { prospectivo } \\
\text { unicêntrico. }\end{array}$ & $\begin{array}{l}\text { Foram analisados } 57 \text { pacientes. Curvas de } \\
\text { diferença com MR-proADM cut-off definido } \\
\text { para } 1,8 \mathrm{nmol} / \mathrm{L} \text { foram testadas usando log- } \\
\text { rank teste. A capacidade preditiva foi } \\
\text { comparada usando a área sob a curva e } \\
\text { intervalo de confiança de } 95 \% \text { de diferentes } \\
\text { curvas de características de operação do } \\
\text { receptor. }\end{array}$ & $\begin{array}{l}\mathrm{Na} \text { admissão, o nível de dímero-D e } \\
\text { proteína C reativa estavam aumentados. } 38 \\
\text { pacientes precisaram de ventilação } \\
\text { mecânica e } 13 \text { foram afetados por uma } \\
\text { grande superinfecção bacteriana. A } \\
\text { mortalidade geral foi de } 54,4 \% \text { e nenhum } \\
\text { paciente veio a óbito após a alta da UTI. O } \\
\text { biomarcador dímero-D não mostrou } \\
\text { qualquer diferença entre os grupos de } \\
\text { sobreviventes e não sobreviventes. }\end{array}$ & $\begin{array}{l}\text { Em pacientes de UTI COVID-19, } \\
\text { MR-proADM apresentaram } \\
\text { valores elevados em pacientes } \\
\text { não sobreviventes e podem prever } \\
\text { a mortalidade com mais precisão } \\
\text { do que outros biomarcadores. }\end{array}$ \\
\hline
\end{tabular}


Research, Society and Development, v. 11, n. 2, e21011225731, 2022

(CC BY 4.0) | ISSN 2525-3409 | DOI: http://dx.doi.org/10.33448/rsd-v11i2.25731

\begin{tabular}{|c|c|c|c|c|c|c|}
\hline 97 & $\begin{array}{l}\text { Extracorporeal Membrane } \\
\text { Oxygenation Therapy for } \\
\text { Critically Ill Coronavirus Disease } \\
\text { 2019 Patients in Wuhan, China: A } \\
\text { Retrospective Multicenter Cohort } \\
\text { Study. } \\
\text { (J. Fang et al., 2021) }\end{array}$ & $\begin{array}{l}\text { Analisar a relação da } \\
\text { oxigenação por membrana } \\
\text { extracorpórea com os níveis } \\
\text { de dímero-D. }\end{array}$ & $\begin{array}{l}\text { Estudo de coorte } \\
\text { retrospectivo } \\
\text { multicêntrico. }\end{array}$ & $\begin{array}{l}\text { Um total de } 630 \text { pacientes foram analisados } \\
\text { em diferentes hospitais em Wuhan. Os } \\
\text { pacientes foram divididos em dois grupos, } \\
\text { sendo eles: grupo desmamado e grupo não } \\
\text { desmamado. }\end{array}$ & $\begin{array}{l}\text { Dos } 630 \text { pacientes, } 536 \text { receberam terapia } \\
\text { com IMV e 94, terapia ECMO. Dímero-D, } \\
\text { proteína C reativa e IL-6 estavam elevados } \\
\text { em ambos os grupos. Os pacientes do } \\
\text { grupo não desmamado eram mais velhos. } \\
\text { Metade dos pacientes apresentavam } \\
\text { comorbidades, especialmente hipertensão e } \\
\text { diabetes. }\end{array}$ & 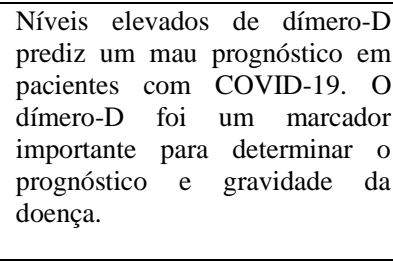 \\
\hline 98 & $\begin{array}{l}\text { Clinical features and risk factors } \\
\text { for severecritically ill COVID-19 } \\
\text { adult patients in Jiangsu, China A } \\
\text { multiple-centered, retrospective } \\
\text { study. } \\
\text { (Zhao et al., 2020) }\end{array}$ & $\begin{array}{l}\text { Avaliar quais são os fatores } \\
\text { que determinam que um } \\
\text { paciente esteja em estado } \\
\text { grave da COVID-19. }\end{array}$ & $\begin{array}{l}\text { Estudo } \\
\text { retrospectivo } \\
\text { multicêntrico. }\end{array}$ & $\begin{array}{l}\text { Foram analisados } 583 \text { pacientes adultos com } \\
\text { COVID-19. Os pacientes foram divididos } \\
\text { entre grupo grave/criticamente enfermos e } \\
\text { grupo leve a moderado. Foram coletados } \\
\text { dados sobre DPOC, ALT, AST, dímero-D, } \\
\text { tempo de protrombina, infecções e resultados } \\
\text { de testes de laboratório. }\end{array}$ & $\begin{array}{l}499 \text { eram do grupo leve/moderado e } 84 \text { do } \\
\text { grupo grave/criticamente enfermo. Os } \\
\text { pacientes em estado grave tinham } \\
\text { problemas de saúde coexistentes em } \\
\text { comparação com os pacientes } \\
\text { leves/moderados. Os níveis de dímero-D e } \\
\text { linfócitos foram associados com a } \\
\text { progressão da COVID-19. Idade avançada, } \\
\text { níveis mais elevados de dímero-D e } \\
\text { presença de linfopenia na admissão foram } \\
\text { fatores de risco para pacientes com } \\
\text { COVID-19. }\end{array}$ & $\begin{array}{l}\text { Os fatores intimamente } \\
\text { relacionados para a progressão da } \\
\text { doença grave - criticamente é a } \\
\text { idade avançada, valores elevados } \\
\text { de dímero-D e diminuição do } \\
\text { conteúdo de células de linfócitos. }\end{array}$ \\
\hline 99 & $\begin{array}{l}\text { Comparison of acute pneumonia } \\
\text { caused by SARS-COV-2 and } \\
\text { other respiratory viruses in } \\
\text { children: a retrospective multi- } \\
\text { center cohort study during } \\
\text { COVID-19 outbreak. } \\
\text { (G.L. Ren et al., 2021) } \\
\end{array}$ & $\begin{array}{l}\text { Descrever as manifestações } \\
\text { clínicas, tratamento e } \\
\text { resultados de COVID-19 } \\
\text { em crianças em } \\
\text { comparação com as de } \\
\text { outras fontes de pneumonia } \\
\text { viral. }\end{array}$ & $\begin{array}{l}\text { Estudo de coorte } \\
\text { retrospectivo } \\
\text { multicêntrico. }\end{array}$ & $\begin{array}{l}\text { Foram incluídas neste estudo } 348 \text { crianças, } \\
\text { divididas em coorte de crianças com COVID- } \\
19 \text { e crianças com outros vírus. Uso de } \\
\text { drogas, imunoterapia, transfusão de sangue e } \\
\text { necessidade de suporte de oxigênio foram } \\
\text { coletados como índices de tratamento. }\end{array}$ & $\begin{array}{l}\text { Em comparação com a coorte de } \\
\text { pneumonia viral, as crianças da coorte } \\
\text { COVID-19 foram principalmente expostas } \\
\text { a membros da família com COVID-19 e } \\
\text { tiveram menores níveis de dímero-D e } \\
\text { proporção de casos graves do que aqueles } \\
\text { na coorte de pneumonia viral }\end{array}$ & $\begin{array}{l}\text { Os sintomas e a gravidade da } \\
\text { pneumonia por COVID-19 em } \\
\text { crianças não foram mais graves } \\
\text { do que aqueles em crianças com } \\
\text { outra pneumonia viral. }\end{array}$ \\
\hline 100 & $\begin{array}{l}\text { Anemia is associated with severe } \\
\text { illness in COVID-19: a } \\
\text { retrospective cohort study. } \\
\text { (Tao et al., 2021) }\end{array}$ & $\begin{array}{l}\text { avaliar as características } \\
\text { clínicas de pacientes com } \\
\text { anemia e explorar melhor a } \\
\text { relação entre a anemia e a } \\
\text { gravidade da COVID-19. }\end{array}$ & $\begin{array}{l}\text { Estudo } \\
\text { observacional } \\
\text { retrospectivo } \\
\text { unicêntrico. }\end{array}$ & $\begin{array}{l}\text { Foram incluídos } 222 \text { pacientes com COVID- } \\
\text { 19. Os pacientes foram classificados como do } \\
\text { tipo grave ou não grave. Foram coletadas } \\
\text { amostras respiratórias dos pacientes, } \\
\text { realizado teste de RT-PCR e exames de rotina } \\
\text { foram realizados dentro de } 24 \text { horas após a } \\
\text { admissão. }\end{array}$ & $\begin{array}{l}\text { Dos } 222 \text { pacientes, } 79 \text { pacientes estavam } \\
\text { com anemia, os quais eram mais propensos } \\
\text { a ter comorbidades e COVID-19 grave. Os } \\
\text { anêmicos apresentaram maiores elevações } \\
\text { de proteína C reativa, procalcitonina, } \\
\text { creatinina, VHS, dímero-D, mioglobina, } \\
\text { entre outros achados. }\end{array}$ & $\begin{array}{l}\text { A anemia é um fator de risco } \\
\text { independente associado à doença } \\
\text { grave de COVID-19, e os } \\
\text { profissionais de saúde devem ser } \\
\text { mais sensíveis aos níveis de } \\
\text { hemoglobina de pacientes com } \\
\text { COVID-19 na admissão. }\end{array}$ \\
\hline 101 & $\begin{array}{l}\text { Myocardial injury in severe } \\
\text { COVID-19 is similar to } \\
\text { pneumonias of other origin: } \\
\text { results from a multicentre study. } \\
\text { (Jirak et al., 2020) }\end{array}$ & $\begin{array}{l}\text { Investigar a relação da } \\
\text { lesão miocárdica com a } \\
\text { COVID-19. }\end{array}$ & $\begin{array}{l}\text { Estudo } \\
\text { retrospectivo } \\
\text { multicêntrico. }\end{array}$ & $\begin{array}{l}\text { Foram analisados } 156 \text { pacientes em estado } \\
\text { crítico sob ventilação mecânica. Os pacientes } \\
\text { foram classificados em grupo de pacientes } \\
\text { com COVID-19 e pacientes sem COVID-19. }\end{array}$ & $\begin{array}{l}\text { Dos } 156 \text { pacientes, } 76 \text { tinham COVID-19 e } \\
76 \text { apresentaram pneumonia grave de outra } \\
\text { origem. O comprometimento da função } \\
\text { sistólica não foi diferente, mas a lesão } \\
\text { miocárdia foi frequente em pacientes } \\
\text { portadores de COVID-19. Embora os } \\
\text { marcadores inflamatórios (proteína C } \\
\text { reativa e interleucina 6) não tenham sido } \\
\text { diferentes entre os grupos, o dímero-D e a } \\
\text { incidência de eventos tromboembolísticos } \\
\text { foram maiores no grupo COVID-19. }\end{array}$ & $\begin{array}{l}\text { Lesão miocárdica foi frequente na } \\
\text { COVID-19 grave com } \\
\text { necessidade de ventilação } \\
\text { mecânica. Embora a mortalidade } \\
\text { também tenha sido semelhante, a } \\
\text { COVID-19 é causada pelo } \\
\text { aumento da trombogenicidade e } \\
\text { altas taxas de embolia pulmonar. }\end{array}$ \\
\hline
\end{tabular}


Research, Society and Development, v. 11, n. 2, e21011225731, 2022

(CC BY 4.0) | ISSN 2525-3409 | DOI: http://dx.doi.org/10.33448/rsd-v11i2.25731

\begin{tabular}{|c|c|c|c|c|c|c|}
\hline 102 & $\begin{array}{l}\text { Clinical characteristics and } \\
\text { treatment outcome of COVID-19 } \\
\text { patients with stroke in China: A } \\
\text { multicenter retrospective study. } \\
\text { (X. Y. Ji et al.,2020) }\end{array}$ & $\begin{array}{l}\text { Descobrir as características } \\
\text { clínicas de pacientes com } \\
\text { COVID-19 que tiveram } \\
\text { AVC. }\end{array}$ & $\begin{array}{l}\text { Estudo } \\
\text { observacional } \\
\text { retrospectivo } \\
\text { multicêntrico }\end{array}$ & $\begin{array}{l}\text { Foram incluídos } 27 \text { pacientes com AVC e } \\
\text { COVID-19. Foram coletados dados } \\
\text { epidemiológicos, demográficos, clínicos, } \\
\text { laboratoriais e de tratamento. }\end{array}$ & $\begin{array}{l}\text { Dos } 27 \text { pacientes, } 9 \text { estavam em estado } \\
\text { grave e } 18 \text { em estado não grave. Pacientes } \\
\text { com COVID-19 e AVC tiveram níveis } \\
\text { aumentados de Dímero-D, proteína C } \\
\text { reativa e fibrinogênio, entre outros. O } \\
\text { dímero-D estava aumentado em } 14 \text { dos } 27 \\
\text { pacientes. A gravidade se relacionou com o } \\
\text { aumento de proteína C reativa, entre outros, } \\
\text { mas não com dímero-D e demais } \\
\text { marcadores de coagulação. }\end{array}$ & $\begin{array}{l}\text { Pacientes com COVID-19 e AVC } \\
\text { tem pior indicadores de } \\
\text { coagulação. }\end{array}$ \\
\hline 103 & $\begin{array}{l}\text { Biomarkers and short-term } \\
\text { prognosis in COVID-19. } \\
\text { (Peiró et al., 2021) }\end{array}$ & 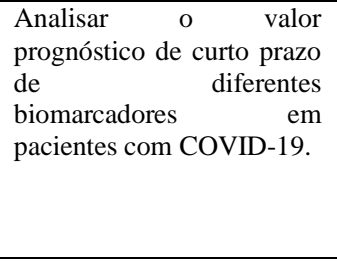 & $\begin{array}{l}\text { Estudo } \\
\text { observacional } \\
\text { retrospectivo } \\
\text { unicêntrico. }\end{array}$ & $\begin{array}{l}\text { Um total de } 196 \text { pacientes foram incluidos } \\
\text { com sintomas e testes laboratoriais } \\
\text { confirmados por COVID-19. Na admissão, } \\
\text { os pacientes foram avaliados quanto ao seu } \\
\text { estado clínico e fatores de risco. }\end{array}$ & $\begin{array}{l}\text { Níveis de dímero-D elevado na admissão } \\
\text { foram associados a risco aumentado de } \\
\text { morte por todas as causas. Pacientes com } \\
\text { maiores concentrações de dímero-D e } \\
\text { especialmente aqueles com maiores } \\
\text { concentrações de cTnI foram também } \\
\text { associados a idade avançada e fatores de } \\
\text { risco cardiovascular. }\end{array}$ & $\begin{array}{l}\text { O estudo demonstrou que cTnI, } \\
\text { dímero D, CRP e LDH pode ser } \\
\text { usado para estratificação de risco } \\
\text { de mortalidade de curto prazo em } \\
\text { pacientes admitidos com COVID- } \\
19 .\end{array}$ \\
\hline 104 & $\begin{array}{l}\text { Prognostic Value of Antithrombin } \\
\text { Levels in COVID-19 Patients and } \\
\text { Impact of Fresh Frozen Plasma } \\
\text { Treatment: A Retrospective } \\
\text { Study. } \\
\text { (Anakli et al., 2021) }\end{array}$ & $\begin{array}{lr}\text { Avaliar os valores } \\
\text { prognósticos pelos } & \text { níveis } \\
\text { de atividade } & \text { de } \\
\text { antitrombina (AT) } & \text { e o } \\
\text { impacto do plasma } & \text { fresco } \\
\text { congelado (PFC). } & \end{array}$ & $\begin{array}{l}\text { Estudo } \\
\text { intervencional } \\
\text { retrospectivo } \\
\text { multicêntrico. }\end{array}$ & $\begin{array}{l}\text { Foram incluídos } 104 \text { pacientes com COVID- } \\
\text { 19. Os pacientes que tinham níveis de AT } \\
\text { maiores que } 75 \% \text { foram tratados com PFC. } \\
\text { Foram coletados dados demográficos, } \\
\text { clínicos, laboratoriais e de tratamento } \\
\text { anticoagulante dos pacientes na admissão } \\
\text { para a UTI. Além da atividade de AT, os } \\
\text { níveis de dímero-D foram registrados antes e } \\
\text { depois do tratamento com PFC. }\end{array}$ & $\begin{array}{l}\text { Níveis elevados de AT e de dímero-D } \\
\text { foram correlacionados com maior taxa de } \\
\text { mortalidade. O tratamento com PFC } \\
\text { promoveu redução significativa nos níveis } \\
\text { de Dímero-D em pacientes com COVID- } \\
19 .\end{array}$ & $\begin{array}{l}\text { A deficiência aguda de AT } \\
\text { contribuiu para } \\
\text { desenvolvimento de quadros } \\
\text { trombóticos. O tratamento com } \\
\text { PFC promoveu diminuição nos } \\
\text { níveis de dímero-D e uma } \\
\text { melhora no prognóstico desses } \\
\text { pacientes. }\end{array}$ \\
\hline 105 & $\begin{array}{l}\text { Evaluation of the relation between } \\
\text { cardiac biomarkers and thorax } \\
\text { computerized tomography } \\
\text { findings in COVID-19 patients. } \\
\text { (Ileri et al., 2021) }\end{array}$ & $\begin{array}{l}\text { Explorar relação entre os } \\
\text { níveis de troponina e a } \\
\text { gravidade do COVID- } 19 .\end{array}$ & $\begin{array}{l}\text { Estudo } \\
\text { intervencional } \\
\text { prospectivo } \\
\text { unicêntrico. }\end{array}$ & $\begin{array}{l}\text { Foram incluídos } 104 \text { pacientes com COVID- } \\
19 \text {, confirmado por teste de PCR quantitativo, } \\
\text { e com pneumonia, confirmado por TC do } \\
\text { tórax. }\end{array}$ & $\begin{array}{l}\text { Embora todos os pacientes apresentassem } \\
\text { resultados positivos na TC de tórax } \\
\text { compatível com pneumonia COVID-19, A } \\
\text { PCR foi positiva em apenas } 74 \text { pacientes. } \\
\text { Níveis elevados de troponina, LDH, } \\
\text { proteína C reativa (CRP) e dímero-D foram } \\
\text { detectados na maioria dos pacientes. } \\
\text { Pacientes com achados graves de TC } \\
\text { tinham níveis mais elevados de dímero-D. }\end{array}$ & $\begin{array}{l}\text { Pacientes com COVID-19 com } \\
\text { manifestações graves em TC, } \\
\text { progressão da doença e } \\
\text { necessidade de UTI têm maiores } \\
\text { níveis de troponina, ferritina, D- } \\
\text { dímero, LDH e CRP, sugerindo o } \\
\text { uso de níveis de troponina em } \\
\text { estratificação de risco de } \\
\text { pacientes com COVID-19. }\end{array}$ \\
\hline 106 & $\begin{array}{l}\text { Characteristics and outcomes in } \\
\text { hospitalized COVID- } 19 \text { patients } \\
\text { during the first } 28 \text { days of the } \\
\text { spring and autumn pandemic } \\
\text { waves in Milan: Na observational } \\
\text { prospective study. } \\
\text { (Radovanovic et al., 2021) }\end{array}$ & $\begin{array}{l}\text { Comparar as características } \\
\text { e os resultados de pacientes } \\
\text { com } \quad \text { COVID-19 } \\
\text { hospitalizados. }\end{array}$ & $\begin{array}{l}\text { Estudo } \\
\text { observacional } \\
\text { prospectivo } \\
\text { unicêntrico. }\end{array}$ & 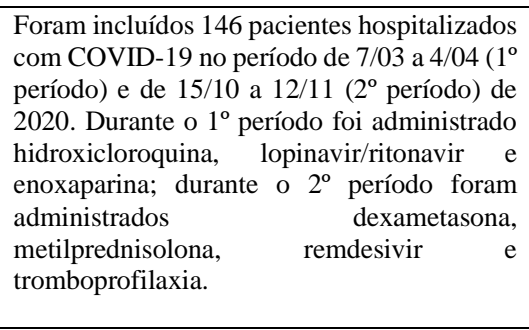 & $\begin{array}{l}\text { Dos } 146 \text { pacientes, } 70 \text { durante o } 1^{\circ} \text { período } \\
\text { e } 76 \text { durante o } 2^{\circ} \text { período, a prevalência de } \\
\text { insuficiência respiratória foi de } 30 \% \text { vs. } \\
12 \% \text { e de elevação do D-dímero, de } 34 \% \\
\text { vs. } 15 \% \text {, respectivamente. Desse modo, a } \\
\text { anticoagulação e os corticosteroides do } 2^{\circ} \\
\text { período reduziram esses parâmetros. } \\
\text { Mortalidade foi reduzida, enquanto a } \\
\text { necessidade de intubação não mudou. O } \\
\text { tempo de internação foi comparável, mas a }\end{array}$ & $\begin{array}{l}\text { Mudanças nos paradigmas de } \\
\text { tratamento, maior consciência } \\
\text { social da doença e uma melhor } \\
\text { preparação do sistema de saúde } \\
\text { pode ter reduzido a mortalidade } \\
\text { em pacientes hospitalizados com } \\
\text { COVID-19 durante as duas ondas } \\
\text { pandêmicas consecutivas. }\end{array}$ \\
\hline
\end{tabular}


Research, Society and Development, v. 11, n. 2, e21011225731, 2022

(CC BY 4.0) | ISSN 2525-3409 | DOI: http://dx.doi.org/10.33448/rsd-v11i2.25731

\begin{tabular}{|c|c|c|c|c|c|c|}
\hline & & & & & $\begin{array}{l}\text { proporção de pacientes com alta hospitalar } \\
\text { foi maior no } 2^{\circ} \text { período. }\end{array}$ & \\
\hline 107 & $\begin{array}{l}\text { Association of D-dimer elevation } \\
\text { with inflammation and organ } \\
\text { dysfunction in ICU patients with } \\
\text { COVID-19 in Wuhan, China: a } \\
\text { retrospective observational study. } \\
\text { (W. Zhang et al.,2021) }\end{array}$ & $\begin{array}{l}\text { Avaliar se o nível elevado } \\
\text { de dímero- } \mathrm{D} \text { estava } \\
\text { relacionado à falência de } \\
\text { múltiplos órgãos e a um } \\
\text { maior risco de morte. }\end{array}$ & $\begin{array}{c}\text { Estudo } \\
\text { observacional } \\
\text { retrospectivo } \\
\text { unicêntrico. }\end{array}$ & $\begin{array}{l}\text { Este estudo incluiu } 158 \text { pacientes com } \\
\text { COVID-19. Dados clínicos e laboratoriais } \\
\text { foram coletados. A relação entre a elevação } \\
\text { do dímero-D e disfunção orgânica foi } \\
\text { analisada. }\end{array}$ & $\begin{array}{l}\text { Aproximadamente } 63,9 \% \text { dos pacientes } \\
\text { com COVID-19 tinham aumento de } \\
\text { dímero-D na admissão à UTI. A taxa de } \\
\text { mortalidade de } 14 \text { dias na UTI foi maior em } \\
\text { pacientes com alto nível de dímero-D do } \\
\text { que naqueles com nível de dímero-D } \\
\text { normal. }\end{array}$ & $\begin{array}{l}\text { Nível de dímero-D está } \\
\text { intimamente relacionado à } \\
\text { gravidade do COVID-19 e pode } \\
\text { influenciar a probabilidade de } \\
\text { início rápido de lesão de órgão } \\
\text { após a admissão. }\end{array}$ \\
\hline
\end{tabular}


Research, Society and Development, v. 11, n. 2, e21011225731, 2022

(CC BY 4.0) | ISSN 2525-3409 | DOI: http://dx.doi.org/10.33448/rsd-v11i2.25731

\section{Discussão}

O presente estudo apresenta o compilado de informações sobre os níveis de dímero-D associado a COVID-19, visto que este marcador vem sendo utilizado para estratificar a gravidade da doença. Os resultados desta revisão indicam primeiramente que, na maioria dos estudos analisados, houve aumento da coagulação em portadores de Síndrome respiratória aguda grave (SARS), especialmente relacionada aos níveis de dímero-D.

Dos 107 artigos elegíveis, 43 apresentavam como objetivo principal a investigação da relação do aumento da coagulação, evidenciado pelo aumento de dímero-D, com a COVID-19. No entanto, 64 tiveram esta relação evidenciada como uma observação indireta realizada durante o estudo.

Quando analisado os desenhos de estudo, foram incluídos: sessenta e três artigos observacionais $(3,4,7,9,10,11,12,13,16,17,18,20,21,23,24,25,26,27,28,29,30,33,35,36,37,38,39,40,41,42,43,44,45,46,47,48,49,50,51,52,53,54,56,58,59,60,61,63,64,65,66,69,70,72,73,74,75,77,79,82,84,85,87,88$ ,92,93,94,96,100,102,103,106,107). Já em relação ao local de realização dos estudos, dezessete artigos (2,3,12,28,29,36,51,52,59,69,70,77,84,94,96,105,106) eram estudos prospectivos e unicêntricos, nove artigos $(1,6,18,24,25,26,61,75,79)$ prospectivos e multicêntricos, trinta e quatro $(4,10,13,20,21,22,23,27,32,34,35,39,42,43,46,47,55,56,58,60,63,71,72,73,78,82,87,88,91,92,93,100,103,107)$ retrospectivos e unicêntricos e quarenta artigos $(5,7,9,11,14,15,16,17,19,30,31,33,37,38,40,44,45,48,50,53,54,57,62,64,65,66,67,74,76,83,85,86,90,95,97,98,99,101,102,104)$ retrospectivos e multicêntricos.

Em saúde, as pesquisas envolvem diversos tipos de estudos e cada desenho destes possui suas vantagens e desvantagens, cujos métodos são mais propícios a determinada finalidade. Analisando-se o impacto científico dos estudos, sabe-se que o ensaio clínico randomizado é o padrão ouro da pesquisa médica baseada em evidências, seguido pelos ensaios clínicos nãorandomizados, estudos observacionais, estudos de caso-controle e estudos transversais, apresentando menor impacto científico nos formatos de relato de casos, carta ao editor e opinião de experimento (Nedel \& Silveira, 2016; Gil, 2017). Vale ressaltar que os estudos multicêntricos também apresentam maior impacto, uma vez que visam organizar as propostas de artigos, garantindo amplo acesso aos dados, qualidade e precedência (Carvalho et al., 2013).

Desse modo, é observado que a presente revisão integrativa é baseada em estudos de alta relevância científica, uma vez que a maioria dos artigos são observacionais multicêntricos, além de terem sido excluídos os estudos de baixo impacto, como os relatos de casos e carta ao editor.

Diante da importância de uma doença pandêmica, alguns estudos investigaram as características clínicas de pacientes com COVID-19 (4,14,15,18,19,20,24,25,26,30,35,41,47,48,53,58,60,67,70,73,74,86,87,92,98,102). As manifestações clínicas da doença são variáveis, contudo, a idade avançada e a presença de comorbidades foram relatadas como um fator de risco favorável de mortalidade.

Estes resultados corroboram com outros 2 estudos de revisão, nos quais a idade avançada e a presença de comorbidades, especialmente hipertensão arterial sistêmica, diabetes mellitus, coronariopatia, DPOC, doenças malignas (câncer) e obesidade, também foram associados com o mau prognóstico e óbito. Esses dados já são bem estabelecidos e novos artigos vêm enfatizando outras alterações encontradas nos pacientes COVID-19, em especial as relacionadas ao aumento de marcadores inflamatórios e trombóticos. Como exemplo tem-se o aumento da proteína C reativa e diminuição de linfócitos, além do que se deseja enfocar no presente estudo que é o aumento do dímero-D (Bastos et al., 2020; Tian et al., 2020).

Ainda sobre a análise da evolução da doença, quarenta e seis artigos verificaram a associação do aumento de dímero-D com maior gravidade da COVID-19 e/ou mortalidade pela doença (06,09,10,17,19-21,26,29,31,33-37,39,41-45,47-50,53-56,5961,67,68,75,76,78,80,82,90,92,94,98,104,105 e 107), tendo todos eles demonstrado esta relação. Apenas dois artigos indicaram não haver essa relação ${ }^{(96 \text { e 102). }}$ 
Research, Society and Development, v. 11, n. 2, e21011225731, 2022

(CC BY 4.0) | ISSN 2525-3409 | DOI: http://dx.doi.org/10.33448/rsd-v11i2.25731

Outros reforços para tal associação vieram da avaliação dos níveis de dímero-D em portadores de Tromboembolismo venoso (TEV) e suas vertentes, Trombose Venosa profunda (TVP) e Embolia Pulmonar (EP), que quando causada por trombos é denominada tromboembolia pulmonar - TEP), associados ao quadro da COVID-19, demonstrando que essa doença viral promove aumento dos quadros de hipercoagubilidade. Seis artigos ${ }^{(08,11,27,36,38 \text { e } 46)}$ evidenciaram o aumento do risco de TEV em

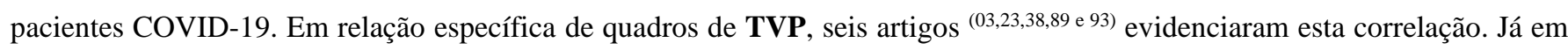
relação à EP ou TEP, também seis artigos (23,83,89,93,94 e 95) reportaram aumento dessas condições em pacientes COVID-19, evidenciado pelo aumento do dímero-D, além de outros biomarcadores de coagulação.

Tanto a TVP, quanto a EP e o TEV são eventos trombóticos e diversos artigos vêm evidenciando alterações no processo de hemostasia dos pacientes com COVID-19, como trombocitopenia leve e níveis aumentados de dímero-D, e correlacionando estes eventos com maior predisposição de eventos trombóticos e, consequentemente, maior taxa de mortalidade (Lippi et al., 2020; Lippi et al., 2017). Ainda no que se refere à ocorrência de EP, muitas vezes associada com quadros de pneumonia grave por COVID-19, é sugerido que o evento trombótico ocorra devido hipercoagulação sistêmica associada à inflamação em COVID19 grave. Esses dados são evidenciados por estudos que demonstraram anormalidades nos níveis de dímero-D após a admissão hospitalar em pacientes com EP (H. Xu et al., 2020; Wichmann et al., 2020).

Tang e colaboradores também relataram sobre a ocorrência frequente de coagulação intravascular disseminada (CID) em pacientes com COVID-19 com insuficiência respiratória grave, evidenciada pelo aumento de dímero-D. A CID pode ser definida como uma síndrome adquirida, caracterizada pela ativação difusa da coagulação intravascular, levando à formação e deposição de fibrina na microvasculatura (Orsini et al., 2020). Pacientes com COVID-19 com alto nível de dímero-D são conhecidos por apresentarem mau prognóstico e isso refletir na ligação direta com os eventos trombóticos e, consequentemente, com maior taxa de mortalidade (Connors et al., 2020).

Por esse motivo, testes que compõem o perfil de coagulação estão sendo investigados em pacientes com a COVID-19 na busca de identificar marcadores de prognóstico da doença (Xavier et al., 2020; Y. Liu et al., 2020b).

No entanto, o mecanismo pelo qual pacientes críticos com COVID-19 desenvolvem quadros de hipercoagulabilidade maior frequência do que a população geral ainda permanece incerto, assim como se esse aumento da coagulação é induzido pelo grau de viremia e pelo próprio vírus, ou se isso é simplesmente uma resposta à inflamação sistêmica profunda no paciente crítico, que são conhecidos fatores de risco para o aumento de coagulação, como no caso de TEV (Chen et al, 2020; Zhang et al, 2020). Essa associação entre o dímero-d elevado e o desenvolvimento de quadros trombóticos é então provavelmente representativa tanto do grau de inflamação sistêmica em pacientes criticamente doentes com COVID-19, quanto da ativação inadequada da cascata de coagulação; no entanto, o grau em que cada um desses componentes contribui para o desenvolvimento de TEV ainda não está claro.

Na presente revisão foram também incluídos oito ${ }^{(4,20,41,43,60,77,81 \text { e } 97)}$ que avaliaram a relação da Diabetes Mellitus com o aumento do dímero-D. Tal associação é baseada nas características inflamatórias do DM que, quando somadas as da própria COVID-19, desencadeiam um grande desequilíbrio entre o processo de coagulação e a fibrinólise, evidenciada pelo prolongamento do tempo de protrombina, inibição relativa do sistema fibrinolítico e aumento dos níveis de dímero-D. Esta relação da inflamação do DM com o aumento do dímero-D pode ser explicada pela resistência à insulina, característica do diabetes tipo 2 (DM2), estar associada à disfunção endotelial e aumento da agregação e ativação plaquetária, anormalidades que favorecem o desenvolvimento de um estado pró-trombótico hiper coagulável. Além disso, este ambiente inflamatório propiciado pela diabetes torna os pacientes mais propensos a infecções (Araujo, 2020; Dunn \& Grant, 2005), o que também pode ser um fator de maior risco de contágio e de agravamento do quadro de COVID-19. 
Research, Society and Development, v. 11, n. 2, e21011225731, 2022

(CC BY 4.0) | ISSN 2525-3409 | DOI: http://dx.doi.org/10.33448/rsd-v11i2.25731

Em quadros de COVID-19 com mau prognóstico pela piora do quadro respiratório, a Oxigenação por Membrana Extracorpórea (ECMO) mostra-se como opção de terapia de suporte, a fim de prevenir a falência pulmonar, como tentativa de redução na mortalidade de pacientes graves com COVID-19 (Pereira et al., 2020). Quando avaliada a relação do aumento de dímero-D com mau prognóstico evidenciado pela necessidade de uso de Oxigenação por Membrana Extracorpórea (ECMO), foram incluídos quatro artigos ${ }^{(19,63,71,98)}$, todos tendo mencionado esta associação. Além disso, a ECMO em si se mostra como um estímulo para o aumento da coagulação e da fibrinólise secundária durante o este suporte, o que resulta em aumentos ainda maiores de dímero-D (Z Guo et al., 2020).

Por fim, no que se refere a estudos de tratamentos medicamentosos que melhorem o quadro de COVID-19 evidenciado pela diminuição do dímero-D, seis artigos avaliaram a ação do tocilizumabe como tratamento para a COVID-19 (1,28,67,68,69 e 82) Com exceção de um artigo que mostrou que tocilizumabe aumentou o dímero-D ${ }^{(69)}$, dois não apresentam resultados dessa avaliação ${ }^{(67,68)}$ e os outros três ${ }^{\left(1,28 \text { e }{ }^{82}\right)}$ relataram diminuição significativa nesse parâmetro, assim como alguns também da proteína $C$ reativa. Esses resultados refletem em melhora do estado clínico do paciente, tendo sido associado com o aumento da probabilidade de sobrevivência dos pacientes hospitalizados (Sciascia et al., 2020). Vale ressaltar que apenas mais dois artigos

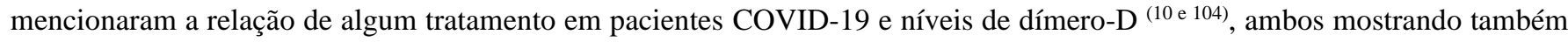
melhora nesse parâmetro. Os demais artigos publicados a respeito de outros possíveis tratamentos não mencionaram alteração do dímero-D, nem mesmo alguma relação entre as variáveis, não tendo sido assim incluídos no presente estudo.

\section{Considerações Finais}

O presente estudo apresenta o compilado de informações sobre a associação do aumento de níveis de dímero-D com a COVID-19, sugerindo aumento da coagulação nesses pacientes. Embora a maioria dos estudos não tenham objetivado tal associação, ela foi evidenciada em quase sua totalidade.

A revisão inclui artigos com desenhos de estudo com alto impacto científico, evidenciando a associação do aumento de dímero-D com maior gravidade da COVID-19 e/ou mortalidade, observada pelo aumento da ocorrência de CID, incluindo estudos em pacientes que evoluíram para quadros trombóticos, como TVP, TEV e EP. Além disso, foi relatada também associação de aumento do dímero-D com outras condições que aumentam a coagulação, como no caso de pacientes diabéticos e em pacientes em uso de ECMO.

Desse modo, embora a relação do aumento da coagulação em pacientes COVID-19, em especial nos que evoluíram para quadros graves, tenha sido evidente nos arquivos aqui reunidos, são necessários ainda mais estudos para se estipular valores de corte deste parâmetro laboratorial como prognóstico desses pacientes.

\section{Referências}

Arcari, L., Luciani, M., Cacciotti, L., Musumeci, M. B., Spuntarelli, V., Pistella, E., \& De Biase, L. (2020). Incidence and determinants of high-sensitivity troponin and natriuretic peptides elevation at admission in hospitalized COVID-19 pneumonia patients. Internal and Emergency Medicine. 15(8), 1467-76. https://doi.org/10.1007/s11739-020-02498-7

Adam, S. S., Key, N. S., \& Greenberg, C. S. (2009). D-dimer antigen: current concepts and future prospects. Blood, The Journal of the American Society of Hematology.113 (13), 2878-87. https://doi.org/10.1182/blood-2008-06-165845

Al-Samkari, H., Karp Leaf, R. S., Dzik, W. H., Carlson, J. C., Fogerty, A. E., Waheed, A., \& Rosovsky, R. P. (2020). COVID-19 and coagulation: bleeding and thrombotic manifestations of SARS-CoV-2 infection. Blood. 136 (4), 489-500. https://doi.org/10.1182/blood.2020006520

Alvim, A. L. S., Volpato, A. T., de Sá Gomes, E. M., Cunha, E. T., Vilaça, H. M., Mayrink, L. B., \& Mendes, R. L. C. (2020). Síndrome inflamatória multissistêmica em crianças e adolescentes com COVID-19: uma revisão de literatura. Journal of Infection Control. 9 (3), 162-165. Retrieved from: http://jicabih.com.br/index.php/jic/article/view/330 
Research, Society and Development, v. 11, n. 2, e21011225731, 2022

(CC BY 4.0) | ISSN 2525-3409 | DOI: http://dx.doi.org/10.33448/rsd-v11i2.25731

Akter, F., Mannan, A., Mehedi, H. H., Rob, M. A., Ahmed, S., Salauddin, A., \& Hasan, M. M. (2020). Clinical characteristics and short term outcomes after recovery from COVID-19 in patients with and without diabetes in Bangladesh. Diabetes \& Metabolic Syndrome: Clinical Research \& Reviews, v. 14, (6), 20312038. https://doi.org/10.1016/j.dsx.2020.10.016

Anaklı, İ., Özcan, P. E., Polat, Ö., Orhun, G., Alay, G. H., Tuna, V., \& Esen, F. (2021) et al. Prognostic Value of Antithrombin Levels in COVID-19 Patients and Impact of Fresh Frozen Plasma Treatment: A Retrospective Study. Turkish Journal of Hematology. 38 (1), 15. https://doi.org/10.4274/tjh.galenos.2021.2020.0695

Anghebem, M. I., Rego, F. G. D. M., \& Picheth, G. (2020). COVID-19 e Diabetes: a relação entre duas pandemias distintas. Rev bras anal clin, 52 (2), 154-9. https://doi.org/10.21877/2448-3877.20200001

Artifoni, M., Danic, G., Gautier, G., Gicquel, P., Boutoille, D., Raffi, F., \& Lecomte, R. (2020). Systematic assessment of venous thromboembolism in COVID19 patients receiving thromboprophylaxis: incidence and role of D-dimer as predictive factors. Journal of thrombosis and thrombolysis. 50, 211-216. https://doi.org/10.1007/s11239-020-02146-z

Auld, S. C., Caridi-Scheible, M., Blum, J. M., Robichaux, C., Kraft, C., Jacob, J. T., \& Murphy, D. (2020). ICU and ventilator mortality among critically ill adults with COVID-19. MedRxiv. 26. https://doi.org/10.1101/2020.04.23.20076737

Avdeev, S. N., Yaroshetskiy, A. I., \& Nuralieva, G. S. (2021). Can We Reliably Predict the Failure of Non-invasive Ventilation in COVID-19-associated Acute Hypoxemic Respiratory Failure? https://doi.org/10.1513/AnnalsATS.202101-047LE

Avruscio, G., Camporese, G., Campello, E., Bernardi, E., Persona, P., Passarella, C., \& Simioni, P. COVID-19 and venous thromboembolism in intensive care or medical ward. Clinical and Translational Science. 13 (6), 1108-1114. https://doi.org/10.1111/cts.12907

Bemtgen, X., Zotzmann, V., Benk, C., Rilinger, J., Steiner, K., Asmussen, A., \& Staudacher, D. L. (2021). Thrombotic circuit complications during venovenous extracorporeal membrane oxygenation in COVID-19. Journal of Thrombosis and Thrombolysis. 51 (2), 301-307. https://doi.org/10.1007/s11239-020-02217-1

Bhatti, R., Khamis, A. H., Khatib, S., Shiraz, S., \& Matfin, G. (2020). Clinical Characteristics and Outcomes of Patients with Diabetes Admitted for COVID-19 Treatment in Dubai: Single-Centre Cross-Sectional Study. JMIR public health and surveillance. 6 (4), 22-471. https://doi.org/10.2196/22471

Brito, D. A. (2020). Necessidade de terapia anticoagulante como forma de prevenção de eventos tromboembólicos em pacientes com Covid-19. REVISTA SANARME. 03, 94. Retrieved from: https://www.researchgate.net/profile/Andre-Fukushima/publication/344524024

Bocci, M. G., Maviglia, R., Consalvo, L. M., Grieco, D. L., Montini, L., Mercurio, G., \& Franceschi, F. (2020). Thromboelastography clot strength profiles and effect of systemic anticoagulation in COVID-19 acute respiratory distress syndrome: a prospective, observational study. Eur Rev Med Pharmacol Sci. 24 (23), 12466-12479. Retrieved from: https://www.europeanreview.org/wp/wp-content/uploads/12466-12479.pdf.

Bossini, N., Alberici, F., Delbarba, E., Valerio, F., Manenti, C., Possenti, S., \& Brescia. (2020). Kidney transplant patients with SARS-CoV-2 infection: the Brescia renal COVID Task force experience. American Journal of Transplantation. 20 (11), 3019-3029. https://doi.org/10.1111/ajt.16176

Carneiro, T., Dashkoff, J., Leung, L. Y., Nobleza, C. O. H. S., Marulanda-Londono, E., Hathidara, M., \& Cervantes-Arslanian, A. M. (2020). Intravenous tPA for Acute Ischemic Stroke in Patients with COVID-19. Journal of Stroke and Cerebrovascular Diseases. 29 (11), 105201. https://doi.org/10.1016/j.jstrokecerebrovasdis.2020.10520

Carvalho, M. S., Barreto, M. L., Coeli, C. M., Raposo, R. M., Mota, E. L. A., \& Duncan, B. B. (2013). Comitê de publicações em estudo multicêntrico e sistema informatizado de apoio-publiELSA. Revista de Saúde Pública. 47, 48-53. https://doi.org/10.1590/s0034-8910.2013047003810

Cen, Y., Chen, X., Shen, Y., Zhang, X. H., Lei, Y., Xu, C., \& Liu, Y. H. (2020). Risk factors for disease progression in patients with mild to moderate coronavirus disease 2019da multi-centre observational study. Clin Microbiol Infect. https://doi.org/10.1016/j.cmi.2020.05.041

Cezar-Junior, A. B., Faquini, I. V., Silva, J. L. J., de Carvalho Junior, E. V., Lemos, L. E. A. S., Freire Filho, J. B. M., \& Azevedo-Filho, H. R. C. (2020). Subarachnoid hemorrhage and COVID-19: Association or coincidence? Medicine, v. 99, n. 51. https://doi.org/10.1097/MD.0000000000023862

Chen, N., Li, Y., Fan, H., Tian, A., Yuan, H., Jiang, Z., \& Zhu, C. (2020). Analysis of dynamic disturbance in blood coagulation function of patients with Coronavirus Disease 2019: A retrospective observational study. Medicine. 99, 43. https://doi.org/10.1097/MD.0000000000022635

Chen, Z., Zhang, F., Hu, W., Chen, Q., Li, C., Wu, L., \& Yue, J. (2021). Laboratory markers associated with COVID-19 progression in patients with or without comorbidity: a retrospective study. Journal of clinical laboratory analysis. 35 (1), 23644. https://doi.org/10.1002/jcla.23644

Cheng, S., Wu, D., Li, J., Zou, Y., Wan, Y., Shen, L., \& Zhu, R (2020). Risk factors for the critical illness in SARS-CoV-2 infection: a multicenter retrospective cohort study. Respiratory research. 21 (1), 1-12, 2020. https://doi.org/10.1186/s12931-020-01492-Z

Choi, J. J., Wehmeyer, G. T., Li, H. A., Alshak, M. N., Nahid, M., Rajan, M., \& DeSancho, M. T. (2020). D-dimer cut-off points and risk of venous thromboembolism in adult hospitalized patients with COVID-19. Thrombosis research. 196, 318-321. https://doi.org/10.1016.j.thromres.2020.09.022

Choudry, F. A., Hamshere, S. M., Rathod, K. S., Akhtar, M. M., Archbold, R. A., Guttmann, O. P., \& Jones, D. A. (2020). High thrombus burden in patients with COVID-19 presenting with ST-segment elevation myocardial infarction. Journal of the American College of Cardiology. 6 (10), 1168-1176. https://doi.org/10.1016/j.jacc.2020.07.022

Corominas, H., Castellví, I., Pomar, V., Antonijoan, R., Mur, I., Matas, L., \& Domingo, P. (2021). Effectiveness and safety of intravenous tocilizumab to treat COVID-19-associated hyperinflammatory syndrome: covizumab-6 observational cohort. Clinical Immunology. $223,108631$. https://doi.org/10.1016/j.clim.2020.108631 
Research, Society and Development, v. 11, n. 2, e21011225731, 2022

(CC BY 4.0) | ISSN 2525-3409 | DOI: http://dx.doi.org/10.33448/rsd-v11i2.25731

Cummings, M. J., Baldwin, M. R., Abrams, D., Jacobson, S. D., Meyer, B. J., Balough, E. M., \& O'Donnell, M. R. (2020) Epidemiology, clinical course, and outcomes of critically ill adults with COVID-19 in New York City: a prospective cohort study. The Lancet. https://doi.org/10.1016/S0140-6736(20)31189-2

Davies, P., Evans, C., Kanthimathinathan, H. K., Lillie, J., Brierley, J., Waters, G., \& Ramnarayan, P. (2020). Intensive care admissions of children with paediatric inflammatory multisystem syndrome temporally associated with SARS-CoV-2 (PIMS-TS) in the UK: a multicentre observational study. The Lancet Child \& Adolescent Health. 4 (9), 669-677. https://doi.org/10.1016/S2352-4642(20)30215-7

Demelo-Rodríguez, P., Cervilla-Muñoz, E., Ordieres-Ortega, L., Parra-Virto, A., Toledano-Macías, M., Toledo-Samaniego, N., \& Galeano-Valle, F. (2020). Incidence of asymptomatic deep vein thrombosis in patients with COVID-19 pneumonia and elevated D-dimer levels. Thrombosis Research. https://doi.org/10.1016/j.thromres.2020.05.018

Deeh, P. B. D., Kayri, V., Orhan, C., \& Sahin, K. (2020). Status of Novel Coronavirus Disease 2019 (COVID-19) and Animal Production. Frontiers in Veterinary Science. 7. https://doi.org/10.3389\%2Ffvets.2020.586919

Duan, J., Wang, X., Chi, J., Chen, H., Bai, L., Hu, Q., \& Guo, S. (2020). Correlation between the variables collected at admission and progression to severe cases during hospitalization among patients with COVID-19 in Chongqing. Journal of medical virology. 92 (11), 2616-2622. doi: https://doi.org/10.1002/jmv.26082

Dunn, E. J., \& Grant, P. J. (2005). Type 2 diabetes: an atherothrombotic syndrome. Current Molecular Medicine. 5 (3), $323-332$. https://doi.org/10.2174/1566524053766059

Edul, V. S. K., Eguillor, J. F. C., Ferrara, G., Estenssoro, E., Siles, D. S. P., Cesio, C. E. \& Dubin, A. (2021). Microcirculation alterations in severe COVID-19 pneumonia. Journal of Critical Care. 61, 73-75. https://doi.org/10.1016/j.jcrc.2020.10.002

Fang, J., Li, R., Chen, Y., Qin, J. J., Hu, M., Huang, C. L., \& Wei, X. (2021). Extracorporeal Membrane Oxygenation Therapy for Critically Ill Coronavirus Disease 2019 Patients in Wuhan, China: A Retrospective Multicenter Cohort Study. Current Medical Science.41 (1), 1-13. https://doi.org/10.21203/rs.3.rs$53559 / \mathrm{v} 1$

Fang, S., Wang, H., Lu, L., Jia, Y., ... \& Xia, Z. (2020). Decreased complement C3 levels are associated with poor prognosis in patients with COVID-19: A retrospective cohort study. International immunopharmacology, v. 89, p. 107070. https://doi.org/10.1016/j.intimp.2020.107070

Garcia-Olivé, I., Sintes, H., Radua, J., Capa, J. A., \& Rosell, A. (2020). D-dimer in patients infected with COVID-19 and suspected pulmonary embolism. Respiratory medicine. 169,106023. https://doi.org/10.1016/j.rmed.2020.106023

García-Ortega, A., Oscullo, G., Calvillo, P., López-Reyes, R., Méndez, R., Gómez-Olivas, J. D., \& Martínez-García, M. Á. (2021). Incidence, risk factors, and thrombotic load of pulmonary embolism in patients hospitalized for COVID-19 infection. Journal of Infection. 82 (2), 261-269. https://doi.org/10.1016/j.jinf.2021.01.003

Grasselli, G., Tonetti, T., Protti, A., Langer, T., Girardis, M., Bellani, G., \& Seccafico, C. (2020). Pathophysiology of COVID-19-associated acute respiratory distress syndrome: a multicentre prospective observational study. The lancet Respiratory medicine. 8 (12), 1201-1208. https://doi.org/10.1016/S2213$2600(20) 30370-2$

Gil-Rodrigo, A., Miró, Ò., Piñera, P., Burillo-Putze, G., Jiménez, S., Martín, A., \& Llorens, P. (2020). Evaluación de las características clínicas y evolución de pacientes con COVID-19 a partir de una serie de 1000 pacientes atendidos en servicios de urgencias españoles. Emergencias. 233-241. https://doi.org/mdl32692000 ?src=similardocs\#

Gómez-Belda, AB, Fernández-Garcés, M., Mateo-Sanchis, E., Madrazo, M., Carmona, M., Piles-Roger, L., \& Artero, A. (2021). COVID-19 in older adults: What are the differences with younger patients? Geriatrics \& gerontology international. 21 (1), 60-65. https://doi.org/10.1111/ggi.14102

Gonçalves, J. M. F., Pérez, J. M. H., Sorensen, M. A., Pérez, A. L. W., de la Rosa, E. M. R., Castilla, J. L. T., \& Ramallo-Fariña, Y. (2020). Biomarkers of acute respiratory distress syndrome in adults hospitalised for severe SARS-CoV-2 infection in Tenerife Island, Spain. BMC Research Notes. 13 (1), 1-7. https://doi.org/10.1186/s13104-020-05402-w

Guo, T., Shen, Q., Guo, W., He, W., Li, J., Zhang, Y. \& Peng, H. (2020). Clinical Characteristics of Elderly Patients with COVID-19 in Hunan Province, China: A Multicenter, Retrospective Study. Gerontology. 1-9. https://doi.org/10.1159/000508734

Guo, Z., Sun, L., Li, B., Tian, R., Zhang, X., Zhang, Z. \& Li, X. (2021). Anticoagulation management in severe coronavirus disease 2019 patients on extracorporeal membrane oxygenation. Journal of Cardiothoracic and Vascular Anesthesia. 35 (2), 389-397. https://doi.org/10.1053/j.jvca.2020.08.067

Helms, J., Tacquard, C., Severac, F., Leonard-Lorant, I., Ohana, M., Delabranche, X. \& Meziani, F. (2020). High risk of thrombosis in patients with severe SARS-CoV-2 infection: a multicenter prospective cohort study. Intensive care medicine. 1-10. https://doi.org/10.1007/s00134-020-06062-x

Huang, S., Wang, J., Liu, F., Liu, J., Cao, G., Yang, C., \& Xiong, B. (2020). COVID-19 patients with hypertension have more severe disease: a multicenter retrospective observational study. Hypertension Research. 1-8. https://doi.org/10.1038/s41440-020-0485-2

Huang, D., Yang, H., Yu, H., Wang, T., Yao, R. \& Liang, Z. (2020). A novel risk score to predict cardiovascular complications in patients with coronavirus disease 2019 (COVID-19): A retrospective, multicenter, observational study. Immunity, inflammation and disease. 8 (4), 638-649. https://doi.org/10.1002/iid3.353

Iba, T., Levy, J. H., Connors, J. M., Warkentin, T. E., Thachil, J., \& Levi, M. (2020). The unique characteristics of COVID-19 coagulopathy. Critical Care. 24 (1), 1-8. https://doi.org/10.1186/s13054-020-03077-0 
Research, Society and Development, v. 11, n. 2, e21011225731, 2022

(CC BY 4.0) | ISSN 2525-3409 | DOI: http://dx.doi.org/10.33448/rsd-v11i2.25731

Ileri, C., Dogan, Z., Ozben, B., Karaoglu, C., Gunay, N., Tigen, K., \& Uyan, C. (2021). Evaluation of the relation between cardiac biomarkers and thorax computed tomography findings in COVID-19 patients. Biomarkers in Medicine, v. 15, n. 4, p. 285-293. https://doi.org/10.2217/bmm-2020-0388

Ji, L., Cao, C., Gao, Y., Zhang, W., Xie, Y., Duan, Y., \& Xie, M. (2020). Prognostic value of bedside lung ultrasound score in patients with COVID-19. Critical Care. 24 (1), 1-12. https://doi.org/10.1186/s13054-020-03416-1

Ji, X. Y., Ma, Y., Shi, N. N., Liang, N., Chen, R. B., Liu, S. H., \& Wang, Y. Y. (2021). Clinical characteristics and treatment outcome of COVID-19 patients with stroke in China: A multicenter retrospective study. Phytomedicine. 81, 153-433. https://doi.org/10.1016/j.phymed.2020.153433

Jirak, P., Larbig, R., Shomanova, Z., Fröb, E. J., Dankl, D., Torgersen, C., \& Motloch, L. J. (2021). Myocardial injury in severe COVID-19 is similar to pneumonias of other origin: results from a multicentre study. ESC heart failure. 8 (1), 37-46. https://doi.org/10.1002/ehf2.13136

Kho, J., Ioannou, A., Van den Abbeele, K., Mandal, A. K., \& Missouris, C. G. (2020). Pulmonary embolism in COVID-19: clinical characteristics and cardiac implications. The American journal of emergency medicine. 38 (10), 2142-2146. https://doi.org/10.1016/j.ajem.2020.07.054

Kocas, B. B., Cetinkal, G., Ser, O. S., Kilci, H., Keskin, K., Ozcan, S. N., \& Kilickesmez, K. (2021). The relation between left ventricular global longitudinal strain and troponin levels in patients hospitalized with COVID-19 pneumonia. The International Journal of Cardiovascular Imaging, 37(1), 125-133. https://doi.org/10.1007/s10554-020-02102-1

Köche, J. C. (2011). Fundamentos de metodologia científica. Editora Vozes. Retrieved from: https://www.academia.edu/download/38106165/192008010Fundamentos-de-Metodologia-Cien-Jose-Carlos-Koche-pdf_1.pdf.

Korkmaz, M. F., Türe, E., Dorum, B. A. \& K1lıç, Z. B. (2020). The epidemiological and clinical characteristics of 81 children with COVID-19 in a pandemic hospital in Turkey: an observational cohort study. Journal of Korean medical science. 35, p. 25. https://doi.org/10.3346/jkms.2020.35.e236

Ladikou, E. E., Sivaloganathan, H., Milne, K. M., Arter, W. E., Ramasamy, R., Saad, R., \& Chevassut, T. (2020). Von Willebrand factor (vWF): marker of endothelial damage and thrombotic risk in COVID-19?. Clinical Medicine. 20 (5), 178. https://dx.doi.org/10.7861\%2Fclinmed.2020-0346

Larsen, K., Coolen-Allou, N., Masse, L., Angelino, A., Allyn, J., Bruneau, L., \& Allou, N. (2020). Detection of pulmonary embolism in returning travelers with hypoxemic pneumonia due to COVID-19 in Reunion Island. The American Journal of Tropical Medicine and Hygiene. 103 (2), 844-846. https://dx.doi.org/10.4269\%2Fajtmh.20-0597

Li, H. Y., Wang, J. W., Xu, L. W., Zhao, X. L., Feng, J. X., \& Xu, Y. Z. (2020). Clinical analysis of 132 cases COVID-19 from Wuhan. Medicine. 99 (44). https://doi.org/10.1097/MD.0000000000022847

Li, Y., Li, H., Zhu, S., Xie, Y., Wang, B., He, L., \& Xie, M. (2020). Prognostic value of right ventricular longitudinal strain in patients with COVID19. Cardiovascular Imaging.13 (11), 2287-2299. https://doi.org/10.1016/j.jcmg.2020.04.014

Li, Y., Li, K., Xiong, W., Wang, X., Liu, C., Liu, C., Tan, W., Luo, B., Zhu, Y., Wu, Y., Yin, H., Li, X., \& Li, Z. (2020b). Clinical characteristics and viral shedding kinetics of 38 asymptomatic patients with coronavirus disease 2019: A retrospective observational study. Medicine. 99 (51), 23547. https://doi.org/10.1097/MD.0000000000023547

Li, Y., Li, M., Wang, M., Zhou, Y., Chang, J., Xian, Y., \& Hu, B. (2020). Acute cerebrovascular disease following COVID-19: a single center, retrospective, observational study. Stroke and vascular neurology. AVC e neurologia vascular. 5 (3). 10.1136/svn-2020-000431

Liu, Q., Song, N. C., Zheng, Z. K., Li, J. S., ... \& Li, S. K. (2020). Laboratory findings and a combined multifactorial approach to predict death in critically ill patients with COVID-19: a retrospective study. Epidemiology \& Infection, 148. https://doi.org/10.1017/S09502688200001442

Liu, S., Luo, H., Wang, Y., Cuevas, L. E., Wang, D., Ju, S. \& Yang, Y. (2020). Clinical characteristics and risk factors of patients with severe COVID-19 in Jiangsu province, China: a retrospective multicentre cohort study. BMC infectious diseases. 20 (1), 1-9. https://doi.org/10.1186/s12879-020-05314-x

Loffi, M., Regazzoni, V., Toselli, M., Cereda, A., Palmisano, A., Vignale, D., \& Danzi, G. B. (2021). Incidence and characterization of acute pulmonary embolism in patients with SARS-CoV-2 pneumonia: A multicenter Italian experience. PLoS One. 16(1), 245-565. https://doi.org/10.1371/journal.pone.0245565

Luo, H. C., You, C. Y., Lu, S. W. \& Fu, Y. Q. (2021). Characteristics of coagulation alteration in patients with COVID-19. Annals of hematology. 10 (1), 4552. https://doi.org/10.1007/s00277-020-04305-X

Lu, Y., Huang, Z., Wang, M., Tang, K., Wang, S., Gao, P., \& Zhao, J. (2021). Clinical characteristics and predictors of mortality in young adults with severe COVID-19: a retrospective observational study. Annals of Clinical Microbiology and Antimicrobials. 20 (1), 1-9. https://doi.org/10.1186/s12941-020-00412-9

Mahmoud-Elsayed, H. M., Moody, W. E., Bradlow, W. M., Khan-Kheil, A. M., Senior, J., Hudsmith, L. E. \& Steeds, R. P. (2020). Echocardiographic findings in patients with COVID-19 pneumonia. Canadian Journal of Cardiology. 36 (8), 1203-1207. https://doi.org/10.1016/j.cjca.2020.05.030

Maatman, T. K., Jalali, F., Feizpour, C. \& Douglas, A. (2020). Routine venous thromboembolism prophylaxis may be inadequate in the hypercoagulable state of severe coronavirus disease. Critical care medicine. https://dx.doi.org/10.1097\%2FCCM.0000000000004466

Mei, J., Hu, W., Chen, Q., Li, C., Chen, Z., Fan, Y., \& Wang, Q. L. (2020). Development and external validation of a COVID-19 mortality risk prediction algorithm: a multicentre retrospective cohort study. BMJ Open. 10 (12), e044028. 10.1136/bmjopen-2020-044028

Mishra, Y., Pathak, B. K., Mohakuda, S. S., Tilak, T. V. S. V. G. K., Sen, S., Harikrishnan, P., \& Singh, A. R. (2020). Relation of D-dimer levels of COVID-19 patients with diabetes mellitus. Diabetes \& Metabolic Syndrome: Clinical Research \& Reviews. 14 (6), 1927-1930. https://doi.org/10.1016/j.dsx.2020.09.035 
Research, Society and Development, v. 11, n. 2, e21011225731, 2022

(CC BY 4.0) | ISSN 2525-3409 | DOI: http://dx.doi.org/10.33448/rsd-v11i2.25731

Montrucchio, G., Sales, G., Rumbolo, F., Palmesino, F., Fanelli, V., Urbino, R., \& Brazzi, L. (2021). Effectiveness of mid-regional pro-adrenomedullin (MRproADM) as prognostic marker in COVID-19 critically ill patients: an observational prospective study. Plos one. 16 (2), e0246771. https://doi.org/10.1371/journal.pone.0246771

Nascimento, J. H. P., Gomes, B. F. D. O., Carmo, P. R. D., Petriz, J. L. F., Rizk, S. I., Costa, I. B. S. D. S., \& Oliveira, G. M. M. D. (2020). COVID-19 e estado de hipercoagulabilidade: uma nova perspectiva terapêutica. Arquivos Brasileiros de Cardiologia. 114 (5), 829-833. https://doi.org/10.36660/abc.20200308

Peiró, Ó. M., Carrasquer, A., Sánchez-Gimenez, R., Lal-Trehan, N., del-Moral-Ronda, V., Bonet, G., \& Bardaji, A. (2021). Biomarkers and short-term prognosis in COVID-19. Biomarkers. 1-28. https://doi.org/10.1080/1354750X.2021.1874052

Pereira, A. J. S. P., Pereira, I. S. P., Duarte, A. S., \& Roque, M. A. V. (2020). Avaliação do impacto da oxigenação por membrana extracorpórea (ECMO) na COVID-19: uma revisão sistemática. Brazilian Journal of Health Review. 3 (5), 14227-14237. https://doi.org/10.34119/bjhrv3n5-225

Pérez-Sáez, M. J., Blasco, M., Redondo-Pachón, D., Ventura-Aguiar, P., Bada-Bosch, T., Pérez-Flores, I., \& Spanish Society of Nephrology COVID-19 Group. (2020). Use of tocilizumab in kidney transplant recipients with COVID-19. American Journal of Transplantation. 20 (11), 3182-3190. https://doi.org/10.1111/ajt.16192

Planquette, B., Le Berre, A., Khider, L., Yannoutsos, A., Gendron, N., de Torcy, M., \& Emmerich, J. (2021). Prevalence and characteristics of pulmonary embolism in 1042 COVID-19 patients with respiratory symptoms: A nested case-control study. Thrombosis research. 197, 94-99. https://doi.org/10.1016/j.thromres.2020.11.001

Price, CC, Altice, FL, Shyr, Y., Koff, A., Pischel, L., Goshua, G., \& Malinis, M. (2020). Tocilizumab treatment for cytokine release syndrome in hospitalized patients with coronavirus disease 2019: survival and clinical outcomes. Chest. 158 (4), 1397-1408. https://doi.org/10.1016/j.chest.2020.06.006

Qiu, H., Wu, J., Hong, L., Luo, Y., Song, Q. \& Chen, D. (2020). Clinical and epidemiological features of 36 children with coronavirus disease 2019 (COVID19) in Zhejiang, China: an observational cohort study. The Lancet Infectious Diseases. https://doi.org/10.1016/S1473-3099(20)30198-5

Radovanovic, D., Pini, S., Franceschi, E., Pecis, M., Airoldi, A., Rizzi, M. \& Santus, P. (2021). Characteristics and outcomes in hospitalized COVID-19 patients during the first 28 days of the spring and autumn pandemic waves in Milan: An observational prospective study. Respiratory medicine. 178, 106323. https://doi.org/10.1016/j.rmed.2021.106323

Ramiro, S., Mostard, R. L., Magro-Checa, C., Van Dongen, C. M., Dormans, T., Buijs, J., \& Landewé, R. B. (2020). Historically controlled comparison of glucocorticoids with or without tocilizumab versus supportive care only in patients with COVID-19-associated cytokine storm syndrome: results of the CHIC study. Annals of the rheumatic diseases. 79 (9), 1143-1151. http://dx.doi.org/10.1136/annrheumdis-2020-218479

Ren, G. L., Wang, X. F., Xu, J., Li, J., Meng, Q., Xie, G. Q., \& Shi, Y. (2021). Comparison of acute pneumonia caused by SARS-COV-2 and other respiratory viruses in children: a retrospective multi-center cohort study during COVID-19 outbreak. Military Medical Research. 8 (1), 1-14. https://doi.org/10.1186/s40779-021-00306-7

Ren, L., Yao, D., Cui, Z., Chen, S., \& Yan, H. (2020). Corona Virus Disease 2019 patients with different disease severity or age range: A single-center study of clinical features and prognosis. Medicine, v. 99, n. 49. https://dx.doi.org/10.1097\%2FMD.0000000000022899

Roberts, M. B., Izzy, S., Tahir, Z., Al Jarrah, A., Fishman, J. A. \& El Khoury, J. (2020). COVID-19 in solid organ transplant recipients: Dynamics of disease progression and inflammatory markers in ICU and non-ICU admitted patients. Transplant Infectious Disease. 22 (5), e13407. https://doi.org/10.1111/tid.13407

Santana, A.C.C, Sousa, C.J.P \& Ribeiro, C.H.M.A. Alterações hematológicas em pacientes infectados com SARS-CoV-2: uma revisão integrativa. (2021). Research, Society and Development. 10 (12), 578101220932. http://dx.doi.org/10.33448/rsd-v10i12.20932

Santos, C.S., Morales, C.M., Álvarez, E.D., Castro, C. A., Robles, A.L. \& Sandoval, T.P. (2020).. Determinants of COVID-19 disease severity in patients with underlying rheumatic disease. Clinical rheumatology. 39 (9), 2789-2796. https://doi.org/10.1007/s10067-020-05301-2

Schiaffino, S., Giacomazzi, F., Esseridou, A., Cozzi, A., Carriero, S., Mazzaccaro, D. P., \& Sardanelli, F. (2021). Pulmonary thromboembolism in coronavirus disease 2019 patients undergoing thromboprophylaxis. Medicine. 100 (1). https://dx.doi.org/10.1097\%2FMD.0000000000024002

Sciascia, S., Aprà, F., Baffa, A., Baldovino, S., Boaro, D., Boero, R., \& Cinnirella, G. (2020). Pilot prospective open, single-arm multicentre study on off-label use of tocilizumab in severe patients with COVID-19. Clin Exp Rheumatol. 38 (3), 529-532. Retrieved from: https://www.researchgate.net/profile/SimoneBaldovino/publication/341100068 https://doi.org/32359035/

Sengupta, V., Sengupta, S., Lazo, A., Woods, P., Nolan, A. \& Bremer, N. (2020). Exosomes derived from bone marrow mesenchymal stem cells as treatment for severe COVID-19. Stem Cells and Development. 29 (12). https://doi.org/10.1089/scd.2020.0080

Sharma, S., Keswani, P., Bhargava, A., Sharma, R., Shekhawat, A., \& Bhandari, S. (2020). Overview of Early Cases of Coronavirus Disease 2019 (COVID-19) at a Tertiary Care Centre in North India. Annals of the Academy of Medicine, Singapore. 49, 449-55. Retrieved from: https://annals.edu.sg/pdf/49VolNo7Jul2020/V49N7p449.pdf.

Shi, J., Zhang, W., Sang, L., Qu, Z. \& Zhong, M. (2021). Coagulation dysfunction in ICU patients with coronavirus disease 2019 in Wuhan, China: a retrospective observational study of 75 fatal cases. Aging (Albany NY). 13 (2), 1591. https://dx.doi.org/10.18632\%2Faging.202223

Sisó-Almirall, A., Kostov, B., Mas-Heredia, M., Vilanova-Rotllan, S., Sequeira-Aymar, E., Sans-Corrales, M., \& Benavent-Àreu, J. (2020). Prognostic factors in Spanish COVID-19 patients: A case series from Barcelona. PloS one. 15 (8), e0237960. https://doi.org/10.1371/journal.pone.0237960

Smadja, D. M., Guerin, C. L., Chocron, R., Yatim, N., Boussier, J., Gendron, N., \& Diehl, J. L. (2020). Angiopoietin-2 as a marker of endothelial activation is a good predictor factor for intensive care unit admission of COVID-19 patients. Angiogenesis, 1-10. https://doi.org/10.1007/s10456-020-09730-0 
Research, Society and Development, v. 11, n. 2, e21011225731, 2022

(CC BY 4.0) | ISSN 2525-3409 | DOI: http://dx.doi.org/10.33448/rsd-v11i2.25731

Suardi, L. R., Pallotto, C., Esperti, S., Tazzioli, E., Baragli, F., Salomoni, E., \& Blanc, P. (2020). Risk factors for non-invasive/invasive ventilatory support in patients with COVID-19 pneumonia: A retrospective study within a multidisciplinary approach. International Journal of Infectious Diseases. 100, 258-263. https://doi.org/10.1016/j.ijid.2020.09.012

Suh, Y. J., Hong, H., Ohana, M., Bompard, F., Revel, M. P., Valle, C., \& Yoon, S. H. (2021). Pulmonary embolism and deep vein thrombosis in COVID-19: a systematic review and meta-analysis. Radiology. 298 (2), E70-E80. https://doi.org/10.1148/radiol.2020203557

Sun, T., Guo, L., Tian, F., Dai, T., Xing, X., Zhao, J., \& Li, Q. (2020). Remote rehabilitation for patients with COVID-19. Journal of rehabilitation medicine, 52 (9), 95. https://doi.org/10.1080/17476348.2020.1811687

Tao, Z., Xu, J., Chen, W., Yang, Z., Xu, X., Liu, L., \& Liu, J. (2021). Anemia is associated with severe illness in COVID-19: a retrospective cohort study. Journal of medical virology. 93(3), 1478-1488. https://doi.org/10.1002/jmv.26444

Tian, J., Yuan, X., Xiao, J., Zhong, Q., Yang, C., Liu, B., \& Wang, Z. (2020). Características clínicas e fatores de risco associados à gravidade da doença COVID19 em pacientes com câncer em Wuhan, China: um estudo de coorte multicêntrico, retrospectivo. The Lancet Oncology. 21 (7), 893-903. https://doi.org/10.1016/S1470-2045(20)30309-0

Torres, J. P., Izquierdo, G., Acuña, M., Pavez, D., Reyes, F., Fritis, A., \& Tapia, L. I. (2020). Multisystem inflammatory syndrome in children (MIS-C): Report of the clinical and epidemiological characteristics of cases in Santiago de Chile during the SARS-CoV-2 pandemic. International Journal of Infectious Diseases. 100, 75-81. https://doi.org/10.1016/j.ijid.2020.08.062

Viecca, M., Radovanovic, D., Forleo, G. B. \& Santus, P. (2020). Enhanced platelet inhibition treatment improves hypoxemia in patients with severe COVID-19 and hypercoagulability. A case control, proof of concept study. Pharmacological research. 158, 104950. https://doi.org/10.1016/j.phrs.2020.104950

Xie, J., Wu, W., Li, S., Hu, Y., Hu, M., Li, J., \& Du, B. (2020). Clinical characteristics and outcomes of critically ill patients with novel coronavirus infectious disease (COVID-19) in China: a retrospective multicenter study. Intensive care medicine. 46 (10), 1863-1872. https://doi.org/10.1007/s00134-020-06211-2

Xie, Y., You, Q., Wu, C., Cao, S., Qu, G., Yan, X., \& Zhang, H. (2020). Impact of cardiovascular disease on clinical characteristics and outcomes of coronavirus disease 2019 (COVID-19). Circulation Journal, CJ-20. https://doi.org/10.1253/circj.CJ-20-0348

Xu, H., Martin, A., Singh, A., Narasimhan, M., Lau, J., Weinberg, M., \& Rao, G. (2020). Pulmonary embolism in patients hospitalized with COVID-19 (from a New York health system). The American journal of cardiology. 133, 148-153. https://doi.org/10.1016/j.amjcard.2020.07.036

Xu, Z., Shi, L., Wang, Y., Zhang, J., Huang, L., Zhang, C., \& Wang, F. S. (2020). Pathological findings of COVID-19 associated with acute respiratory distress syndrome. The Lancet respiratory medicine. 8 (4), 420-422. https://doi.org/10.1016/S2213-2600(20)30076-X

Yaghi, S., Ishida, K., Torres, J., Mac Grory, B., Raz, E., Humbert, K., \& Frontera, J. (2020). SARS-CoV-2 and stroke in a New York healthcare system. Stroke. 51 (7), 2002-2011. https://doi.org/10.1161/STROKEAHA.120.030335

Yan, X., Wang, S., Ma, P., Yang, B., Si, D., Liu, G., \& Yang, P. (2021). Cardiac injury is associated with inflammation in geriatric COVID-19 patients. Journal of Clinical Laboratory Analysis. 35 (1), e23654. https://doi.org/10.1002/jcla.23654

Yang, C., Liu, F., Liu, W., Cao, G., Liu, J., Huang, S., \& Xiong, B. (2021). Myocardial injury and risk factors for mortality in patients with COVID-19 pneumonia. International Journal of Cardiology. 326, 230-236. https://doi.org/10.1016/j.ijcard.2020.09.048

Yao, Y., Chen, W., Wu, X., Shen, L., Fu, Y., Yang, Q., \& Zhou, H. (2020). Clinical characteristics of COVID-19 patients in three consecutive generations of spread in Zhejiang, China. Clinical Microbiology and Infection. 26 (10), 1380-1385. https://doi.org/10.1016/j.cmi.2020.06.018

Wang, C., Zhou, L., Chen, J., Yang, Y., Huang, T., Fu, M., \& Chen, X. (2020). The differences of clinical characteristics and outcomes between imported and local patients of COVID-19 in Hunan: a two-center retrospective study. Respiratory Research. 21 (1), 1-10. https://doi.org/10.1186/s12931-020-01551-5

Wang, J., Guo, S., Zhang, Y., Gao, K., Zuo, J., Tan, N., \& Wang, W. (2020). Clinical features and risk factors for severe inpatients with COVID-19: A retrospective study in China. PloS one. 15 (12). https://doi.org/10.1371/journal.pone.0244125

Wang, J., Zhang, H., Qiao, R., Ge, Q., Zhang, S., Zhao, Z., \& Shen, N. (2020b). Thrombo-inflammatory features predicting mortality in patients with COVID19: the FAD-85 score. Journal of International Medical Research. 48 (9). https://doi.org/10.1177\%2F0300060520955037

Wang, M., Zhu, Q., Fu, J., Liu, L., Xiao, M., \& Du, Y. (2020). Differences of inflammatory and non-inflammatory indicators in Coronavirus disease-19 (COVID19) with different severity. Infection, Genetics and Evolution. 85, 104511. https://doi.org/10.1016/j.meegid.2020.104511

Wang, P., Sha, J., Meng, M., Wang, C., Yao, Q., Zhang, Z., \& Chu, Y. (2020). Risk factors for severe COVID-19 in middle-aged patients without comorbidities: a multicenter retrospective study. Journal of translational medicine. 18 (1), 1-12. https://doi.org/10.1186/s12967-020-02655-8

Wang, T., Tang, C., Chen, R., Ruan, H., Liang, W., Guan, W., \& Li, S. (2020). Clinical features of coronavirus disease 2019 patients with mechanical ventilation: A nationwide study in China. Critical care medicine. https://dx.doi.org/10.1097\%2FCCM.0000000000004473

Wichmann, D., Sperhake, J. P., Lütgehetmann, M., Steurer, S., Edler, C., Heinemann, A., \& Kluge, S. (2020). Autopsy findings and venous thromboembolism in patients with COVID-19: a prospective cohort study. Annals of internal medicine. 173(4), 268-277. https://doi.org/10.7326/M20-2003

Zhang, N., Wang, C., Zhu, F., Mao, H., Bai, P.... \& Zhou, M. (2020). Risk Factors for Poor Outcomes of Diabetes Patients With COVID-19: A Single-Center, Retrospective Study in Early Outbreak in China. Front Endocrinol (Lausanne). 11, 571037. 10.3389/fendo.2020.571037 
Research, Society and Development, v. 11, n. 2, e21011225731, 2022

(CC BY 4.0) | ISSN 2525-3409 | DOI: http://dx.doi.org/10.33448/rsd-v11i2.25731

Zhang, S., Xu, Y., Li, J., Wu, K., Wang, T., Su, X., \& Zhong, N. (2020). Symptomless multi-variable apnea prediction index assesses adverse outcomes in patients with Corona Virus Disease 2019. Sleep medicine. 75, 294-300. https://doi.org/10.1016/j.sleep.2020.08.031

Zhang, Y., Li, H., Zhang, J., Cao, Y., Zhao, X., Yu, N., \& Liu, X. (2020). The clinical characteristics and outcomes of diabetes mellitus and secondary hyperglycaemia patients with coronavirus disease 2019: a single-center, retrospective, observational study in Wuhan. Diabetes, obesity \& metabolism. https://doi.org/10.1111/dom.14086

Zhang, W., Sang, L., Shi, J., Zhong, M., Jiang, L., Song, B., \& Zheng, X. (2021). Association of D-dimer elevation with inflammation and organ dysfunction in ICU patients with COVID-19 in Wuhan, China: a retrospective observational study. Aging (Albany NY). 13(4), 4794. https://dx.doi.org/10.18632\%2Faging.202496 